\section{F (mit nachfolgender römischer Ziffer)}

> Gerinnungsfaktoren

\section{$F 1+2(F 1.2)$}

> Prothrombinfragmente $1+2$

\section{F2}

- Prothrombin

F5

> Gerinnungsfaktor V

F7

> Gerinnungsfaktor VII

F8

> Gerinnungsfaktor VIII
F10

> Gerinnungsfaktor X

F11

> Gerinnungsfaktor XI

F12

> Gerinnungsfaktor XII

F13

> Gerinnungsfaktor XIII

\section{FAAS}

> Flammenatomabsorptionsspektrometrie/-spektroskopie

\section{FAB}

- Ionisationsmethoden (Massenspektrometrie)

- Massenspektrometrie 


\section{Fab-Fragmente}

\section{H. Renz und B. Gierten}

Englischer Begriff Fab fragments

Definition Antigenbindender Teil von Immunglobulinen nach Spaltung durch Papain.

Beschreibung Die Proteinase Papain spaltet $>$ Immunglobulin $\mathrm{G}$ im Bereich der prolinreichen Hinge-Region ( $\triangleright$ Schwerketten) N-terminal der Disulfidbindung der Schwerketten. Neben einem Fc-Fragment entstehen dadurch zwei 47 kDa schwere Fab-Fragmente (,,antigen-binding fragment"). Bestehend aus der Kombination der variablen Teile von Schwer- und Leichtketten bilden die N-terminalen Enden der Fab-Fragmente die funktionelle Tasche des Immunglobulins, in der ein Antigen spezifisch binden kann. Durch unterschiedliche Kombination verschiedener Genbereiche (V = ,variety“, $\mathrm{J}=$,,joining“, $\mathrm{D}=$,diversity“) wird die Aminosäuresequenz und damit Tertiär- und Quartärstruktur des Fab-Fragments bestimmt.

Dieser Molekülbereich wird als hypervariable Region bezeichnet, da sich hinter den Bezeichnungen für die Genbereiche zahlreiche weitgehend voneinander unabhängig $\mathrm{zu}$ variierende Gene verbergen. Diese immensen genetischen Kombinationsmöglichkeiten bestimmen die Vielfältigkeit der möglichen Antigene.

\section{Literatur}

Cruse JM, Lewis RE (1999) Atlas of immunology. Springer, Berlin/ Heidelberg/New York, S 116-121

\section{FAB-Klassifikation}

H. Baum

\section{Englischer Begriff FAB classification}

Definition Einteilungsschema der akuten Leukämien an Hand morphologischer und zytochemischer Kriterien.

Beschreibung Die Klassifikation der akuten myeloischen (AML) und lymphatischen Leukämien erfolgte im Jahr 1976 durch eine Französisch-Amerikanisch-Britische Arbeitsgemeinschaft (FAB) primär anhand morphologischer und zyto-
FAB-Klassifikation, Tab. 1 Einteilung der akuten myeloischen Leukämien (AML) an Hand der FAB-Klassifikation

\begin{tabular}{|c|c|c|}
\hline Subtyp & Besonderheiten & Morphologie \\
\hline $\begin{array}{l}\text { AML M1 } \\
\text { (myelozytär ohne } \\
\text { Ausreifung) }\end{array}$ & $\begin{array}{l}\text { Mind. } 3 \% \\
\text { Myeloperoxidase- } \\
\text { (MPO-)positive } \\
\text { Blasten }\end{array}$ & $\begin{array}{l}\text { Typ-1- und Typ-2- } \\
\text { Blasten }>90 \% \text { aller } \\
\text { Blasten }\end{array}$ \\
\hline $\begin{array}{l}\text { AML M2 } \\
\text { (myelozytär mit } \\
\text { Ausreifung) }\end{array}$ & $\begin{array}{l}\text { Zellen zeigen } \\
\text { Ausreifungstendenz, } \\
\text { einzelne Auer- } \\
\text { Stäbchen häufig }\end{array}$ & $\begin{array}{l}\text { Typ-1- und Typ-2- } \\
\text { Blasten 30-89\% aller } \\
\text { Blasten }\end{array}$ \\
\hline $\begin{array}{l}\text { AML M3 } \\
\text { (promyelozytär) }\end{array}$ & $\begin{array}{l}\text { Auer-Stäbchen in } \\
\text { Faggot-Form M3v: } \\
\text { mikrogranuläre Form } \\
\text { mit monozytoidem } \\
\text { Kern }\end{array}$ & $\begin{array}{l}\text { Hypergranulierte } \\
\text { promyelozyten- } \\
\text { ähnliche Zellen }\end{array}$ \\
\hline $\begin{array}{l}\text { AML M4 } \\
\text { (myelomonozytär) }\end{array}$ & $\begin{array}{l}\text { In einem Teil der } \\
\text { Blasten ist } \\
\text { Myeloperoxidase } \\
\text { (MPO), im anderen } \\
\text { Teil die unspezifische } \\
\text { Esterase positiv }\end{array}$ & $\begin{array}{l}\text { Wie M2 mit mind. } \\
20 \% \text { Monozyten- } \\
\text { oder } \\
\text { Promonozytenanteil }\end{array}$ \\
\hline $\begin{array}{l}\text { AML M5 } \\
\text { (monozytär) }\end{array}$ & $\begin{array}{l}\text { Zwei Varianten: } \\
\text { M5a: gering } \\
\text { differenziert } \\
\text { M5b: gut differenziert }\end{array}$ & $\begin{array}{l}\text { Wie M2, allerdings } \\
\text { sind die Blasten } \\
\text { MPO-negativ und } \\
\text { unspezifische } \\
\text { Esterase positiv }\end{array}$ \\
\hline $\begin{array}{l}\text { AML M6 } \\
\text { (erythrozytär) }\end{array}$ & $\begin{array}{l}\text { Eisenfärbung häufig } \\
\text { positiv }\end{array}$ & $\begin{array}{l}\text { Erythroblasten } \\
>50 \% \text { der } \\
\text { kernhaltigen Zellen } \\
\text { im Knochenmark }\end{array}$ \\
\hline $\begin{array}{l}\text { AML M7 } \\
\text { (megakaryozytär) }\end{array}$ & & $\begin{array}{l}\text { Ausgeprägte } \\
\text { Polymorphie der } \\
\text { Blasten }\end{array}$ \\
\hline
\end{tabular}

chemischer Kriterien von Knochenmarkaspiraten. Die myeloischen Leukämien wurden anhand dieser morphologischen und zytochemischen Kriterien in 6 Entitäten (M1-M6) (Tab. 1) und die akuten lymphatischen Leukämien in 3 Entitäten (L1-L3) unterschieden. Allerdings entsprechen die 3 Entitäten der Lymphoblasten nicht einzelnen Subtypen der akuten lymphatischen Leukämien, sodass hiermit keine Zuordnung getroffen werden kann. Zusätzlich erfolgte eine Abgrenzung gegenüber den myelodysplastischen Syndromen. Die Klassifikation wurde mehrmals überarbeitet und neue Subformen eingefügt (M4Eo, M3v, M7).

\section{Literatur}

Bennett JM, Catovsky D, Daniel MT et al (1976) Proposal for the classification of the acute leukaemias. Brit Med J 33:451-458

\section{FABP}

Fettsäurebindungsprotein, cardiales 


\section{Fachzeitschriften der Klinischen}

Chemie und Laboratoriumsmedizin

A. M. Gressner und O. A. Gressner

Englischer Begriff journals of clinical chemistry and laboratory medicine

Definition Zeitschriften mit vorwiegend klinisch-chemischem, laboratoriumsmedizinischem und/oder pathobiochemischem Inhalt.

\section{Beschreibung Auswahl:}

- Clinical Chemistry:

- http://intl.clinchem.org

- Clinica Chimica Acta:

- http://www.sciencedirect.com/science/journal/00098981

- http://www.elsevier.com/locate/clinchem

- Clinical Chemistry and Laboratory Medicine

- http://www.degruyter.de

- Clinical Biochemistry

- http://www.info.sciencedirect.com/science/journal/ 00099120

- Annals of Clinical Biochemistry

- http://www.acb.org.uk/Annclinbiochem

- Laboratoriumsmedizin/Journal of Laboratory Medicine

- http://www.degruyter.com/journals/labmed/

\section{FACIT}

Kollagene

\section{F-Actin-Autoantikörper}

- Autoantikörper gegen F-Actin

\section{Factor VIII-clotting-activity}

> Gerinnungsfaktor VIII

\section{Faeces}

- Stuhlprobe

\section{FAEE}

> Fettsäureethylester

\section{FAES}

- Flammenatomabsorptionsspektrometrie/-spektroskopie

\section{FAFS}

- Fluoreszenzspektrometrie/-spektroskopie

\section{Faggot-Form}

\section{H. Baum}

Englischer Begriff multiple auer rods; faggot cells

Definition Auftreten von mehreren Auer-Stäbchen in einer leukämischen Zelle.

Beschreibung Der englische Begriff „Faggot“ kann mit Holzbündel oder Reisigbündel übersetzt werden. Er bezeichnet den Nachweis von vielen $>$ Auer-Stäbchen in einer leukämischen Zelle. Das Vorkommen von Auer-Stäbchen in Faggot-Form ist charakteristisch für eine akute myeloische Leukämie (AML) M3 (früher als Promyelozytenleukämie beschrieben) in der $>$ FAB-Klassifikation.

Die Abbildung zeigt die typische Faggot-Form der AuerStäbchen bei einer AML-M3 (1000×, May-GrünwaldGiemsa-Färbung):

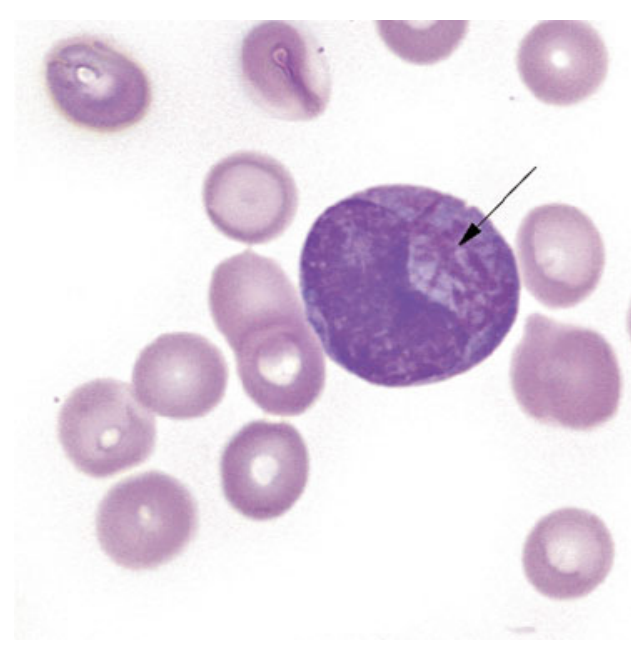




\section{Literatur}

Bennett JM, Catovsky D, Daniel MT et al (1976) Proposal for the Classification of the Acute Leukaemias. Brit J Haematol 33:451-458

\section{FAI \\ - Androgenindex, freier}

\section{Fäkale Lipasekonzentration}

> Pankreaslipase im Stuhl

\section{Faktor (Gerinnung)}

> Gerinnungsfaktoren

\section{Faktor I}

$>$ Fibrinogen

\section{Faktor II}

$>$ Prothrombin

\section{Faktor-V-Leiden}

> Protein-C-Resistenz, aktivierte

\section{Faktor-Xa-Inhibitoren}

T. Stief

\section{Synonym(e) FXa-Inhibitoren}

Englischer Begriff factor Xa inhibitors (F10a inhibitors)

Definition Als zentrale Serinprotease in der plasmatischen Gerinnung ist der aktivierte Faktor X (= F10a) ein ideales Ziel neuer Antikoagulanzien.
Beschreibung Neue direkte FXa-Inhibitoren (Rivaroxaban, Apixaban, Edoxaban) binden direkt an den sowohl im Prothrombinkomplex gebundenen als auch an den freien FXa (F10a). Rivaroxaban war der erste orale direkte Faktor-XaInhibitor, der für die Prävention von Thrombosen nach Operationen am Hüft- oder Kniegelenk zugelassen wurde. Rivaroxaban hat eine ca. 10.000-fach höhere Affinität für FXa als für andere Serinproteasen. Seine Bioverfügbarkeit beträgt 80-100 \%, die maximale Plasmakonzentration wird 2-4 h nach oraler Gabe erreicht, und die biologische Halbwertszeit von Rivaroxaban wird mit 7-11 h angegeben. Rivaroxaban wird vorwiegend über die Leber metabolisiert (CYP3A4, CYP2J2). Die neuen oralen Antikoagulanzien könnten evtl. die Vitamin-K-Antagonisten ablösen, allerdings sind die Nebenwirkungen dieser Xenobiotika (z. B. paradoxe intrinsische Thrombingenerierung über die Seitenketten) noch nicht geklärt. Auch zur Vermeidung des Risikos schwerer Blutungen sollten alle Inhibitoren von F10a (oder von F2a, wie Dabigatran) gemonitort werden über einen ultraspezifischen F10a-/F2a-Generierungstest wie den EXCA (,extrinsic coagulation activity assay“; oder den INCA [,,intrinsic coagulation activity assay"]): 10-20\% EXCAAktivität ist das Ziel für eine therapeutische Einstellung eines (Thrombose-) gefährdeten Patienten, Patienten mit $<10 \%$ EXCA haben ein Blutungsrisiko; die prophylaktische Einstellung hat einen Zielbereich von 20-40 \% EXCA (oder INCA), Patienten mit $>40 \%$ EXCA haben ein Thromboserisiko.

Die neuen ultraspezifischen F10a-/F2a-Generierungstests zeigen auch, dass das therapeutische Ziel von 10-20 \% EXCA für bestimmte Antikoagulanzien, wie beispielsweise Fondaparinux (ein synthetisch hergestelltes Pentasaccharid) nicht erreichbar ist, sie sind zu schwach für eine ausreichende Antikoagulation eines Risikopatienten. Problematisch ist auch, dass die neuen oralen direkten Hemmer von F10a oder von Thrombin (sog. neue orale Antikoagulanzien [NOAC]= direkte orale Antikoagulanzien [DOAC]) im Gegensatz zu niedermolekularem Heparin nicht profibrinolytisch wirken. Einmal entstandene Mikro- oder Makrothromben werden von den NOAC nicht zerstört.

\section{Literatur}

Bauer KA (2008) New anticoagulants. Curr Opin Hematol 15:509-515 Stief TW (2007) The efficiency of anti-factor Xa and anti-factor IIa anticoagulants. Blood Coagul Fibrinolysis 18:265-269

Stief TW (2013a) Rivaroxaban or Dabigatran at less than $20 \%$ of their therapeutic plasma concentration can pathologically trigger thrombin generation. Hemost Lab 6:65-76

Stief T (2013b) LMWH stimulates blood ROS generation. Hemost Lab 6:175-184

Stief TW, Fareed J (2000) The antithrombotic factor singlet oxygen/light $(1 \mathrm{O} 2 / \mathrm{hv})$. Clin Appl Thromb Hemost 6:22-30 


\section{Fällung}

> Ausfällen

\section{Fällungsreagenzien}

K. J. Lackner und D. Peetz

Englischer Begriff precipitating agents

Definition Fällungsreagenzien im weiteren Sinne sind Substanzen, die geeignet sind, bestimmte Substanzen oder Substanzklassen aus einer Lösung auszufällen.

Beschreibung Beispiele für in der Labordiagnostik häufig verwendete Fällungsreagenzien sind Substanzen zur Ausfällung von Protein wie Trichloressigsäure oder zur Ausfällung ApoB-haltiger Lipoproteine zur Bestimmung von HDLCholesterin wie Phosphorwolframsäure/ $\mathrm{MgCl}_{2}$, Heparin$\mathrm{MnCl}_{2}$ oder Dextransulfat- $\mathrm{MgCl}_{2}$.

\section{Fallverknüpfung}

O. Colhoun

Englischer Begriff case linkage

Definition Zusammenführung der Daten eines Patienten, die in der Labor-EDV unter verschiedenen Patienten-Identifikationsnummern geführt werden.

Beschreibung Die Funktion der Fallverknüpfung eines Labor-EDV-Systems kommt in verschiedenen Bereichen zur Anwendung. Bei Langzeitarchiven - etwa einem Blutbankarchiv - z. B. wenn für ein und denselben Patienten aufgrund unterschiedlicher Schreibweisen durch den Einsender bei 2 verschiedenen Aufträgen unterschiedliche Patienten-Identifikationsnummern erfasst wurden. Hier müssen die Befunde für die dauerhafte Archivierung und den späteren kompletten Zugriff auf einen - mit allen korrekten Daten versehenen Patienten zusammengeführt werden. Beim Einlesen von Aufträgen, die außerhalb der Verwaltungsaufnahmezeiten einer Klinik ausgestellt und nicht mit der endgültigen Patienten-ID versehen wurden, müssen zu einem späteren Zeitpunkt ebenfalls alle erbrachten Laborleistungen für den richtigen Patienten unter dessen endgültiger Personen-ID zusammengeführt werden können.

\section{Falsch-negativer Test}

Testergebnis, falsch-negatives

\section{Falsch-negatives Testergebnis}

Testergebnis, falsch-negatives

\section{Falsch-positiver Test}

Testergebnis, falsch-positives

\section{Falsch-positives Testergebnis}

Testergebnis, falsch-positives

\section{Faltblattstruktur}

Proteinstruktur

\section{Familiäre Schilddrüsenhormon- Resistenz}

- Schilddrüsenhormon-Rezeptor $\beta$-Genmutation

\section{Familiarisierungsphase}

H. Jomaa

Definition Die Familiarisierungsphase ist Teil des Prozesses der Einführung eines neuen Verfahrens oder Geräts in den Laborbetrieb. Sie ist der Verifizierung oder Validierung vorgeschaltet und dient dem Vertrautmachen des Anwenders mit dem neuen Verfahren oder Gerät.

Folgende Fähigkeiten sollen in der Familiarisierungsphase erworben werden:

- Probenvorbereitung

- Gebrauch der Reagenzien 
- Ausführung eines Untersuchungsverfahrens

- Handhabung des Geräts

- Umgang mit benötigter Software

- Erkennen möglicher Fehlermeldungen des Geräts

- Kalibrierung des Geräts

- Wartung des Geräts

Die Dauer der Familiarisierungsphase ist abhängig von der Komplexität des Verfahrens oder Geräts und der Erfahrung des Anwenders. Die vom Hersteller angebotenen Trainingsprogramme können Bestandteil der Familiarisierungsphase sein. Daten, die in der Familiarisierungsphase gesammelt werden, sind in der Regel nicht Bestandteil der Verifizierung und Validierung.

\section{Faraday'sche Gesetze}

$>$ Coulometrie

\section{Faraday-Tyndall-Effekt}

- Tyndall-Phänomen

\section{Farbcodes von Antikoagulanzien}

- Antikoagulanzien in vitro

- Vakuumröhrchen

\section{Färbeindex}

H. Baum

Synonym(e) FI; Hämoglobinquotient

Englischer Begriff color index

Definition Relativzahl als Kenngröße des > Hämoglobin$(\mathrm{Hb}-)$ gehalts der Erythrozyten (Ery).

Beschreibung Die Bestimmung des Färbeindex (FI) ist eine Methode zur Abschätzung des Hämoglobingehalts des Blutes im Vergleich zur Norm nach der Formel

$\mathrm{FI}=\mathrm{Hb}($ in $\%$ der Norm $) / \operatorname{Ery}(\mathrm{T} / \mathrm{L}) \times 20$
Dabei wird der Normalwert des Bluthämoglobingehalts mit $145 \mathrm{~g} / \mathrm{L}(=100 \%)$ angenommen (Referenzbereich: $0,9-1)$.

\section{Literatur}

Begemann H, Harwerth HG (1967) Praktische Hämatologie, 3. Aufl. Georg Thieme Verlag, Stuttgart, S 281

\section{Fårbemethoden, mikrobiologische}

W. Stöcker

Englischer Begriff microbiological staining methods

Definition Klassische Methoden zum Nachweis von Mikroorganismen. Sie werden zur groben taxonomischen Klassifikation und Bewertung bestimmter Eigenschaften der Mikroorganismen genutzt. Neben Einfach- und Differenzierungsfärbungen gibt es auch Spezialfärbungen (z. B. nach Kinyoun, Neisser, Ziehl-Neelsen; > Fluoreszenzfärbung nach Coons).

Einfachfärbungen Die Methylenblau- oder die Fuchsinfärbung färben die Bakterienzellen meist gleichmäßig und einheitlich an und erhöhen dadurch den optischen Kontrast. Diese Färbungen dienen dazu, die Bakterien im Hellfeld darzustellen.

Ansatz für die alkalische Methylenblau-Färbung nach Löffler:

- $30 \mathrm{~mL}$ Stammlösung: 0,1 \% Methylenblau in Wasser

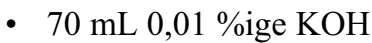

Färbedauer: dünne Ausstriche: 5-15 s, dicke Ausstriche: $45 \mathrm{~s}$. Die Bakterien färben sich blau an.

Differenzialfärbungen Beispiel: Gram-Färbung. Man lässt mindestens 2 verschiedene Farbstoffe hintereinander auf den Ausstrich einwirken. Nach dem ersten Färbeschritt behandelt man die Zellen mit einem geeigneten Lösungsmittel oder einer Säure. Dabei werden manche Bakterien wieder entfärbt, während andere den Farbstoff festhalten. Diese Unterschiede im Färbeverhalten kann man zur Vordifferenzierung der Bakterien nutzen: Es lassen sich 2 große Gruppen unterscheiden: grampositive und gramnegative Bakterien, die unter anderem unterschiedlich auf manche Antibiotika reagieren.

In der ersten Phase lässt man Karbol-Gentianaviolett einwirken, wodurch sich alle Bakterien anfärben. Bei einer nachfolgenden Behandlung mit Lugol-Lösung (Iod-Kaliumiodid 
1:2 in Wasser) bilden sich größere Farbstoffkomplexe, die

Bakterien erscheinen dunkelblau (,Beizung“).

In der zweiten Phase wird mit $96 \%$ Ethanol behandelt, wobei gramnegative Bakterien den Farbstoff wieder freigeben, während die grampositiven Bakterien mit ihrer dickeren Mureinhülle die blauen Farbstoffkomplexe festhalten. Abschließend wird mit verdünntem Karbolfuchsin gegengefärbt, damit auch die gramnegativen Bakterien (rot) zur Darstellung kommen.

Anfärbung säurefester Bakterien Das Prinzip der ZiehlNeelsen-Färbung beruht darauf, dass die Zellwand säurefester Bakterien besondere Lipide (Wachse, Mykolsäuren) enthält, sodass sie sich mit den üblichen Verfahren schlecht anfärben. Man lässt unter Hitzeeinwirkung Karbolfuchsin einwirken, sodass der Farbstoff einerseits trotz der Lipidhülle eindringt, andererseits aber bei normaler Temperatur nur schwer wieder aus den Bakterien extrahiert werden kann. Danach lässt man bei normaler Temperatur Salzsäure oder ein Gemisch aus Alkohol und Salzsäure einwirken, wobei fast alle Bakterien den Farbstoff wieder abgeben, bis auf die säurefesten Stäbchen, die rot gefärbt bleiben und im gefärbten Ausstrich leichter zu identifizieren sind. Diese Kontrastfärbung ist eine wichtige differenzialdiagnostische Hilfe zur Identifizierung vor allem von Erregern der Tuberkulose und der Lepra.

Pilzfärbung Bei der Grocott-Methenamin-Silberfärbung entstehen durch die Behandlung mit Chromsäure Aldehydgruppen. Diese werden durch die folgende Reaktion mit einem Methenamin-Silbernitrat-Komplex schwarz, sodass sich die Pilzbestandteile deutlich von einem blassgrünen Hintergrund abheben.

Methenamin-Silbernitrat-Lösung:

- Mischen von $5 \mathrm{~mL} 5 \%$ Silbernitratlösung und $100 \mathrm{~mL}$ $3 \%$ Methenaminlösung ergibt die Basislösung

- Mischen von $25 \mathrm{~mL}$ Basislösung mit $25 \mathrm{~mL}$ destilliertem Wasser und $2 \mathrm{~mL} 5 \%$ Boraxlösung ergibt die Arbeitslösung

Herstellung der Bakterienausstriche AufObjektträgern dünn ausgebreitete Bakteriensuspensionen lässt man lufttrocknen und fixiert sie in der Regel durch dreimaliges langsames Durchziehen durch die Flamme. Da die Hitzefixation die Bakterienstruktur verändern kann, ist es bei morphologischen Untersuchungen besser, mit Ethanol zu fixieren.

\section{Farbintensitätsmessgerät}

- Kolorimeter

\section{Farbintensitätsmessung}

- Kolorimetrie

\section{Farbkennzeichnung der \\ Probenbehälter (-gefäße) für \\ Venenblut}

H. Jomaa

Englischer Begriff colour codes for single-use containers for venous blood specimen collection

Definition Unterscheidung der Probengefäße für Venenblut durch Verschluss-, Deckel-, Etiketten- oder Aufdruckfarben.

Probengefäße für Venenblut enthalten verschiedene Zusätze wie Gelpräparationen zur Stabilisierung der Barriere zwischen Serum/Plasma und Blutkuchen nach Zentrifugation, Gerinnungsaktivierung, Gerinnungshemmung (z. B. Citrat, Heparin, EDTA) und/oder zur Stabilisierung der Probe (Fluorid als Inhibitor der Glykolyse). Zur Identifizierung der Zusätze wurde eine Farbkennzeichnung der Verschlüsse und der Etiketten eingeführt. Die Farbkennzeichnungssysteme sind herstellerspezifisch.

Eine erste Normung der Farbkodierung erfolgte 1995 mit der Publikation des Standards ISO 6710:1995 durch die internationale Organisation für Normung (ISO, International Organisation for Standarization). Dieses Dokument enthielt ein einheitliches Farbkennzeichnungssystem. Bei der Überarbeitung dieser ISO konnte kein Konsens mehr erreicht werden, sodass diese in der EU verworfen und durch die Europäische Norm EN 14820:2004, „Gefäße zur einmaligen Verwendung für die venöse Blutentnahme beim Menschen", abgelöst wurde. Jedoch wurde das einheitliche Farbkennzeichnungssystem in der EN 14820:2004 nicht weitergeführt. Ähnlich wurde im Standard CLSI GP39-A6 (CLSI = Clinical and Laboratory Standards Institute) aus dem Jahr 2010 das einheitliche Farbkennzeichnungssystem verworfen. Verschiedene Versuche, einen weltweit gültigen Farbcode zu etablieren, sind bisher gescheitert.

\section{Literatur}

Europäische Norm EN 14820 v. 27.05.2004 Europ. Komitee für Normung (CEN)

Simundic AM, Cornes MP, Grankvist K, Lippi G, Nybo M, Ceriotti F, Theodorsson E, Panteghini M, on behalf of the European Federation for Clinical Chemistry and Laboratory Medicine (EFLM) (2015) Colour coding for blood collection tube closures - a call for harmonization. Clin Chem Lab Med 53:371-376 


\section{Farbstoffbindungsmethode}

> Bromkresolgrünmethode

\section{Farbstoffe im Liquor (CSF)}

$>$ Liquor-Pigmente

\section{Farbstoffeliminationstest der Leber}

> Indocyaningrün-Test

\section{Farbtest nach Lieberman-Burchard}

\ Liebermann-Burchard-Reaktion

\section{Färbung, Blutbild}

\section{H. Baum}

\section{Synonym(e) Blutausstrichfärbung}

Englischer Begriff blood smear stain

Definition Färbung eines Blutausstrichs zur morphologischen Beurteilung der zellulären Bestandteile.

Physikalisch-chemisches Prinzip Ein getrockneter und in Methanol fixierter Blutausstrich wird mit basischen und/oder sauren Farbstoffen gefärbt. Die am häufigsten verwendete Methode ist die kombinierte May-Grünwald-Giemsa-Färbung ( $\triangleright$ Pappenheim-Färbung). Eosinsaures Methylenblau (gesättigte methanolische Lösung des getrockneten Niederschlags von Eosin und Methylenblau in Aqua dest.) färbt Erythrozyten hellrot, Kerne blau, eosinophile Granula ziegelrot, basophile Granula tiefblau, neutrophile Granula hell- bis purpurrot, Thrombozyten blassblau. Anschließend erfolgt eine Gegenfärbung mit Azur-Eosin-Methylenblau-Lösung (verdünnt 1+33,3 mit Aqua dest; $\mathrm{pH} 6,8-7,0$ ).

Einsatzgebiet Morphologische Differenzierung der zellulären Bestandteile des peripheren Blutes.
Untersuchungsmaterial Ausstrichpräparat des peripheren Blutes.

\section{Instrumentierung}

- Manuelle Methode: Glaswaren zur Aufnahme der Flüssigkeiten sowie der in speziellen Ständern fixierten Objektträger

- Automatisiert: Analysengeräte, die sowohl einen Ausstrich anfertigen als auch eine Färbung durchführen

Fehlermöglichkeit Inkubationsdauer nicht korrekt, pHWert des Puffers falsch, Färbezeiten nicht exakt eingehalten.

Praktikabilität - Automatisierung - Kosten Einfach durchzuführende Handmethode. Es gibt Analysensysteme, die automatisch einen Ausstrich herstellen, identifizieren und anschließend eine Färbung durchführen.

Bewertung - Methodenhierarchie (allg.) Definitive Methode zur morphologischen Differenzierung der Leukozyten im peripheren Blut.

\section{Literatur}

Koeppen KM, Heller S (1991) Differentialblutbild - Analytik. In: Boll I, Heller S (Hrsg) Praktische Blutzelldiagnostik. Springer, Berlin/Heidelberg/New York, S 165-167

\section{Färbung, Urin}

W. G. Guder

Synonym(e) Harnfarbe-Beurteilung; Uroskopie

\section{Englischer Begriff urine colour}

Definition Die Färbung des Urins stellt eine wesentliche Komponente der Analyse des Urins mit diagnostischen Zielen dar („Uroskopie“). Es beschreibt die visuell sichtbare Färbung des Urins, vgl. dazu folgende Tabelle:

\begin{tabular}{|c|c|c|}
\hline Aussehen & Ursachen & Symptom bei \\
\hline Blass, wässrig & Verdünnter Urin & $\begin{array}{l}\text { Polyurie, Diabetes } \\
\text { insipidus, Diabetes } \\
\text { mellitus, } \\
\text { Hypostenurie }\end{array}$ \\
\hline Bernsteingelb & $\begin{array}{l}\text { Gallenfarbstoffe, } \\
\text { Nahrungsfarbstoffe } \\
\text { (z. B. Flavine) }\end{array}$ & $\begin{array}{l}\text { Normaler Urin, } \\
\text { Vitamin } \mathrm{B}_{2} \text {, } \\
\text { Einnahme von } \\
\text { Medikamenten }\end{array}$ \\
\hline
\end{tabular}

(Fortsetzung) 


\begin{tabular}{|c|c|c|}
\hline Aussehen & Ursachen & Symptom bei \\
\hline Gelborange & $\begin{array}{l}\text { Gallenfarbstoffe, } \\
\text { Nahrungsfarbstoffe } \\
\text { (z. B. Rhabarber, Folia } \\
\text { Sennae) }\end{array}$ & $\begin{array}{l}\text { Konzentrierter Urin, } \\
\text { Cholestase }\end{array}$ \\
\hline $\begin{array}{l}\text { Bräunlich- } \\
\text { (,,bier“)braun }\end{array}$ & Biliverdin, Bilirubin & Hepatischer Ikterus \\
\hline $\begin{array}{l}\text { Rötlich- } \\
\text { rötlichbraun }\end{array}$ & $\begin{array}{l}\text { Hämoglobin(derivate), } \\
\text { Myoglobin, } \\
\text { Porphyrine, } \\
\text { Medikamente (z. B. } \\
\text { L-Dopa, Metronidazol, } \\
\text { Chinin, Phenacetin, } \\
\text { Rote-Bete-Konsum) }\end{array}$ & $\begin{array}{l}\text { Hämaturie, } \\
\text { Hämoglobinurie, } \\
\text { Rhabdomyolyse, } \\
\text { Therapeutika }\end{array}$ \\
\hline $\begin{array}{l}\text { Gelbgrün, } \\
\text { blaugrün }\end{array}$ & $\begin{array}{l}\text { Gallenfarbstoffe im } \\
\text { alkalischen Urin, } \\
\text { Indikane, Polycyanin, } \\
\text { Chlorophyll }\end{array}$ & $\begin{array}{l}\text { Cholestase, } \\
\text { Farbstoffe, } \\
\text { Pseudomonas- } \\
\text { Infektion, } \\
\text { Mundspülmittel }\end{array}$ \\
\hline $\begin{array}{l}\text { Dunkelbraun- } \\
\text { schwarz, evtl. } \\
\text { beim Stehen } \\
\text { dunkelnd }\end{array}$ & $\begin{array}{l}\text { Methämoglobin, } \\
\text { Homogentisinsäure, } \\
\text { Melanin, Porphyrine, } \\
\text { Serotonin, } \\
\text { Medikamente }\end{array}$ & $\begin{array}{l}\text { Hämolyse, } \\
\text { Alkaptonurie, } \\
\text { Melanom, } \\
\text { „Melanose“, } \\
\text { Chlorpromazin, } \\
\text { Methyl-Dopa }\end{array}$ \\
\hline $\begin{array}{l}\text { Weiß, milchig- } \\
\text { trüb oder wolkig }\end{array}$ & $\begin{array}{l}\text { Eiter, Schleim, Lipide, } \\
\text { Chylus, Paraffin, } \\
\text { Bakterien, } \\
\text { Kontrastmittel }\end{array}$ & $\begin{array}{l}\text { Infektion der } \\
\text { ableitenden } \\
\text { Harnwege, } \\
\text { Chylusfistel, } \\
\text { Vaginalcreme }\end{array}$ \\
\hline Trüb-blau & Indikan, Medikamente & $\begin{array}{l}\text { Systemische Infektion } \\
\text { (Typhus, Sepsis) }\end{array}$ \\
\hline
\end{tabular}

Beschreibung Die Farbe des Urins stellt nicht nur für den Laien, sondern auch für den Arzt seit der Antike ein mit dem Auge sichtbares Zeichen zur Beurteilung des Gesundheitsstands dar. War die Betrachtung des Urins durch die Uroskopie im Mittelalter charakterisiert durch die Differenzierung von 20 verschiedenen Farben, die im Zusammenhang mit der 4-Säfte-Lehre der Antike interpretiert wurden, ist die Harnfarbe seit dem 19. Jahrhundert, als man die Ursachen der meisten Harnfarben identifizierte, Basis für die Diagnose/das Symptom, da zahlreiche Symptome/Erkrankungen nach der Harnfarbe benannt wurden: Hämaturie, Porphyrie, Alkaptonurie, Melanurie, Schwarzwasserfieber.

\section{Literatur}

Hofmann W, Ehrich JHH, Guder WG, Keller F, Scherberich J (2011)

Diagnostische Pfade bei Nierenerkrankungen. J Lab Med 35:127-146

Vosswinckel P (1993) Der Schwarze Urin. Blackwell Wissenschaft, Berlin

\section{Färbung mit Amidoschwarz}

> Amidoschwarz-Färbung

\section{Färbung nach Gram}

Gram-Färbung

Fas

Fas-Rezeptor

\section{Faserproteine}

> Proteine, fibrilläre

\section{FasL}

$\checkmark$ Fas-Ligand

\section{Fas-Ligand}

S. Holdenrieder und P. Stieber

Synonym(e) CD95-Ligand; FasL

\section{Englischer Begriff Fas ligand}

Definition Der Fas-Ligand bindet an zellständige oder lösliche Formen des Fas-Rezeptors ( $\triangleright$ Fas-Rezeptor); in ersterem Fall erfolgen eine Aktivierung des Oberflächenrezeptors und eine Überleitung des Zelltodsignals in das Zellinnere.

Synthese - Verteilung - Abbau - Elimination > Fas-
Rezeptor.

Der Fas-Ligand wird auf einer Vielzahl von Zellen, insbelöslicher Form in Serum und Plasma vor. Er ist ein wesentlicher Bestandteil der physiologischen und pathologischen Apoptoseinduktion.

Funktion - Pathophysiologie Für eine Reihe klinischer Fragestellungen wurde die lösliche Form des Fas-Liganden in Serum und Plasma quantifiziert. Im Gegensatz zum löslichen Fas-Rezeptor hat der Fas-Ligand proapoptotische Wirkung, die jedoch vom Vorhandensein löslicher Fas-Rezeptoren abhängt. Bei einer hohen Konzentration an löslichen 
Fas-Rezeptoren wird eine beträchtliche Anzahl von FasLiganden bereits von diesen gebunden und steht dann nicht mehr für die Apoptoseinduktion zur Verfügung. Das Gleichgewicht löslicher Formen der Fas-Rezeptoren und -Liganden kann insbesondere bei der Pathogenese bzw. Progression von malignen Tumoren von Bedeutung sein.

Untersuchungsmaterial - Entnahmebedingungen Serum, Plasma.

Analytik \Enzymimmunoassay (EIA), \ Enzyme-linked Immunosorbent Assay (ELISA).

Referenzbereich - Erwachsene Median 0,06 ng/mL (methodenabhängig).

Indikation Prognosemarker bei verschiedenen soliden $\mathrm{Tu}$ moren.

Interpretation Generell wurden bei Patienten mit verschiedenen malignen Erkrankungen höhere Serumwerte des löslichen Fas-Liganden beobachtet als bei gesunden Personen, so bei Karzinomen des Magens, der Blase und beim Melanom, wobei bei einigen eine Korrelation mit dem Tumorstadium beschrieben wurde.

Allerdings ist der Einfluss der relevanten organspezifischen, benignen Erkrankungen sowie von benignen Nierenund Leberschäden wie auch von Infektionen noch nicht systematisch beschrieben, weshalb eine generelle Empfehlung für die diagnostische Wertigkeit derzeit nicht gegeben werden kann.

Darüber hinaus war eine hohe Konzentration des löslichen Fas-Liganden beim Magen- und Blasenkarzinom sowie beim multiplen Myelom mit einer ungünstigen Prognose assoziiert. Dies konnte insbesondere in der multivariaten Analyse für das Magenkarzinom gezeigt werden.

Diagnostische Wertigkeit Potenzieller Prognosemarker.

\section{Literatur}

Holdenrieder S, Stieber P (2004) Apoptotic markers in cancer. Clin Biochem 37:605-617

Krammer PH (2000) CD95's deadly mission in the immune system. Nature 407:789-795

\section{Fas-Rezeptor}

S. Holdenrieder und P. Stieber

Synonym(e) APO1; APO1-Rezeptor; CD95; CD95-Rezeptor; Fas;

\section{Englischer Begriff Fas receptor}

Definition Der Fas-/Apo1-/CD-95-Rezeptor ist ein glykosiliertes Transmembranprotein und gleichzeitig Mitglied der Tumornekrosefaktor-(TNF-)Rezeptorfamilie, das die Überleitung des Zelltodsignals in das Zellinnere bewerkstelligt.

Struktur Der Fas-Rezeptor besteht aus einem extrazellulären Anteil von 2-6 cysteinreichen Domänen und einem intrazellulären Anteil, der die ,death domain“ enthält.

Synthese - Verteilung - Abbau - Elimination Nach Bindung von spezifischen Liganden - wie dem Fas-Liganden ( $\triangleright$ Fas-Ligand) - oder stimulierenden Antikörpern werden die Fas-Rezeptoren durch Trimerisierung aktiviert. Dadurch lagern sich im Zellinnern weitere Proteine an die Todesdomänen an und bilden den ,death-inducing signaling complex“ (DISC). An diesem werden Initiatorcaspasen aktiviert, die dann das Apoptosesignal zu den Effektorcaspasen weiterleiten. Diese sind für den geregelten Abbau der Zellbestandteile und die daraus resultierenden, charakteristischen, morphologischen Veränderungen der Apoptose verantwortlich.

Der Fas-Rezeptor wird auf einer Vielzahl von Zellen exprimiert und ist ein wesentlicher Bestandteil der physiologischen und pathologischen Apoptoseinduktion.

Funktion - Pathophysiologie Für eine Reihe klinischer Fragestellungen wurde die lösliche Form des Fas-Rezeptors im Serum und Plasma quantifiziert. Nach Abspaltung von der Zelloberfläche ist der lösliche Rezeptor nicht mehr in der Lage, Apoptose zu induzieren. Außerdem bindet er lösliche Fas-Liganden, die dann nicht mehr für die Apoptoseinduktion zur Verfügung stehen. Insgesamt stellt der lösliche FasRezeptor somit einen antiapoptotischen Mechanismus dar, der u. a. auch bei malignen Tumoren bei der Pathogenese bzw. Progression der Erkrankung von Bedeutung sein kann.

Untersuchungsmaterial - Entnahmebedingungen Serum, Plasma.

Analytik > Enzymimmunoassay (EIA), \ Enzyme-linked Immunosorbent Assay (ELISA).

Referenzbereich - Erwachsene Median 1,8 ng/mL (methodenabhängig).

Indikation Prognosemarker bei verschiedenen soliden Tumoren.

Interpretation Generell wurden bei Patienten mit verschiedenen malignen Erkrankungen höhere Serumkonzentrationen des löslichen Fas-Rezeptors beobachtet als bei gesunden Personen, so bei Karzinomen des Kolons, des Magens, der Leber, 
der Brust, anderer gynäkologischer Organe, der Niere, beim Melanom und beim Non-Hodgkin-Lymphom. In einigen dieser Tumoren korrelierte Fas mit dem Tumorstadium und der Progredienz der Erkrankung. Allerdings ist der Einfluss der relevanten organspezifischen, benignen Erkrankungen sowie von benignen Nieren- und Leberschäden wie auch von Infektionen noch nicht systematisch beschrieben, weshalb eine generelle Empfehlung für die diagnostische Wertigkeit derzeit nicht gegeben werden kann.

Darüber hinaus war ein hoher Fas-Wert in einer Reihe von soliden Tumoren mit einer ungünstigen Prognose assoziiert. Dies konnte insbesondere in der multivariaten Analyse für gynäkologische Karzinome, das Mammakarzinom, das Nierenzellkarzinom und das Non-Hodgkin-Lymphom gezeigt werden.

Diagnostische Wertigkeit Potenzieller Prognosemarker.

\section{Literatur}

Holdenrieder S, Stieber P (2004) Apoptotic markers in cancer. Clin Biochem 37:605-617

Krammer PH (2000) CD95's deadly mission in the immune system. Nature 407:789-795

\section{Fast Atom Bombardment}

- Ionisationsmethoden (Massenspektrometrie)

\section{Fatty Acid Binding Protein, cardiales}

> Fettsäurebindungsprotein, cardiales

\section{Faxserver}

\section{O. Colhoun}

\section{Englischer Begriff fax server}

Definition Funktionalität des Labor-EDV-Systems, mit welcher der Versand von Befunden per Telefax organisiert wird.

Beschreibung Bereitstellung der Funktionalität eines Telefaxservers für die Übermittlung von Laborbefunden an entsprechend in den $>$ Stammdaten gekennzeichnete Empfänger per Telefax zusätzlich zum oder anstelle eines gedruckten Befunds.

\section{Fäzestrockengewicht}

- Stuhltrockengewicht

\section{Fc-Epsilon-Rezeptor-Antikörper}

- Autoantikörper gegen IgE-Rezeptoren

\section{Fc-Fragmente}

Englischer Begriff $\mathrm{Fc}$ fragments

Definition Konstanter Teil der Schwerkette von $>$ Immunglobulinen nach Spaltung mit Papain.

Beschreibung Die Proteinase Papain spaltet $>$ Immunglobulin $\mathrm{G}$ im Bereich der prolinreichen Hinge-Region ( $\triangleright$ Schwerketten) N-terminal der Disulfidbindung der Schwerketten. Dadurch entsteht ein $50 \mathrm{kDa}$ schweres Fc-Fragment (,crystallizable fragment") und zwei Fab-Fragmente (,antigenbinding fragment"). Das resultierende Fc-Fragment kann Komplement fixieren und determiniert andere biologische Funktionen, wie z. B. Bindung an zelluläre Oberflächen sowie Plazentagängigkeit.

\section{Literatur}

Cruse JM, Lewis RE (1999) Atlas of immunology. Springer, Berlin/ Heidelberg/New York, S 116-121

\section{FD}

> Ionisationsmethoden (Massenspektrometrie)

\section{FDA}

- Food and Drug Administration

\section{FDL-Test}

- Pankreolauryltest 


\section{FDP}

D-Dimer

\section{FECH}

$\triangleright$ Ferrochelatase

\section{Fehlende Methylierung}

> Hypomethylierung

\section{Fehler}

- Fehler, zufälliger

- Messabweichung

\section{$\alpha$-Fehler}

$>$ Fehler 1. Art

\section{$\beta$-Fehler}

Fehler 2. Art

\section{Fehler 1. Art}

R.-D. Hilgers, N. Heussen und S. Stanzel

$\operatorname{Synonym}(e) \alpha$-Fehler

\section{Englischer Begriff type I error}

Definition Ein Fehler 1. Art liegt vor, wenn auf der Basis eines statistischen Tests ( $\vee$ Test, statistischer) eine Entscheidung für die Annahme der $>$ Alternativhypothese getroffen wird, obwohl die $>$ Nullhypothese gültig ist.

Beschreibung Der Fehler 1. Art stellt eine mögliche Fehlentscheidung eines statistischen Tests dar. Entscheidet man sich auf der Basis eines statistischen Tests fälschlicherweise für die Ablehnung der Nullhypothese, begeht man einen Fehler 1. Art. Die Wahrscheinlichkeit für einen Fehler 1. Art wird üblicherweise als $>$ Irrtumswahrscheinlichkeit $\alpha$ bezeichnet. Bei der Anwendung statistischer Tests wird der Wert von $\alpha$ a priori festgelegt.

Analog spricht man im diagnostischen Test $(\triangleright$ Test, diagnostischer) von einem falsch-positiven Testergebnis ( $\triangleright$ Testergebnis, falsch-positives).

\section{Literatur}

Hilgers R-D, Bauer P, Scheiber V (2002) Einführung in die Medizinische Statistik. Springer, Berlin/Heidelberg/New York

\section{Fehler 2. Art}

R.-D. Hilgers, N. Heussen und S. Stanzel

Synonym(e) $\beta$-Fehler

Englischer Begriff type II error

Definition Ein Fehler 2. Art liegt vor, wenn auf der Basis eines statistischen Tests ( $\triangleright$ Test, statistischer) eine Entscheidung für die Beibehaltung der $\triangleright$ Nullhypothese getroffen wird, obwohl die $\triangleright$ Alternativhypothese gültig ist.

Beschreibung Der Fehler 2. Art stellt eine mögliche Fehlentscheidung eines statistischen Tests dar. Entscheidet man sich auf der Basis eines statistischen Tests fälschlicherweise für die Beibehaltung der Nullhypothese, begeht man einen Fehler 2. Art. Die Wahrscheinlichkeit für einen Fehler 2. Art wird üblicherweise als $>$ Irrtumswahrscheinlichkeit $\beta$ bezeichnet. Bei der Anwendung statistischer Tests ist der Wert von $\beta$ im Allgemeinen unbekannt. In Modellrechnungen, die die Basis für Fallzahlplanungen bilden, betrachtet man üblicherweise den Wert $(1-\beta)$, der die Macht ( des Tests angibt.

Dem Fehler 2. Art entspricht im diagnostischen Test $(\triangleright$ Test, diagnostischer) ein falsch-negatives Testergebnis ( $\triangleright$ Testergebnis, falsch-negatives).

\section{Literatur}

Hilgers R-D, Bauer P, Scheiber V (2002) Einführung in die Medizinische Statistik. Springer, Berlin/Heidelberg/New York 


\section{Fehler, grober}

\section{G. Schumann}

\section{Englischer Begriff gross error}

Definition Messabweichung, die bei korrektem Arbeiten zu vermeiden wäre.

Beschreibung Grobe Fehler ( $\triangleright$ Fehler, grober) sind von systematischen Fehlern ( $\triangleright$ Messabweichung, systematische) zu unterscheiden. Als grobe Fehler werden beispielsweise die Nichteinhaltung der Standardarbeitsanweisungen, Verwechslungen von Reagenzien, Proben, Filtern oder Pipetten bezeichnet. Während die Ursachen solcher grober Fehler meist sofort erkennbar sind, können sie bei systematischen Fehlern nicht immer aufgedeckt werden. Die Differenzierung in systematische und grobe Fehler erfolgt gelegentlich subjektiv und dem Ausmaß der Abweichung entsprechend.

So kann die Verwendung einer unkorrekten Standardlösung zu einem groben Fehler führen, wenn versehentlich eine Stammlösung anstatt der Gebrauchsverdünnung eingesetzt wurde, und zu einem systematischen Fehler, wenn beim Ansetzen der Gebrauchsverdünnung eine nicht geeichte Pipette mit einer systematischen Minus-(bzw. Plus-)Abweichung benutzt wurde.

\section{Literatur}

Management in der Laboratoriumsmedizin (2000) Teil 1: Grundbegriffe. DIN 58936-1, 3.1.10.4. Beuth-Verlag, Berlin

\section{Fehler, systematischer}

- Messabweichung, systematische

\section{Fehler, zufälliger}

R.-D. Hilgers, N. Heussen und S. Stanzel

Synonym(e) Fehler; Zufällige Messabweichung

Englischer Begriff random error

Definition Unter einem zufälligen Fehler ( $\vee$ Fehler, zufälliger) versteht man die zufällige $>$ Variabilität der Messergeb- nisse bei der mehrmaligen Durchführung von Messwiederholungen.

Beschreibung Die Ursachen für das Auftreten zufälliger Fehler sind im Einzelnen nicht bekannt und daher nicht analysierbar. Das Wesen zufälliger Fehler besteht darin, dass Abweichungen von einem Sollwert sich im Mittel ausgleichen ( $\triangleright$ Mittelwert, arithmetischer) und nicht $\mathrm{zu}$,starke“ Variabilität auftritt. Mithilfe der $>$ Präzisionskontrolle können zufällige und systematische Fehler ( $\triangleright$ Messabweichung, systematische) voneinander abgegrenzt werden.

\section{Literatur}

Qualitätskontrolle im Medizinischen Laboratorium von A bis Z - Ein Leitfaden in Schlagworten, 2., überarb. Aufl. Behring Diagnostika https://doi.org/10.1515/labm.1995.19.1-12.218

\section{Fehlerarten}

\section{R.-D. Hilgers, N. Heussen und S. Stanzel}

\section{Englischer Begriff error types; types of error}

Definition Mit Fehlerarten bezeichnet man die möglichen Fehlentscheidungen eines statistischen Tests ( $>$ Test, statistischer).

Beschreibung Trifft man aufgrund eines statistischen Tests eine Entscheidung, so kann diese richtig oder falsch sein. Die möglichen Ergebnisse dieses Entscheidungsprozesses lassen sich durch 2 richtige Entscheidungen und 2 Fehlentscheidungen charakterisieren (s. Tabelle).

Entscheidungsschema eines statistischen Tests:

\begin{tabular}{|l|l|l|}
\hline Testergebnis & Realität & $\mathrm{H}_{1}$ \\
\hline Signifikant & Richtige Entscheidung & $\begin{array}{l}\text { Falsche Entscheidung; } \\
\text { Fehler 1. Art: falsch- } \\
\text { positiv }\end{array}$ \\
\hline $\begin{array}{l}\text { Nicht } \\
\text { signifikant }\end{array}$ & $\begin{array}{l}\text { Falsche Entscheidung; } \\
\begin{array}{l}\text { Fehler 2. Art: falsch- } \\
\text { negativ }\end{array}\end{array}$ & Richtige Entscheidung \\
\hline
\end{tabular}

Entscheidet man sich auf der Basis des statistischen Tests für die Annahme der $>$ Alternativhypothese, obwohl die Nullhypothese zutrifft, begeht man einen sog. Fehler 1. Art. Entscheidet man sich hingegen für die Beibehaltung der Nullhypothese, obwohl die Alternativhypothese zutrifft, spricht man von einem Fehler 2. Art. 
Die möglichen Fehlentscheidungen eines statistischen Tests können in Analogie zum diagnostischen Test ( diagnostischer) als falsch-positives ( $\triangleright$ Testergebnis, falschpositives; entspricht Fehler 1. Art) bzw. falsch-negatives Testergebnis ( $\vee$ Testergebnis, falsch-negatives; entspricht Fehler 2. Art) bezeichnet werden (s. Abbildung im Stichwort - Erwartungswert von Messwerten).

\section{Literatur}

Hilgers R-D, Bauer P, Scheiber V (2002) Einführung in die Medizinische Statistik. Springer, Berlin/Heidelberg/New York

\section{Fehlerbehebung}

- Troubleshooting

\section{Fehlergrenze}

$>$ Grenzwert der Messabweichung

\section{Fehlerterme}

- Residuen

\section{Fehling, Hermann Christian von}

\section{A. M. Gressner und O. A. Gressner}

Lebensdaten Deutscher Chemiker, geboren am 9. Juni 1811 in Lübeck, gestorben am 1. Juli 1885 in Stuttgart.

Verdienste Nach einer Ausbildung zum Apotheker in Lübeck studierte Fehling in Heidelberg Chemie und Naturwissenschaften, wo er auch promovierte. Anschließend war er im Labor bei J. von Liebig ( $\triangleright$ Liebig, Justus von) in Gießen tätig, ging aber 1839 als Chemielehrer an eine Gewerbeschule in Stuttgart, wo er bis 1883 tätig blieb. Fehling wurde bekannt durch die von ihm entwickelte Methode zur semiquantitativen Bestimmung von Traubenzucker (Glukose) im Urin. Die - Fehling-Probe mit alkalischer Kupfertartratlösung (FehlingLösung) stellt eine weder $>$ Glukose- noch zuckerspezifische Reduktionsprobe dar und ist heute obsolet.

\section{Fehling-Probe}

A. M. Gressner und O. A. Gressner

Synonym(e) Fehling-Test; Glukosenachweis nach Fehling

Englischer Begriff Fehling's test

Definition Unspezifische, daher seit Langem obsolete kolorimetrische Reduktionsprobe zur semiquantitativen Bestimmung von $\triangleright$ Glukose im Urin.

Beschreibung Von dem Chemiker H.C. von Fehling ( $\triangleright$ Fehling, Hermann Christian von) entwickelte nicht zuckerspezifische Reduktionsprobe ( $\triangleright$ Reduktionsproben) im enteiweißten Urin, bei der $\mathrm{Cu}$ (II) (Kupfersulfat) in alkalischer Lösung durch Erhitzen zu $\mathrm{Cu}$ (I) reduziert wird. Durch Kochen wird das ausfallende gelbliche Kupferoxid $\left(\mathrm{Cu}_{2} \mathrm{O}\right)$ in einen orange-roten Niederschlag überführt (positive Reaktion). Ein positiver Ausfall zeigt lediglich die Anwesenheit reduzierender Substanzen (z. B. Pentosen, > Fruktose, $\checkmark$ Galaktose, Laktose, $>$ Vitamin $\mathrm{C}$ u. a.) an und ist somit nicht spezifisch für Glukose.

\section{Literatur}

Hallmann L (1994) Klinische Chemie und Mikroskopie, 11. Aufl. Georg Thieme Verlag, Stuttgart/New York

\section{Fehling-Test}

- Fehling-Probe

\section{Feinmassenbestimmung}

> Präzisionsmassenbestimmung

\section{Felddesorption}

Massenspektrometrie

\section{Feldeffektortransistoren, ionenselektive}

> Ionenselektive Elektrode 


\section{4-Felder-Tafel (für Befundvalidierung)}

- Entscheidungstafel

\section{Feldionisation}

- Massenspektrometrie

\section{Fenestrated cell}

H. Baum

Synonym(e) Downey-Zelle

Englischer Begriff fenestrated cell

Definition Virustransformierter Lymphozyt mit charakteristischer zarter Vakuolisierung des Zytoplasmas (s. Abbildung) bei akuter Epstein-Barr-Virusinfektion.

Die Abbildung zeigt die typische zarte Vakuolisierung und gezipfelte Zytoplasmagrenze, an die sich Erythrozyten anlagern $(1000 \times$, May-Grünwald-Giemsa-Färbung):

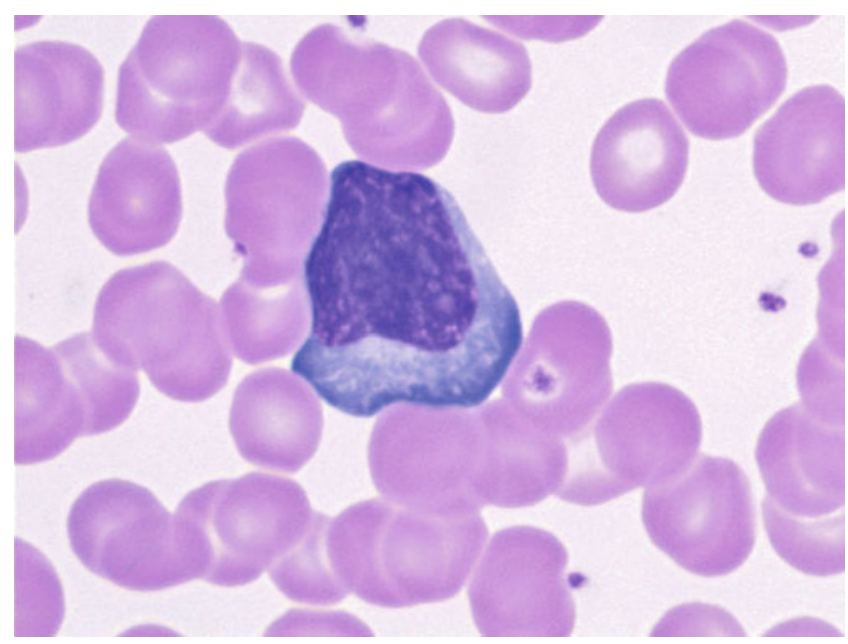

Beschreibung Bei einer akuten Infektion mit $\triangleright$ EpsteinBarr-Viren können häufig morphologisch auffällige Lymphozyten mit breitem, dunkelbasophilem Zytoplasmasaum und großem, unregelmäßig geformtem Kern mit aufgelockertem Kemchromatin nachgewiesen werden. Teilweise zeigen diese Zellen eine zarte Vakuolisierung. Diese zart vakuolisierten Zellen werden als „fenestrated cells“ oder Downey-Zellen bezeichnet und stellen aktivierte T-Lymphozyten dar.

\section{Literatur}

Theml H (1993) Infektiöse Mononukleose. In: Begemann H, Rastetter J (Hrsg) Klinische Hämatologie, 4. Aufl. Georg Thieme Verlag, Stuttgart, S 654

\section{Fentanyl(e)}

C. Vidal und W.-R. Külpmann

Englischer Begriff fentanyl(s)

Definition Gruppe von stark wirksamen Opioiden (s. > Opioide), zu denen Alfentanil, Fentanyl, Sufentanil gehören.

Strukturformel:<smiles>CCC(=O)N(c1ccccc1)C1CCN(CCc2ccccc2)CC1</smiles>

Molmasse Fentanyl: 336,46 g.

Synthese - Verteilung - Abbau - Elimination Fentanyl wird präoperativ i. v. appliziert, bei Tumorschmerzen als Pflaster. Bei Fentanylmissbrauch wird das Opioid auch inhalativ, intranasal und peroral appliziert.

Halbwertszeit 1-7 Stunden (Plasma).

Funktion - Pathophysiologie Bei Überdosierung kommt es zu den üblichen Symptomen einer Opioidintoxikation, u. a. respiratorische Insuffizienz, Koma und Krampfanfälle.

Untersuchungsmaterial - Entnahmebedingungen Serum (S), Plasma (P), Urin.

Analytik HPLC, GC-MS, LC-MS/MS.

Indikation Verdacht auf Opioid-(Fentanyl-)Intoxikation, selten im Rahmen der Hirntoddiagnostik.

Interpretation Therapeutischer Bereich $(\mathrm{S}, \mathrm{P})$ : 0,005-0,3 $\mathrm{mg} / \mathrm{L}$ (therapeutische Konzentrationen beziehen sich auf Patienten unter kontrollierter Beatmung, beispielsweise intraoperativ); toxisch: $>0,003-0,005 \mathrm{mg} / \mathrm{L}$; komatös-letal: $>0,003-0,02 \mathrm{mg} / \mathrm{L}$. 
Fentanyl spielt vermutlich seiner kurzen Wirkungsdauer wegen kaum eine Rolle in der Drogenszene, ebenso wie die (ebenfalls verschreibungspflichtigen) Abkömmlinge Alfentanil, Remifentanil und Sufentanil. Im Gegensatz dazu gewinnen (nicht verkehrsfähige und nicht verschreibungsfähige) Derivate des Fentanyl, wie z. B. Benzylfentanyl, Carfentanil, p-Fluorofentanyl, $\beta$-Hydroxyfentanyl, Lofentanil, Acetyl- $\alpha$-methylfentanyl, $\beta$-Hydroxy-3-methylfentanyl, $\alpha$-Methylfentanyl (,China White"), 3-Methylfentanyl, $\alpha$-Methylthiofentanyl, 3-Methylthiofentanyl, Thenylfentanyl, Thiofentanyl zunehmende Bedeutung. Diese Verbindungen sind länger wirksam als Fentanyl und stärker wirksam als Morphin (Fentanyl 300-fach, Carfentanil 7500-fach).

Bei Zufuhr dieser Drogen (Injektion oder Schnupfen) treten ähnliche Effekte auf wie bei Heroin. Die starke Wirksamkeit geht mit einer sehr niedrigen tödlichen Dosis einher. Wegen der niedrigen Konzentrationen entgehen die Substanzen leicht dem Nachweis.

\section{Literatur}

Sticht G, Käferstein H, von Meyer L (2009) Fentanyl. In: Külpmann WR (Hrsg) Clincal toxicological analysis. Wiley-VCH, Weinheim, S $222-228$

\section{Fenton-Reaktion}

\section{K. J. Lackner und D. Peetz}

\section{Englischer Begriff Fenton reaction}

Definition Oxidation von $\alpha$-Hydroxysäuren oder 1,2-Glykolen in Gegenwart von $\mathrm{H}_{2} \mathrm{O}_{2}$ und $\mathrm{Fe}^{++} \mathrm{zu} \alpha$-Ketosäuren bzw. Hydroxyaldehyden.

Beschreibung Fenton-Reaktionen sind in vivo u. a. wahrscheinlich für die Oxidation von Lipiden relevant.

\section{Ferment}

Enzym

\section{Ferritin}
G. Töpfer

Englischer Begriff ferritin
Definition Ferritin ist das wichtigste Eisenspeicherprotein, dessen Serumkonzentration mit dem Versorgungszustand der Zellen mit $>$ Eisen (Füllungszustand des Körpereisenspeichers) korreliert, wenn interferierende Einflussfaktoren auszuschließen sind.

Struktur Das Ferritinmolekül liegt in der Form einer innen mit $\mathrm{Fe}^{3+}$ als Oxyhydroxid-Phosphat-Komplex (gebunden an Glutaminsäure) mehr oder weniger ausgekleideten Hohlkugel (bis $4500 \mathrm{Fe}^{3+}$-Ionen) vor, wie in der folgenden Abbildung dargestellt:

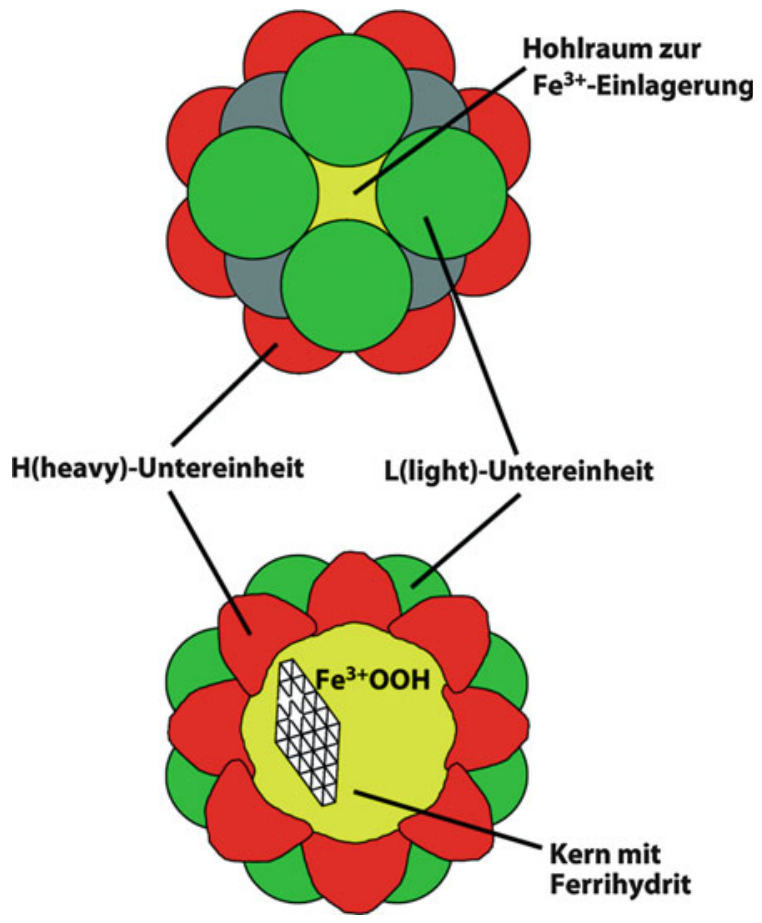

Durch Proteinumhüllung wird das toxische $\mathrm{Fe}^{3+}$ abgeschirmt. Das Molekül besteht aus einer Proteinhülle (Apoferritin) von 24 identischen Untereinheiten. Diese Untereinheiten sind entweder basisch (L-Form) oder sauer (H-Form). In Herz, Plazenta und Tumoren werden saure und in Milz, Knochenmark und Leber basische Untereinheiten sowie in der Niere basische und saure Untereinheiten gefunden. Eisenspeicherzellen im Knochenmark weisen fast ausschließlich die basischen Isoferritine auf, desgleichen das Ferritin des Blutserums, dessen Konzentration proportional zur Eisenmenge in den Eisenspeichern gemessen wird. Die Ferritinsynthese in den einzelnen Organen erfolgt meist nicht ausschließlich in der H-Form oder der L-Form, sondern in einem von Einflüssen wie Entzündung, Infektion und Xenobiotika geprägten Verhältnis beider Formen (durch TNF- $\alpha$ und IL-1 $\beta$ wird die H-Form begünstigt, die verstärkt Eisen aufnehmen kann) $(1 \mu \mathrm{g} / \mathrm{L}$ Serumferritin entspricht $8 \mathrm{mg}=149 \mu \mathrm{mol}$ Speichereisen). Das Eisenspeicherferritin wandelt sich bei Eisenüberladung des Moleküls in Hämosiderin um, das in 
Sideroblasten (s. > Sideroblast) bei gefülltem Eisenspeicher angereichert gefunden wird und mit der $>$ BerlinerblauReaktion darstellbar ist. Serumferritin unterscheidet sich von Zellferritin durch einen anderen Syntheseweg und ist im Gegensatz zum Zellferritin glykosiliert und nahezu eisenfrei. 20 \% des Körpereisens befinden sich im Eisenspeicher.

Molmasse $474 \mathrm{kDa}$ (Apoferritin).

Synthese - Verteilung - Abbau - Elimination Ferritin kommt in einigen Bakterien in Pflanzen und Tieren als Eisenspeicherprotein vor. Serumferritin ist ein Akute-PhaseProtein (s. - Akute-Phase-Proteine). Im Gegensatz zum - Eisen existiert kein zirkadianer Rhythmus und im Gegensatz zum \ Transferrin keine Östrogenabhängigkeit und keine Abhängigkeit von der Lebersynthese. Die Herkunft des Serumferritins ist bislang nicht geklärt, aufgrund des Ausmaßes der Glykosylierung ist die Sekretion aus dem retikulohistiozytären System (RHS) wahrscheinlich. Unter physiologischen Bedingungen besteht eine Korrelation zwischen Eisengehalt dieses Systems und der Serumferritinkonzentration. Serumferritin wird nahezu vollständig von der Leber aufgenommen.

Halbwertszeit Ca. 10 Minuten.

Funktion - Pathophysiologie Die Funktion des Serumferritins ist ungeklärt. Der Beitrag zum Eisentransport ist unbedeutend. Ferritin kommt zellulär in einigen Bakterien, in Pflanzen und Tieren als Eisenspeicherprotein (Metalloprotein) vor. Die Ferritinbildung in der menschlichen Zelle ist vom Eisengehalt abhängig. Bei hohem Eisengehalt ist die Ferritinsynthese gegenüber der Synthese des Transferrinrezeptors begünstigt, bei niedrigem Eisengehalt dagegen die Synthese des Transferrinrezeptors ( $\triangleright$ Transferrinrezeptor, löslicher). Die Menge des Depoteisens beträgt etwa ein Viertel bis ein Drittel des Gesamteisenbestands und befindet sich hauptsächlich im RHS. Wenn die Eisenkonzentration im Gewebe auf $>250-300 \mathrm{mg} / 100 \mathrm{~g}$ steigt, wandelt sich Ferritin (Eisengehalt $20 \%$ ) in Hämosiderin (Eisengehalt 30-37\%) um. Ferritin ist leichter als Hämosiderin wieder für die $\gg$ Hämoglobin-Synthese mobilisierbar. Die Füllung der Eisenspeicher wird nach Berlinerblau-Färbung von Knochenmarkausstrichen am Intensitätsgrad der Eisenspeicherung der Retikulumzellen (Sideromakrophagen) halb quantitativ abgelesen. Direkt zu diesem Eisennachweis korreliert physiologischerweise die Konzentration des Serumferritins (s. o.).

Saure, relativ eisenarme Isoferritine werden in das Serum bei verstärktem Zelluntergang (ineffektive Erythropoese, Tumoren, Leukämien, Lymphome) freigesetzt und im Testsystem in gewissem Umfang mit gemessen. Eine
Unterscheidung von den basischen, relativ eisenreichen Isoferritinen ist mittels $\triangleright$ Immunoassay derzeit nicht möglich. Es könnten sich bei genauerer Bestimmbarkeit der Isoferritine zukünftig Einsatzmöglichkeiten als Tumormarker eröffnen.

Untersuchungsmaterial - Entnahmebedingungen Serum, Heparin-, EDTA-, Citrat-Plasma.

Probenstabilität Serum: $20-25{ }^{\circ} \mathrm{C} 7$ Tage, $4-8{ }^{\circ} \mathrm{C} 7$ Tage, $-20{ }^{\circ} \mathrm{C} 1 \mathrm{Jahr}$.

Wird erhöht durch Ethanol, Fe-Salze und orale Kontrazeptiva, wird erniedrigt durch $\triangleright$ Erythropoetin.

Präanalytik Geringe Hämolyse stört nicht. Die vollständige Erythrozytenlyse einer Blutprobe würde das Ergebnis durch Freisetzung der Erythrozytenferritine um etwa 60 \% steigern.

\section{Analytik}

- $>$ Radioimmunoassay

- Fluoreszenzimmunoassay

- $>$ Enzymimmunoassay

- Lumineszenzimmunoassay

- Latexverstärkte Nephelometrie ( $\triangleright$ Immunnephelometrie)

- Latexverstärkte Turbidimetrie ( $\triangleright$ Immunturbidimetrie)

Kalibration mit (basischem) Leichtketten-Isoferritin ist erforderlich. Dies ist im gentechnologisch hergestellten WHO-Standard (,preparation 94/572“) verwirklicht, aber noch nicht in allen kommerziellen Tests erfolgt die Kalibration in Anlehnung an diesen Standard, sodass die Methoden zwar gut korrelieren, jedoch unterschiedliche Ergebnisse und auch Referenzbereiche aufweisen.

Konventionelle Einheit $\mu \mathrm{g} / \mathrm{L}$.

Referenzbereich - Frauen $>16$ Jahre: $15-150 \quad \mu \mathrm{g} / \mathrm{L}$ (latexverstärkte $\$ Immunturbidimetrie, WHO-Standard, Milzferritin 80/578).

Referenzbereich - Männer $>16$ Jahre: $30-400 \quad \mu \mathrm{g} / \mathrm{L}$ (latexverstärkte $\triangleright$ Immunturbidimetrie, WHO-Standard, Milzferritin 80/578).

Referenzbereich - Kinder Bis 30 Tage 150-450 $\mu \mathrm{g} / \mathrm{L}$ (latexverstärkte $>$ Immunturbidimetrie, WHO-Standard, Milzferritin $80 / 578$ ), bis 90 Tage $80-500 \mu \mathrm{g} / \mathrm{mL}$, bis $1 \mathrm{Jahr}$ $20-200 \mu \mathrm{g} / \mathrm{mL}$, bis 16 Jahre $20-200 \mu \mathrm{g} / \mathrm{mL}$.

\section{Indikation}

- Eisenmangelanämie 
- Speichereisenmangel

- Verlaufskontrolle bei Eisentherapie

- Differenzialdiagnose bei Anämien

- Verdacht auf Eisenüberladung (z. B. Hämochromatose)

- Verlaufskontrolle bei Eisenmobilisierung

\section{Interpretation}

- Abfall des Ferritins unter den Referenzbereich schon bei Speichereisenmangel ohne Mangel an Funktionseisen (löslicher Transferrinrezeptor noch nicht erhöht) und ohne manifeste Anämie (MCV Ø, $\mathrm{Hb} \varnothing$ ) (prälatenter Eisenmangel). $12 \mu \mathrm{g} / \mathrm{L}$ wird als Schwellenwert betrachtet. Kommt zum Speichereisenmangel eine Erniedrigung der Transferrinsättigung $(<15 \%)$ hinzu, spricht man von latentem Eisenmangel und bei Abfall des Hämoglobins unter den Referenzbereich von manifestem Eisenmangel (Eisenmangelanämie). Ursache ist eine Aufnahmestörung, beispielsweise bei Milch-Ei-Vegetariern oder bei Darmentzündungen.

- Ferritinmangel bei chronischem Blutverlust, Überwachung von Blutspenderinnen, bei denen Blutspende und Hypermenorrhoe einen Eisenmangel auslösen können.

- Ein akuter Blutverlust zeigt einen Ferritinabfall erst nach 1-2 Wochen.

- Bei Kindern, heranwachsenden Jugendlichen im Wachstumsschub, trainierten Athleten und Schwangeren sind die Eisenvorräte sehr gering, jedoch häufig ohne Einschränkung des Funktionseisens. Bei Schwangeren wurde die Feststellung eines Eisenmangels durch Heranziehen des löslichen Transferrinrezeptors erleichtert. Dabei zeigte sich der Eisenmangel eher am erhöhten Transferrinrezeptor als an einem erniedrigten Ferritin.

- Bei chronischen Entzündungen wird ein Eisenmangel ausgeschlossen, wenn das Ferritin $>100 \mu \mathrm{g} / \mathrm{L}$ beträgt. Bei Werten $<12 \mu \mathrm{g} / \mathrm{L}$ ist der Eisenmangel unzweifelhaft. Dazwischen kann ein begleitender Eisenmangel anhand des erhöhten löslichen Transferrinrezeptors festgestellt werden, wobei der Quotient sTfR/log Ferritin die beste Trennschärfe aufweist. Neuere Arbeiten empfehlen deshalb bei Fragestellung Eisenmangel bei chronischer Entzündung, malignen Erkrankungen oder Schwangerschaft, sowohl Ferritin als auch den löslichen Transferrinrezeptor zu bestimmen. Alternativ kann auch das Zink-Protoporphyrin (Zn-Protoporphyrin IX) als Maß für den Funktionseisenmangel bestimmt werden.

- Überwachung der Therapie mit Erythropoetin (EPO) bei Dialysepatienten unter zusätzlicher Eisensubstitution - es werden Ferritinkonzentrationen zwischen 300 und $600 \mu \mathrm{g} / \mathrm{L}$ angestrebt. Weitere Bedingungen sind Transferrinsättigung $>20 \%$ und Erhöhung des löslichen Transferrinrezeptors in den oberen Referenzbereich.
- Frühe Erfassung einer Hämochromatose anhand der Ferritinerhöhung und der Transferrinsättigung $(>55 \%$ bei Männern, $>45 \%$ bei Frauen).

- Sekundäre Eisenüberladung nach Transfusionen und bei ineffektiver Erythropoese. Leberparenchymschäden zeigen neben normalen auch häufig erhöhte Ferritinwerte, wahrscheinlich infolge der verminderten Abbaufunktion und/oder Leberzellnekrosen.

- Hohe Ferritinkonzentrationen im Blutserum werden im Alter gemessen ohne klinischen Befunde, übergewichtige Frauen mit erhöhtem Ferritin haben häufig eine erhöhte Insulinresistenz und erhöhte Leberenzyme. Hohes Ferritin ist bei Typ-2-Diabetikern mit hohem HbA1C assoziiert und sinkt bei Rückgang des Blutzuckers. In der frühen Schwangerschaft gehen hohe Ferritinwerte dem Schwangerschaftsdiabetes voraus. Erhöhtes Ferritin kann auch dem Hochdruck und der Fettsucht vorausgehen. Hohes Ferritin der Mutter im ersten Trimenon korreliert mit vorzeitiger Wehentätigkeit ( $a b$ der 34 . Schwangerschaftswoche). Bei Dialysepatienten mit Herzkrankheit und bei strahlentherapierten Patienten mit Pankreaskarzinom steht ein hoher Ferritinspiegel für eine schlechte Prognose.

- Die Ferritinbestimmung ist sinnvoll zur Überwachung des Eisenspeichers bei Blutspendern (Steuerung einer optimalen Spendefrequenz und Eisensubstitution).

- Sehr hohe Ferritinkonzentrationen (bis $100.000 \mu \mathrm{g} / \mathrm{L}$ ) werden im Serum bei der hämophagozytischen Lymphohistiozytose gemessen. Hohes Ferritin im Serum ist mit dem Fortschreiten der multiplen Sklerose assoziiert. Beim akuten Koronarsyndrom ist Ferritin mit dem CRP korreliert.

- Beim Restless-Legs-Syndrom werden Ferritinwerte unter $50 \mu \mathrm{g} / \mathrm{L}$ beobachtet. Bei Neuroferritinopathie führen Mutationen im L-Ferritingen zu Eisenaggregaten im Gehirn. Das Serumferritin ist dabei niedrig oder im Normbereich.

Zur Interpretation von Kenngrößen des Eisenhaushalts Tab. 1.

Diagnostische Wertigkeit Die Ferritinerhöhung ist bei Eisenüberladung weniger empfindlich und unspezifischer als die Transferrinsättigung vor allem bei Lebererkrankungen, Infektionen und Tumoren. Zur Differenzialdiagnose von Entzündungs-/Tumoranämie sollten immer Ferritin und Akute-Phase-Proteine (z. B. C-reaktives Protein und $\alpha_{1}$-Glykoprotein) mit bestimmt werden. Die Differenzialdiagnostik wird vereinfacht durch zusätzliche Bestimmung des löslichen Transferrinrezeptors (sTfR) ( $\triangleright$ Transferrinrezeptor, löslicher). Besonders bei Anämie bei Ferritinwerten $>12$ und $<100 \mu \mathrm{g} / \mathrm{L}$ zeigt ein normaler sTfR eine Anämie bei chronischer Entzündung und eine 
Ferritin, Tab. 1 Interpretation von Kenngrößen des Eisenhaushalts

\begin{tabular}{|c|c|c|c|c|c|}
\hline CRP & Transferrinsättigung (\%) & $\begin{array}{l}\text { Löslicher Transferrinrezeptor } \\
\text { (sTfR) }\end{array}$ & Ferritin $(\mu \mathrm{g} / \mathrm{L})$ & $\mathrm{Fe}^{2+}(\mu \mathrm{mol} / \mathrm{L})$ & Art der Anämie \\
\hline Normal & $<15$ & Erhöht & $\begin{array}{l}<15 \\
<45 \\
\text { (wenn Transferrinsättigung } \\
<15 \% \text { ) }\end{array}$ & $<7$ & $\begin{array}{l}\text { Eisenmangel (latent, wenn } \mathrm{Hb} \\
\text { und MCV nicht erniedrigt } \\
\text { sind) }\end{array}$ \\
\hline Erhöht & Normal oder erniedrigt & Normal & Normal oder erhöht & $<7(>7)$ & $\begin{array}{l}\text { Entzündungs-/Tumoranämie } \\
\text { ohne Eisenmangel }\end{array}$ \\
\hline Erhöht & Normal oder erniedrigt & Erhöht & Normal oder erhöht & $<7$ & $\begin{array}{l}\text { Entzündungs-/Tumoranämie } \\
\text { mit Eisenmangel }\end{array}$ \\
\hline \multirow[t]{2}{*}{ Normal } & \multirow[t]{2}{*}{$>55$} & Normal oder erniedrigt & $\begin{array}{l}\text { Bei idiopathischer } \\
\text { Hämochromatose erhöht oder } \\
\text { normal }\end{array}$ & Erhöht & Eisenüberladung \\
\hline & & Normal oder erniedrigt & $\begin{array}{l}\text { Bei sekundärer Überladung } \\
\text { erhöht (z. B. bei } \\
\text { Transfusionen) }\end{array}$ & & \\
\hline
\end{tabular}

Erhöhung des sTfR eine Eisenmangelanämie oder eine Mischform (Klinik, Akute-Phase-Proteine) an. Zur Verbesserung der Trennschärfe ist hier der Quotient sTfR/log Ferritin (Ferritinindex) und bei Zugriff auf Messwerte des Retikulozytenhämoglobins der Thomas-Plot geeignet, wobei Studien (Markovic et al. 2005; Skikne et al. 2011) die höhere Trennschärfe sowohl für den Ferritinindex als auch für den löslichen Transferrinrezeptor allein ermittelten. Verbesserungen der Differenzialdiagnostik sind bei Ersatz des Ferritinindexes durch die Hepcidinkonzentration (Hepcidin-Plot) zu erwarten. Auch zur Überwachung des Eisenstoffwechsels in der Schwangerschaft ist der Ferritinindex geeignet: Ferritin ist in der normalen Schwangerschaft teilweise erhöht, sTfR jedoch zuverlässig nur bei Eisenmangel) erhöht. Zur Verlaufskontrolle ist Ferritin meist ausreichend. Hypochrome mikrozytäre Anämien können auch durch eine Kupfermangelernährung ( $>$ Kupfer und $>$ Coeruloplasmin erniedrigt) bedingt sein.

\section{Literatur}

Markovic M, Majkic-Singh N, Subota V (2005) Usefulness of soluble transferrin receptor and ferritin in iron deficiency and chronic disease. Scand J Clin Lab Invest 65(7):571-576

Skikne BS, Punnonen K, Caldron PH, Bennett MT, Rehu M, Gasior GH, Chamberlin JS, Sullivan LA, Bray KR, Southwick PC (2011) Improved differential diagnosis of anemia of chronic disease and iron deficiency anemia: a prospective multicenter evaluation of soluble transferrin receptor and the $\mathrm{sTfR} / \log$ ferritin index. Am J Hematol 86(11):923-927

Thomas C, Thomas L (2002) Biochemical markers and hematologic indices in the diagnosis of functional iron deficiency. Clin Chem 48:1066-1076

Torti FM, Torti SV (2002) Regulation of ferritin genes and protein. Blood 99:3505-3516

Wick M, Pinggera W, Lehmann P (2000) Eisenstoffwechsel, AnämienDiagnostik und -Therapie, 5. Aufl. Springer, Berlin/Heidelberg/New York

\section{Ferritin-Index}

> Thomas-Plot

\section{Ferrochelatase}

\section{T. Stauch}

\section{Synonym(e) FECH; Protohämferrolyase}

\section{Englischer Begriff ferrochelatase}

Definition Durch das Enzym Ferrochelatase erfolgt der Einbau des Eisens als Zentralion in das Protoporphyrin IX. Ausgeprägte Minderaktivitäten dieses Enzyms führen zur Kumulation von freiem Protoporphyrin und in Folge von dessen Einlagerung in der Haut zu hoher Lichtsensitivität im Sinne einer erythropoetischen Protoporphyrie.

Beschreibung Die Diagnosestellung eines möglichen Defektes der Ferrochelatase erfolgt anhand der Analyse der Blutporphyrine $(\mathrm{s}$. $>$ Freies Protoporphyrin und $\triangleright$ Zink-Protoporphyrin in Erythrozyten) sowie durch einen $\triangleright$ Fluoreszenz-Scan im Plasma. Die Aktivitätsbestimmung des Enzyms ist aufwändig und kann nur in vitalen Lymphozyten erfolgen. Dies erfordert auch eine umfangreiche Probenvorbereitung und begründet relevante Einschränkungen, was die Verwahrungs- und Transportzeiten anbelangt. Das Verfahren ist daher wenig routinetauglich und im Wesentlichen wissenschaftlichen Fragestellungen vorbehalten. Alternativ bietet sich die molekulargenetische Analyse des Ferrochelatase-(FECH-)Gens zur Diagnosebestätigung bzw. Identifizierung von möglichen, familiären Merkmalsträgern an (s. a. - Freies Protoporphyrin). 


\section{Ferroxidase}

- Coeruloplasmin

\section{FerroZine}

$\checkmark$ Eisen

\section{Fersenblut}

W. G. Guder

Synonym(e) Kapillarblut aus der Ferse

Englischer Begriff capillary blood from the heel

Definition Empfohlene Probe kapillären Vollbluts bei Neugeborenen.

Beschreibung Bei Neugeborenen und kleinen Kindern wird statt der Fingerbeere die laterale und plantare Oberfläche der Ferse als Ort der kapillären Blutentnahme empfohlen. Dabei ist darauf zu achten, dass die $>$ Lanzetten nicht tiefer als $2 \mathrm{~mm}$ einstechen können (sog. Sicherheitslanzetten), um den Knochen nicht zu treffen.

Nach Reinigung der Haut trocknet man die Punktionsstelle mit sterilem Mull, um Reste des Desinfektionsmittels zu entfernen, die sonst Ursache der Hämolyse sein könnten. Nach Punktion wird der erste Tropfen abgewischt und weitere Tropfen in eine aufsaugende Kapillare (z. B. für die $>$ Blutgasanalyse) oder ein Kapillarblutgefäß gesammelt. Röhrchen mit einem Zusatz werden nach Aufnahme der Blutstropfen mehrmals durch Schwenken gemischt und verschlossen ins Labor befördert.

\section{Literatur}

CLSI (2004) Procedures and devices for collection of diagnostic capillary blood specimens; approved standard-fifth edition document H4-A5. Clinical and Laboratory Standard Institute, Wayne

Vassault A, Couderc R (2015) Special pre-examination conditions in newborns and pediatric samples. in Guder WG, Narayanan S. PreExamination Procedures in Laboratory Diagnostics. Berlin:Walter de Gruyter, S 40-49

\section{FES}

- Flammenemissionsspektrometrie

\section{FESCC}

- Forum of the European Societies of Clinical Chemistry and Laboratory Medicine

\section{Festkörperelektrode}

> Ionenselektive Elektrode

\section{Festphase}

- Stationäre Phase

\section{Festphasenextraktion}

C. Vidal und W.-R. Külpmann

Englischer Begriff solid phase extraction, SPE

Beschreibung Bei der Festphasenextraktion wird die flüssige Probe auf eine feste Phase gegeben, die aus einem Silika- oder Polymergrundgerüst mit mehr oder weniger polaren Gruppen besteht. Sie befindet sich in einem kleinen Glasoder Plastikzylinder („Säule“). Die zu untersuchenden Bestandteile werden mittels Aufgabe eines Lösungsmittels (Eluens) von der festen Phase abgelöst und verlassen mit dem Lösungsmittel die Säule (Eluat), während die anderen Bestandteile an der festen Phase fixiert bleiben oder mit einem anderen Lösungsmittel anschließend freigesetzt werden (s. a. > Mikrosäulen).

\section{Festphasenimmunglobulintest} K. Kleesiek, C. Götting, J. Diekmann, J. Dreier und
M. Schmidt

Synonym(e) Capture test

Englischer Begriff solid phase immunoglobuline technique

Definition In einem Festphasenimmunglobulintest sind Blutgruppenantigene auf Erythrozytenmembranen an die Oberfläche 
der Vertiefung von Mikrotiterplaten fixiert. Der optische Nachweis einer Antigen-Antikörper-Reaktion erfolgt durch den Zusatz von Anti-Human-IgG-beladenen Erythrozyten. Diese Technik kann zur $>$ Blutgruppenbestimmung, zum $\gg$ Antikörpersuchtest und zur Antikörperdifferenzierung eingesetzt werden.

Der Vorteil dieser Technik liegt im Vergleich zum traditionellen Röhrchenansatz in einer höheren Sensitivität und der Möglichkeit einer Mechanisierung. Somit stellt diese Technik auch eine Alternative zum $>$ Säulenagglutinations-Test dar. Das methodische Prinzip des Festphasenimmunglobulintests beruht auf dem indirekten Antihumanglobulintest.

Funktion:

Der Test kann auf der Basis von Mikrotiterplatten (s. - Mikrotiterplatte) in 2 Varianten durchgeführt werden:

- Im Test der ersten Generation sind die Vertiefungen einer Mikrotiterplatte chemisch so präpariert, sodass bei jedem Test Erythrozytenmonolayer aus Suchzellen oder Probandenerythrozyten (Eigenansatz) selbst hergestellt werden.

- Im Test der zweiten Generation sind die Erythrozyten zweier Suchzellen (Antikörpersuchtest) oder mehr bereits in den Vertiefungen einer Mikrotiterplatte fixiert.

Bei einer Antikörperdifferenzierung sind mehr (z. B. 11) antigendefinierte Zellen in den Vertiefungen der Mikrotiterplatte vorhanden. Durch ein spezielles chemisches Verfahren wird die Eigenfärbung der Erythrozyten eliminiert. Die Entfärbung der fixierten Erythrozyten ermöglicht eine visuell eindeutige Beurteilung der Testreaktion nach Zusatz der Indikatorerythrozyten.

Im Einzelnen werden bei der Testdurchführung Erythrozytenmembranen chemisch als erythrozytärer Monolayer in den konvexen Vertiefungen einer Mikrotiterplatte fixiert und dort in Kontakt mit Probandenserum gebracht. Während der Inkubation werden vorhandene Antikörper an die korrespondierenden Erythrozytenantigene gebunden. Das übrige Serum mit allen ungebundenen Antikörpern wird in einem anschließenden Waschschritt entfernt. Die entstandenen IgG-AntikörperAntigen-Komplexe werden durch eine zweite Immunreaktion mit Indikatorerythrozyten, die mit Antikörpern gegen humanes IgG beladen sind, nachgewiesen. Sind Antikörper aus dem Probandenserum an die Erythrozyten des Monolayers gebunden, lagern sich die Indikatorzellen an diese Antikörper an. Nach abschließender Zentrifugation bildet sich ein rosafarbener erythrozytärer Zellrasen aus Indikatorerythrozyten, der sich mehr oder weniger gleichmäßig über den gesamten Boden der jeweiligen Konkavität verteilt. Ist das Probandenserum frei von erythrozytären Antikörpern der Immunglobulinklasse G, so binden die Indikatorzellen nicht an die Zellen des Monolayers und sammeln sich bei einer Zentrifugation in die Mitte der konkaven Vertiefung und bilden dort einen kompakten Erythrozytenknopf.

\section{Literatur}

Eckstein R, Zimmermann R (2015) Immunhämatologie und klinische Transfusionsmedizin, 7. Aufl. Urban \& Fischer/Elsevier Verlag, München

Engelfried CP, Meulenbroek AJ (Hrsg) (2003) Immunohaematology. Sanquin Blood Supply Foundation, Amsterdam

Kiefel V (Hrsg) (2010) Transfusionsmedizin: Grundlagen - Therapie - Methodik, 4. Aufl. Springer, Berlin/Heidelberg/New York

\section{Festphasen-Immunoassay}

Immunoassay, heterogener

\section{Festphasen-Mikroextraktion}

$>$ Solid-phase Micro-Extraction

Fetale Erythroblastose

- Morbus haemolyticus fetalis/neonatorum

\section{Fetale intestinale AP}

Kasahara-Isoenzym

\section{$\alpha_{1}$-Fetoprotein}

\section{S. Holdenrieder und P. Stieber}

Synonym(e) AFP; Alpha-1-Fetoprotein

\section{Englischer Begriff alpha-fetoprotein}

Definition Das humane $\alpha$-Fetoprotein ist ein $70 \mathrm{kDa}$ schweres Glykoprotein mit $4 \%$ Kohlenhydratanteil und einer elektrophoretischen $\alpha_{1}$-Beweglichkeit.

Struktur $\alpha_{1}$-Fetoprotein besteht aus 590 Aminosäuren mit 15 regelmäßig angeordneten Disulfidbrücken und zeigt eine Faltblattstruktur von 3 sich wiederholenden Domänen. Mittels monoklonaler Antikörper wurden 3-7 verschiedene Epitope auf dem AFP-Molekül nachgewiesen. 


\section{Molmasse $70 \mathrm{kDa}$.}

Synthese - Verteilung - Abbau - Elimination Physiologisch wird $\alpha$-Fetoprotein im fetalen Gastrointestinaltrakt, in der fetalen Leber sowie im Dottersack gebildet und ist ab der 4. Schwangerschaftswoche (SSW) im fetalen Serum nachweisbar. Es erreicht dort seine höchste Konzentration in der 12.-16. SSW (ca. 3,0-4,0 g/L) und fällt dann bis zur Geburt allmählich ab. Diaplazentar gelangt es auch in den mütterlichen Kreislauf(Maximum bis $500 \mu \mathrm{g} / \mathrm{L}$ in der 32.-36. SSW) und dient als wichtige klinisch-chemische Kenngröße zur Schwangerschaftsüberwachung. Bei Geburt betragen im Nabelschnurblut die mittleren AFP-Werte etwa $70 \mathrm{mg} / \mathrm{L}$ und nehmen in den folgenden Lebenswochen mit einer Halbwertszeit von ca. 4 Tagen mit großen individuellen Schwankungsbreiten ab. Erst ab dem 10. Lebensmonat werden Werte im Referenzbereich von erwachsenen Personen $<15 \mu \mathrm{g} / \mathrm{L}$ (testabhängig) erreicht.

Halbwertszeit 2-8 Tage.

Funktion - Pathophysiologie AFP-Werte im mütterlichen Serum oder im fetalen Fruchtwasser, die deutlich über dem Referenzbereich der entsprechenden SSW liegen, werden unter anderem bei Vorliegen von Neuralrohrdefekten beobachtet.

Im Erwachsenenalter liegt die wesentliche klinische Bedeutung der $\alpha$-Fetoproteinbestimmung in der Entdeckung und Verlaufsbeobachtung von primären Leberzellkarzinomen und Keimzelltumoren des Hodens, Ovars oder extragonadaler Lokalisation, bei denen hochpathologische Werte beobachtet werden können. Die stark gesteigerte AFP-Freisetzung wird durch die Derepression von für die AFPBildung verantwortlichen Genen erklärt, die bei der Geburt reprimiert wurden. Während irreversible Veränderungen von hepatozytären Vorstufen bzw. persistierende Hepatoblasten für die AFP-Bildung beim primären Leberzellkarzinom mit verantwortlich gemacht werden, leiten sich die AFP-produzierenden Zellen in Keimzelltumoren vom Dottersackepithel (endodermale Sinusstrukturen) ab.

Untersuchungsmaterial - Entnahmebedingungen Serum, Fruchtwasser, Pleuraexsudat, Aszites, Liquor.

Analytik $>$ Enzymimmunoassay (EIA), > Radioimmunoassay (RIA), > Immunradiometrischer Assay (IRMA), $>$ Elektrochemilumineszenz-Immunoassay (ECLIA), insbesondere unter Verwendung von monoklonalen Antikörpern.

\section{Konventionelle Einheit $\mathrm{ng} / \mathrm{mL}$.}

Internationale Einheit $\mathrm{IU} / \mathrm{mL}$.

Umrechnungsfaktor zw. konv. u. int. Einheit $\times 0,7 \mathrm{IU} / \mathrm{ng}$.
Referenzbereich - Erwachsene Serum: Median $2 \mu \mathrm{g} / \mathrm{L}$; $95 \%$-Perzentile $6 \mu \mathrm{g} / \mathrm{L}$; 99 \%-Perzentile $15 \mu \mathrm{g} / \mathrm{L}$ (testabhängig; nicht bei Schwangeren).

Referenzbereich - Kinder Serum: Median $2 \mu \mathrm{g} / \mathrm{L}$; $95 \%$ Perzentile $6 \mu \mathrm{g} / \mathrm{L}$; $99 \%$-Perzentile $15 \mu \mathrm{g} / \mathrm{L}$ (testabhängig; nach den ersten 12-24 Monaten).

\section{Indikation}

- Verlaufsbeobachtung (alle 2-3 Monate) von chronischen Lebererkrankungen

- Verdacht auf hepatozelluläres Karzinom

- Keimzelltumoren (Hoden, Ovar, extragonadal), bei Hodentumoren präoperative Bestimmung obligat, zusammen mit $\beta$ HCG und LDH Staging-Parameter

- Therapiekontrolle und Nachsorge von Keimzelltumoren oder primärem Leberzellkarzinom

Interpretation Die meisten AFP-Assays sind zwar für die Anwendung im Serum und Plasma ausgetestet, können aber auch für die AFP-Bestimmung in anderen Körperflüssigkeiten eingesetzt werden.

Das $\alpha$-Fetoprotein weist in sehr hohen Wertlagen ( $>1000 \mu \mathrm{g} / \mathrm{L})$ eine hohe Tumorspezifität für das primäre Leberzellkarzinom und für nicht seminomatöse Keimzelltumoren auf. Reine Seminome sind definitionsgemäß AFPnegativ. Es kann allerdings auch vereinzelt bei anderen malignen Erkrankungen, insbesondere bei gastrointestinalen Karzinomen (Magenkarzinom, seltener Pankreas- oder Kolonkarzinom), aber auch bei gynäkologischen oder pulmonalen Neoplasien, in z. T. deutlichem Ausmaß freigesetzt werden. Da die Nichtleberzellkarzinome jedoch häufig mit einer erheblichen CEA-Freisetzung einhergehen, ist durch die kombinierte Bestimmung von CEA ( $>$ Carcinoembryonales Antigen) und AFP eine differenzialdiagnostische Unterscheidung häufig gut möglich.

Verschiedene benigne Erkrankungen können ebenfalls gering bis moderat erhöhte AFP-Konzentrationen hervorrufen; bei chronischen Lebererkrankungen wie Leberzirrhose und Hepatitis werden häufig erhöhte individuelle Basiswerte beobachtet.

Aus den patientenbezogenen Parametern Geschlecht und Alter sowie den serologischen Markern AFP, AFP-L3, DCP wurde ein inzwischen mehrfach validierter GALAD-Score entwickelt, der eine den Einzelmarkern deutlich überlegene Differenzierung des hepatozellulären Karzinoms von benignen Lebererkrankungen - selbst in frühen Tumorstadien - ermöglicht und auch zur frühzeitigen Erkennung des HCC bei Risikopatienten eingesetzt werden kann. Darüber hinaus wurde ein prognostischer BALAD-2-Algorithmus aus den Serummarkern Bilirubin, Albumin, AFP-L3, AFP und DCP gebildet, anhand dessen HCC-Patientengruppen mit deutlich unterschiedlichen Überlebenszeiten identifiziert wurden. 


\section{Diagnostische Wertigkeit}

- Primäres hepatozelluläres Karzinom: Früherkennung bei Risikogruppen, Differenzialdiagnose, Prognose, Therapiemonitoring, Rezidiverkennung

- Keimzelltumoren: Früherkennung bei Risikogruppen, Differenzialdiagnose, Prognose, Therapiemonitoring, Rezidiverkennung

\section{Literatur}

Berhane S, Toyoda H, Tada T, Kumada T et al (2016) Role of the GALAD and BALAD-2 serologic models in diagnosis of hepatocellular carcinoma and prediction of survival in patients. Clin Gastroenterol Hepatol 14:875-886

Lamerz R (2012) AFP (Alpha-Fetoprotein). In: Thomas L (Hrsg) Labor und Diagnose, 8. Aufl. TH-Books, Frankfurt am Main, S 1619-1624

Sturgeon CM, Duffy MJ, Hofmann BR et al (2010) National Academy of Clinical Biochemistry Laboratory Medicine Practice Guidelines for use of tumor markers in liver, bladder, cervical, and gastric cancers. Clin Chem 56:e1-48

\section{Fett}

> Triglyzeride

\section{Fett im Stuhl}

- Stuhlfett

\section{Fettleber-Index}

\section{A. M. Gressner und O. A. Gressner}

\section{Synonym(e) FLI}

Englischer Begriff fatty liver index; FLI

Definition Der zur nichtinvasiven Diagnostik der nichtalkoholbedingten Fettleber (NAFLD) eingesetzte Test basiert auf den gemeinsam ausgewerteten Bestimmungen von 3 Laborkenngrößen und 2 klinischen Parametern.

Beschreibung Die bei $20-30 \%$ der europäischen Normalbevölkerung prävalente nichtalkoholische Fettleber (NAFLD, „non alcoholic fatty liver disease") ist kausal assoziiert mit dem metabolischen Syndrom und Diabetes mellitus Typ 2 und stellt ein erhöhtes Risiko für kardiovaskuläre Morbidität und progrediente Lebererkrankungen wie NASH (,nonalcoholic steatohepatitis“), Zirrhose und hepatozelluläres Karzinom dar.

Der zur Diagnose, Schweregradbestimmung und Verlaufskontrolle der Fettleber eingesetzte, nichtinvasive FettleberIndex (FLI) basiert auf der integralen quantitativen Bewertung folgender Parameter:

- > Body-Mass-Index (BMI; Gewicht, kg; Größe, cm)

- Triglyzerid-Konzentration (Serum; > Triglyzeride) im Nüchternzustand (mg/dL)

- $\quad \gamma$-Glutamyltransferase-Aktivität (Serum) im Nüchternzustand (U/L)

- Bauch- bzw. Taillenumfang $(\mathrm{cm})$

Ein FLI $>60$ zeigt mit $78 \%$ iger Wahrscheinlichkeit eine Fettleber an, während ein FLI $<20$ mit 90 \%iger Wahrscheinlichkeit diese ausschließt. Umfangreichen epidemiologischen Untersuchungen zufolge weisen Probanden mit einem FLI $>60$ eine signifikant höhere Prävalenz von Diabetes mellitus Typ 2, metabolischem Syndrom, eingeschränkter Nierenfunktion und kardiovaskulären Erkrankungen auf.

Ein kürzlich von Kantartzis et al. (2017) vorgestellter, erweiterter FLI berücksichtigt zusätzlich die Konzentrationen im Serum von Triglyzeriden und Glukose 2 Stunden nach oraler Aufnahme von $75 \mathrm{~g}$ Glukose ( $\triangleright$ Glukosetoleranztest, oral) sowie das Vorliegen eines mit NAFLD assoziierten genetischen „single-nucleotide polymorphism“ (SNP) rs738409 C > G im PNPLA3-Gen (,,patatin-like phopholipase domain-containing 3“, Adiponutrin). Etwa 50 \% der Probanden mit NAFLD tragen zumindest ein variantes $(G)$ Allel dieses Gens, das mit hohem Leberfettgehalt assoziiert ist. Die Erweiterung des FLI durch die ergänzend eingeführten 3 Kenngrößen steigert den prädiktiven Wert des FLI für die NAFLD-Diagnostik signifikant auf einen AUROC-Wert von 0,86 . Darüber hinaus ist der erweiterte FLI für die Verlaufskontrolle der Abnahme des Leberfettgehaltes bei therapeutischen Maßnahmen wie einer Lebensstiländerung geeignet.

\section{Literatur}

Chen LZ, Xib YN, Geng N et al (2015) PNPLA3I148M variant in nonalcoholic fatty liver disease: demographic and ethnic characteristics and the role of the variant in nonalcoholic fatty liver fibrosis. World J Gastroenterol 21(3):794-802

Kantartzis K, Rettig I, Staiger H et al (2017) An extended fatty liver index to predict non-alcoholic fatty liver disease. Diabetes Metab. https://doi.org/10.1016/j.diabet.2016.11.006. Epub vor Druck

Van den Berg EH, Amini M, Schreuder TC et al (2017) Prevalence and determinants of non-alcoholic fatty liver disease in lifelines: a large Dutch population cohort. PLoS 12(2):e0171502

Yki-Järvinen H (2014) Non-alcoholic fatty liver disease as a cause and a consequence of metabolic syndrome. Lancet Diabetes Endocrinol 2(11):901-910 


\section{Fettmalabsorption}

> Stuhlfett

\section{Fettsäurebindendes Protein, Herztyp}

- Fettsäurebindungsprotein, cardiales

\section{Fettsäurebindungsprotein, cardiales}

D. Peetz

Synonym(e) cFABP; Fettsäurebindendes Protein, Herztyp; hFABP

Englischer Begriff heart-type fatty acid binding protein

Definition Heart-type Fatty Acid Binding Protein (hFABP) gehört zur Familie der ,Fatty Acid Binding“-Proteine, die in allen Fett-metabolisierenden Geweben vorkommen und in der Lage sind, Fettsäuren nichtkovalent zu binden.

Struktur hFABP ist ein relativ kleines, aus 132 Aminosäureresiduen bestehendes Protein. Das Gen für die Synthese von hFABP ist auf dem kurzen Arm des Chromosoms 1 (1p321p33) lokalisiert. Ein Molekül hFABP kann 2 Moleküle Fettsäure binden. Mit den „Fatty Acid Binding“-Proteinen des Intestinums, der Leber, der Skelettmuskulatur, des Fettgewebes, der Nieren, des Nervengewebes weist es Strukturhomologien zwischen 30 und $80 \%$ auf.

Molmasse $15 \mathrm{kDa}$.

Synthese - Verteilung - Abbau - Elimination hFABP ist ein ausschließlich zytosolisch vorkommendes Protein und macht 4-8 \% des Gesamtproteingehalts der Kardiomyozyten aus. In hoher Konzentration (0,5 mg/g Feuchtgewicht) kommt hFABP ausschließlich im Herzen vor, es ist jedoch nicht $100 \%$ herzspezifisch. Die hFABP-Konzentrationen sind in anderen Geweben, wie z. B. den Nieren oder im Gehirn, sehr gering. Höhere hFABP-Konzentrationen werden in der Skelettmuskulatur gefunden $(0,05-0,2 \mathrm{mg} / \mathrm{g}$ Feuchtgewicht). Nach Freisetzung ins Blut wird hFABP über den Urin ausgeschieden.

Halbwertszeit 20 Minuten.
Funktion - Pathophysiologie Fettsäuren sind die Hauptenergiequelle des Herzens. 50-80 \% des Energiebedarfs des Herzens werden durch Fettsäureoxidation gedeckt. Das Herz selbst weist nur eine geringe Fettsäuresynthese auf (ca. 0,1 \% der Gesamtkörpersynthese), ist allerdings für $10 \%$ des Gesamtverbrauchs verantwortlich. Die Funktion der FABP besteht im intrazellulären Transport hydrophober, langkettiger Fettsäuren von der Zellmembran in die Mitochondrien (Fettsäureoxidation). Weiterhin werden Fettsäuren intrazellulär auch für die Synthese von Membranlipiden und Lipidmediatoren benötigt. Beim Gesunden kommt hFABP im Plasma nur in sehr geringer Konzentration von $<5 \mu \mathrm{g} / \mathrm{L}$ vor. Das Verhältnis der zytoplasmatischen zur intravaskulären Konzentration beträgt 200.000:1. Nach einer ischämischen Herzschädigung steigt hFABP rasch im Plasma an und überschreitet nach 2-3 Stunden die obere Referenzbereichsgrenze, erreicht nach 4-6 Stunden die höchste Konzentration und kehrt innerhalb von 20 Stunden in den Referenzbereich zurück. Bei Niereninsuffizienz ist hFABP $>25$ Stunden im Plasma nachweisbar.

Untersuchungsmaterial-Entnahmebedingungen Serum, Plasma, Vollblut.

Analytik Für die Bestimmung von hFABP stehen verschiedene, kommerziell verfügbare ELISA-Teste sowie qualitative und quantitative Point-of-Care-Tests zur Verfügung.

Konventionelle Einheit $\mu \mathrm{g} / \mathrm{L}$.

Referenzbereich - Erwachsene Der Referenzbereich ist methodenabhängig und bewegt sich in der Größenordnung von $0-5 \mu \mathrm{g} / \mathrm{L}$.

Indikation Frühdiagnose des akuten Myokardinfarkts, Diagnose eines Reinfarkts, Diagnose eines perioperativen Myokardinfarkts, Prognoseabschätzung bei akuter Lungenembolie.

Interpretation Für die Diagnose eines akuten Myokardinfarktes weist die Bestimmung von hFABP innerhalb der ersten 30-210 Minuten nach Symptombeginn eine diagnostische Sensitivität von $>80 \%$ auf. Die Spezifität des Testes kann jedoch durch Niereninsuffizienz oder eine begleitende Skelettmuskelschädigung eingeschränkt sein. Aufgrund der kurzen Halbwertszeit kann hFABP für die Diagnose eines Reinfarkts genutzt werden. Nach Bypassoperationen steigt hFABP innerhalb von 30 Minuten nach Reperfusion an und kann daher als Marker für die frühe Erkennung eines perioperativen Myokardinfarktes genutzt werden.

Diagnostische Wertigkeit hFABP ist ein sensitiver, jedoch nicht vollständig herzspezifischer Marker für die Myokardin- 
farktdiagnostik. Im Vergleich zu Myoglobin weist es eine vergleichbare Freisetzungskinetik bei besserer Herzspezifität auf. Durch die Verfügbarkeit hochsensitiver kardialer Troponintests hat sich der Einsatz von hFABP in der Diagnostik des akuten Myokardinfarkts jedoch nicht durchgesetzt. Bei der akuten Lungenembolie ist hFABP einer der empfohlenen prognostischen Marker für die 30-Tage-Mortalität.

\section{Literatur}

Azzazy HME, Pelsers MMAL, Christenson RH (2006) Unbound free fatty acids and heart-type fatty acid-binding protein: diagnostic assays and clinical applications. Clin Chem 52:19-29

Konstantinides SV, Torbicki A, Agnelli G et al (2014) 2014 ESC guidelines on the diagnosis and management of acute pulmonary embolism. Eur Heart J 35:3033-3069

Liou K, Ho S, Ooi SY (2015) Heart-type fatty acid binding protein in early diagnosis of myocardial infarction in the era of high-sensitivity troponin: a systematic review and meta-analysis. Ann Clin Biochem $52: 370-381$

\section{Fettsäureethylester}

T. Arndt

\section{Synonym(e) FAEE}

Englischer Begriff fatty acid ethyl esters

Definition FAEE sind Ethylester gesättigter und ungesättigter langkettiger $>$ Fettsäuren, wie z. B. Myristin-, Palmitin-, Olein- und Stearinsäure.

Struktur Abb. 1.

Molmasse Myristinsäureethylester $\left(\mathrm{C}_{16} \mathrm{H}_{32} \mathrm{O}_{2}, \quad 256,430\right.$ $\mathrm{g} / \mathrm{mol})$, Palmitinsäureethylester $\left(\mathrm{C}_{18} \mathrm{H}_{36} \mathrm{O}_{2}, 284,484 \mathrm{~g} / \mathrm{mol}\right)$, Oleinsäureethylester $\left(\mathrm{C}_{20} \mathrm{H}_{38} \mathrm{O}_{2}, 310,522 \mathrm{~g} / \mathrm{mol}\right)$, Stearinsäureethylester $\left(\mathrm{C}_{20} \mathrm{H}_{40} \mathrm{O}_{2}, 312,583 \mathrm{~g} / \mathrm{mol}\right)$.

Synthese - Verteilung - Abbau - Elimination FAEE werden nach Ethanolkonsum aus freien und gebundenen Fettsäuren durch eine enzymkatalysierte Veresterung mit Ethanol gebildet. Sie sind bereits kurz nach Ethanolaufnahme und bis mindestens 24 Stunden nach Trinkende im Blut nachweisbar. Über die Talkdrüse (Sebum) und ggf. kleine, die Haarwurzel versorgende Blutkapillaren werden FAEE in die Haare eingelagert und dort weitgehend konserviert, während FAEE im Blut durch Esterasen abgebaut werden.

Halbwertszeit Blut und Haare unbekannt.
Funktion - Pathophysiologie Ob FAEE zellschädigende Wirkungen haben, ist nicht abschließend geklärt.

Untersuchungsmaterial - Entnahmebedingungen Haare, d. h. ein bleistiftstarkes $0-3 \mathrm{~cm}$ oder $0-6 \mathrm{~cm}$ langes, direkt über der Kopfhaut geschnittenes (proximales) Segment der am hinteren Scheitelpunkt wachsenden Haare. Zum Einfluss von Haarkosmetika (s. Interpretation).

Probenstabilität In Haaren stabil bei trockener, lichtgeschützter Lagerung.

Präanalytik Keine ethanolhaltige Haarkosmetik, Haare direkt über der Kopfhaut schneiden, jegliche Form der Haarbehandlung und -kosmetik notieren (z. B. Kolorierung, Bleichung, Haarwasser)

Analytik Waschen der Haarprobe mit einem unpolaren Lösungsmittel (Waschflüssigkeit asservieren), Pulverisierung und Aufschluss einer exakt eingewogenen Haarmasse, z. B. Festphasen-Mikroextraktion mit anschließender massenspektrometrischer Analyse unter Verwendung deuterierter FAEEStandards und Bestimmung der Zielanalyte Ethylpalmitat, Ethylmyristat, Ethyloleat und Ethylstearat.

\section{Konventionelle und internationale Einheit ng/mg.}

Referenzbereich - Entscheidungsgrenzen Entscheidungsgrenzen (Cut-offs) der Society of Hair Testing (SoHT 2016):

\begin{tabular}{l|l|l|}
$\begin{array}{l}\text { Palmitinsäureethylester } \\
\text { (Ethylpalmitat) in Kopfhaar }\end{array}$ & $\begin{array}{l}0-3 \mathrm{~cm}- \\
\text { Segment }\end{array}$ & $\begin{array}{l}0-6 \mathrm{~cm}- \\
\text { Segment }\end{array}$ \\
\hline $\begin{array}{l}\text { Chronisch exzessiver } \\
\text { Alkoholkonsum }\end{array}$ & $<0,35 \mathrm{ng} / \mathrm{mg}$ & $<0,45 \mathrm{ng} / \mathrm{mg}$ \\
\hline $\begin{array}{l}\text { Abstinenzbeleg (nur in } \\
\text { Kombination mit Ethylglucuronid) }\end{array}$ & $<0,12 \mathrm{ng} / \mathrm{mg}$ & $<0,15 \mathrm{ng} / \mathrm{mg}$ \\
\hline
\end{tabular}

Indikation Nachweis chronisch exzessiven Alkoholkonsums, Abstinenzbeleg (nicht als Alleinmarker, nur im Zusammenhang mit $\vee$ Ethylglukuronid).

\section{Interpretation}

- Die Entscheidungsgrenzen basieren nach der jüngsten SoHT-Empfehlung aus analytischen Gründen auf der Konzentration des Palmitinsäureethylesters (Cut-offs s. Tabelle). Damit wird der schwierigere Umgang mit einer Analytgruppe vermieden. Die weiteren o. g. Zielanalyte dienen nur mehr der (qualitativen) Bestätigung der Diagnose. Für sie wurden von der SoHT keine Cut-offs definiert.

- FAEE sind für einen Abstinenzbeleg nur Marker der 2. Wahl nach $>$ Ethylglukuronid in den Haaren (und Urin) und nur in Kombination mit diesen und bevorzugt nur bei unklaren EtG-Befunden. 


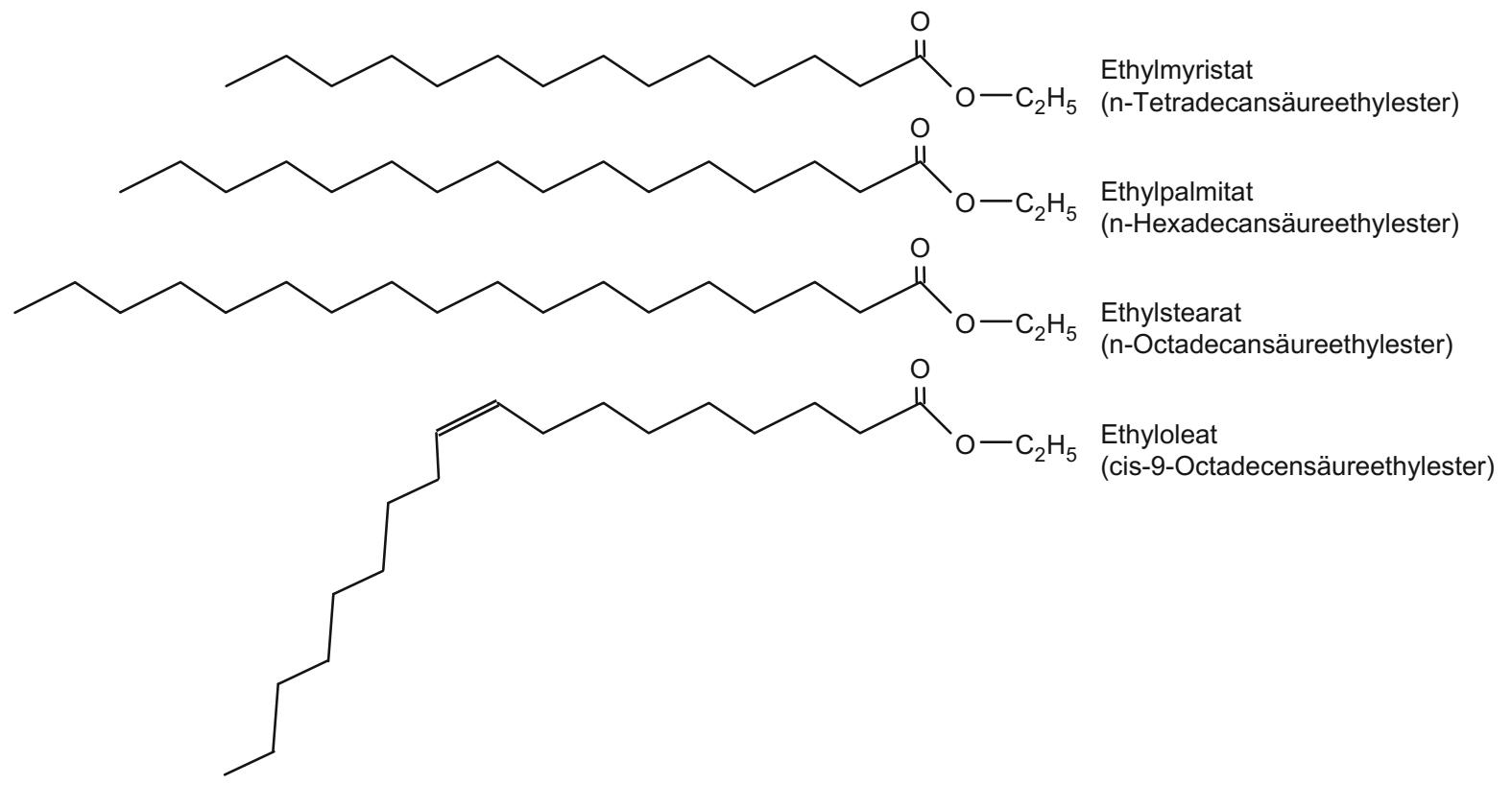

Fettsäureethylester, Abb. 1 FAEE-Zielanalyte, definiert von der Society of Hair Testing

- Haarbehandlung und -pflege (s. Präanalytik) müssen bei der Beurteilung der Messergebnisse berücksichtigt werden, da Kosmetika falsch positive (z. B. Bildung von FAEE aus Fettsäuren und Ethanol im Sebum) und falsch negative (thermische oder chemische Zerstörung der FAEE) Befunde auslösen können.

- Ein 0-3 cm langes Segment reflektiert ein diagnostisches Zeitfenster von ca. 3,5 Monaten (Haarwachstum ca. 0,5 Monate innerhalb der Kopfhaut $+\mathrm{ca} .1 \mathrm{~cm} /$ Monat als Kopfhaar), ein 0-6 cm Segment 6,5 Monate. Durch sequenzielle Analyse von z. B. $1 \mathrm{~cm}$ Abschnitten lässt sich der Zeitpunkt einer Ethanolaufnahme entsprechend eingrenzen.

Diagnostische Wertigkeit Mit den aktuellen Empfehlungen (SoHT 2016) zur Bewertung von FAEE-Konzentrationen im Kopfhaar weicht die SoHT erheblich von ihren früheren Konsensuspapieren ab. In diesen wurde die Summe der Konzentrationen der Zielanalyte zur Bewertung empfohlen (chronisch exzessiver Alkoholkonsum Summe $>0,5 \mathrm{ng} / \mathrm{mg}$ im 0-3 cm- oder $>1 \mathrm{ng} / \mathrm{mg}$ im 0-6 cm-Segment des proximalen Kopfhaars).

Die parallele Bestimmung von FAEE und $\triangleright$ Ethylglukuronid in Haaren soll eine verbesserte diagnostische Aussagekraft herbeiführen, insbesondere bei unklaren EtG-Befunden. $\mathrm{Ob}$ dies mit dem aus präanalytischer Sicht deutlich heikleren FAEE erreicht werden kann, bleibt ebenso wie eine abschlieBende Bewertung der diagnostischen Aussagekraft von FAEE in Haaren als Kenngröße einer Alkoholaufnahme offen.

Im Blut nachweisbare FAEE wurden als Kurzzeitmarker eines Alkoholkonsums beschrieben. Ob inhalative Exposition gegenüber ethanolhaltigen Dämpfen z. B. von Desinfektions- mitteln, zur Bildung von FAEE führen kann (wie für $>$ Ethylglukuronid beschrieben) ist nicht untersucht. FAEE in Blut haben derzeit in die Routinediagnostik keine Bedeutung.

FAEE in Meconium als Biomarker einer pränatalen Ethanolexposition befinden sich noch im Forschungsstadium.

\section{Literatur}

Auwärter V et al (2011) Fatty acid ethyl esters in hair as markers of alcohol consumption. Segmental hair analysis of alcoholics, social drinkers, and teetotalers. Clin Chem 47:2114-2123

Society of Hair Testing (SoHT) (2012) Society of hair testing guidelines for drug testing in hair. Forensic Sci Int 218:20-24

Society of Hair Testing (SoHT) (2016) Consensus for the use of alcohol markers in hair for assessment of both abstinence and chronic excessive alcohol consumption. http://www.soht.org/images/pdf/Revision \%202016_Alcoholmarkers.pdf. Zugegriffen am 20.01.2017

\section{Fettsäuren}

A. C. Sewell

Synonym(e) Monocarbonsäuren

Englischer Begriff fatty acids

Definition Eine Gruppenbezeichnung für Monocarbonsäuren, die aus einer Carboxylgruppe und aus einer unterschied- 
lich langen, aber fast ausschließlich unverzweigten Kohlenwasserstoffkette bestehen.

Beschreibung Fettsäuren unterscheiden sich durch die Anzahl der C-Atome (Kettenlänge) sowie die Anwesenheit, Anzahl und Position von Doppelbindungen. Aufgrund ihrer Kettenlängen werden sie in kurz- (bis $7 \mathrm{C}$-Atome), mittel(8-12 C-Atome) und langkettige (>12 C-Atome) Fettsäuren unterteilt.

Eine gesättigte Fettsäure ist eine Fettsäure, die keine Doppelbindung zwischen den C-Atomen aufweist. Ungesättigte Fettsäuren besitzen eine Doppelbindung, und mehrfach ungesättigte Fettsäuren haben zwei oder mehr Doppelbindungen in der Kette. Die Doppelbindungen sind in der Regel cis-konfiguriert. Es kommen allerdings in der Natur auch Fettsäuren mit trans-konfigurierten Doppelbindungen vor. In der folgenden Tabelle sind Beispiele einiger natürlich vorkommender Fettsäuren (Anzahl C-Atome: Anzahl Doppelbindungen im Kohlenstoffskelett) zusammengestellt:

\begin{tabular}{|c|c|c|}
\hline Kohlenstoffskelett & Systematischer Name & $\begin{array}{l}\text { Gängige } \\
\text { Bezeichnung }\end{array}$ \\
\hline $12: 0$ & $n$-Dodecansäure & Laurinsäure \\
\hline 14:0 & $n$-Tetradecansäure & Myristinsäure \\
\hline $16: 0$ & $n$-Hexadecansäure & Palmitinsäure \\
\hline 18:0 & n-Octadecansäure & Stearinsäure \\
\hline $20: 0$ & $n$-Eicosansäure & Arachinsäure \\
\hline $24: 0$ & $n$-Tetracosansäure & Lignocerinsäure \\
\hline $16: 1$ & cis-9-Hexadecensäure & Palmitoleinsäure \\
\hline 18:1 & cis-9-Octadecensäure & Ölsäure \\
\hline $18: 2$ & $\begin{array}{l}\text { cis-, cis-9,12- } \\
\text { Octadecadiensäure }\end{array}$ & Linolsäure \\
\hline $18: 3$ & $\begin{array}{l}\text { cis-, cis-, cis-9,12,15- } \\
\text { Octadecatriensäure }\end{array}$ & $\alpha$-Linolensäure \\
\hline $20: 4$ & $\begin{array}{l}\text { cis-, cis-, cis-,cis-5,8,11,14- } \\
\text { Icosatetraensäure }\end{array}$ & Arachidonsäure \\
\hline
\end{tabular}

Fettsäuren werden als Triglyzeride im Fettgewebe gespeichert. Die Fettgewebslipolyse wird durch Adrenalin, Noradrenalin ( $\triangleright$ Katecholamine), $\triangleright$ Glukagon oder ACTH ( $>$ Adrenokortikotropes Hormon) gesteuert. Die daraus resultierenden freien Fettsäuren werden mit dem Blut zu den Energie benötigenden Zellen transportiert und dort unter ATP-Verbrauch mit Coenzym A aktiviert. Mithilfe von - Carnitin werden die aktivierten Fettsäuren in die Matrix des Mitochondriums transportiert und dort $\beta$-oxidiert. Endprodukt dieser $\beta$-Oxidation ist u. a. ATP. Zusätzlich findet in den Peroxisomen eine Oxidation der ultralangkettigen Fettsäuren ( $\triangleright$ Überlangkettige Fettsäuren) statt.

Gesättigte Fettsäuren liefern viel Energie, sind jedoch nicht lebensnotwendig. Fette mit hohem Anteil an mittelkettigen Fettsäuren sind einfacher zu verdauen als Fette mit langkettigen Fettsäuren. Omega-6-Fettsäuren werden meist zu entzündungsfördernden $>$ Prostaglandine verstoffwechselt, Omega3-Fettsäuren zu entzündungshemmenden Stoffen.
Von der Deutschen Gesellschaft für Ernährung wird empfohlen, ca. $30 \%$ des Energiebedarfs mit Fett abzudecken. Davon sollten $10 \%$ mit gesättigten, 10-13\% mit einfach und der Rest mit mehrfach ungesättigten Fettsäuren abgedeckt werden. Um das Herz-Kreislauf-Risiko gering zu halten, sollte das Verhältnis von Omega-6- zu Omega-3-Fettsäuren maximal 5:1 betragen.

\section{Fetuin A}

$\alpha_{2}$-HS-Glykoprotein

\section{FEU}

- Fibrinogen-äquivalente Einheiten

\section{FFS}

- Fluoreszenzspektrometrie/-spektroskopie

\section{FgDP}

- Fibrin(ogen)-Degradationsprodukte

\section{FGF21}

- Hepatokine

\section{FGF-23}

- Fibroblast Growth Factor 23

FI

- Färbeindex

- Ionisationsmethoden (Massenspektrometrie)

\section{FIA}

- Fluoreszenzpolarisations-Immunoassay 


\section{FIATA}

- Fibrinogen-Antigen-turbidimetrischer Test

Fibrillarin-Antikörper

> Autoantikörper gegen Nukleoli

\section{Fibrin}

T. Stief

Englischer Begriff fibrin (antithrombin-1)

Definition Fibrin ist das finale Produkt der Gerinnungsaktivierung. Thrombin wandelt lösliches $>$ Fibrinogen in Fibrinmonomer um, das zu unlöslichem Fibrin auspolymerisiert. Fibrin ist die Proteingrundlage des eine Wundfläche abdeckenden Fasernetzes.

Beschreibung Thrombin spaltet die beiden $>$ Fibrinopeptid A-(FPA-)Moleküle am aminoterminalen Ende (in der E-Domäne) der beiden $\mathrm{A} \alpha$-Ketten des Fibrinogens ab. Es entsteht Fibrinmonomer, das bereits auspolymerisieren kann. Bei starker Thrombinaktivität werden zusätzlich auch noch die beiden Fibrinopeptid B-(FPB-)Moleküle am aminoterminalen Ende der beiden B $\beta-$ Ketten des Fibrinogens abgespalten, was die Fibrinpolymerisierung noch verstärkt. Die Proteolyse an den aminoterminalen Enden der $A \alpha$ - und $B \beta$-Ketten ändert die Konformation, Polymerisationsdomänen werden exponiert. Die ebenfalls durch Thrombin aktivierte Transglutaminase $>$ Gerinnungsfaktor XIIIa (F13a) stabilisiert das Fibrinpolymer durch Quervernetzung der $\gamma$-Ketten (in der D-Domäne).

Die Aktivität von Thrombin, die Konzentration an Fibrinogen und an Calcium-Ionen bestimmen die Struktur der sich formenden Fibrinfasern. Insofern sind verschiedene prothrombotische Erkrankungen (mit hoher systemischer Thrombinaktivität wie bei Myokardinfarkt oder Diabetes mellitus) mit festerer Fibrinstruktur assoziiert.

\section{Literatur}

Marchi Cappelletti R (2012) Fibrinogen and fibrin: structure and functional aspects. In: Stief T (Hrsg) Thrombin: function and pathophysiology. Nova Science Publishers, New York, S 261-291

Stief T (Hrsg) (2012) Thrombin - applied clinical biochemistry of the main factor of coagulation. In: Thrombin: function and pathophysio- logy. Nova Science Publishers, New York, S vii-xx. https://www. novapublishers.com/lie/978-1-61942-087-8_Preface.pdf. Zugegrieffen am 12.09.2017

Stief T, Albert A (2013) Water quality routinely tested by RECA. Hemost Lab 6:361-365

\section{Fibrin, lösliches}

- Fibrinmonomere, lösliche

\section{Fibrin-Degradationsprodukt}

$>$ D-Dimer

- Fibrin(ogen)-Degradationsprodukte

\section{Fibrin-Lysezeit}

- Euglobulin-Lysezeit

\section{Fibrinmonomere, lösliche}

T. Stief

Englischer Begriff Fibrin monomers, soluble fibrin

Definition Lösliches Fibrin ist Thrombin-gespaltenes $>$ Fibrinogen (Fibrinmonomer), das auspolymerisiert, quervernetzt wird und z. T. noch in Lösung bleibt.

Beschreibung Fibrinmonomere entstehen durch die Abspaltung des Fibrinopeptids A durch $\triangleright$ Thrombin oder Thrombinähnliche Proteinasen (DesAA-Fibrin). Fibrinmonomer polymerisiert zu Fibrinpolymer, das dann durch Faktor 13a quervernetzt wird. Ein kleiner Teil des gebildeten Fibrins, sogar des quervernetzten Fibrins, ist löslich und zirkuliert mit dem fließenden Blut durch den Körper.

Lösliches Fibrin bildet die Wirkung von Thrombin auf Fibrinogen ab und kann damit zum Nachweis einer gesteigerten Thrombinbildung eingesetzt werden. Erhöhte Konzentrationen werden demzufolge bei Thrombosen oder bei DIC (disseminierte intravasale Koagulopathie) gemessen. Funktionstests basieren beispielsweise darauf, dass lösliches Fibrin die t-PA-vermittelte Umwandlung von $>$ Plasminogen $\mathrm{zu}$ Plasmin katalysiert. Arginin-Anwesenheit erhöht die Spezifität, ansonsten könnte auch Fibrinogen-Fragment X ( durch Plasmin initial gespaltenes Fibrinogen) t-PA stimulieren. Problematisch ist die Präzipitationstendenz von löslichem Fibrin, 
sodass erhöhte Konzentrationen möglicherweise nicht gemessen werden können, da das Fibrin auf dem Endothel auspräzipitierte.

\section{Literatur}

Stief TW (2000) Functional determination of soluble fibrin polymers (SFP) in plasma. Thromb Haemost 84:1120-1121

Wiman B, Ranby M (1986) Determination of soluble fibrin in plasma by a rapid and quantitative spectrophotometric assay. Thromb Haemost 55: $189-193$

\section{Fibrinogen}

\section{T. Stief und P. Kiefer}

Synonym(e) Faktor I

\section{Englischer Begriff fibrinogen}

Definition Fibrinogen ist ein dimeres wasserlösliches Protein, die Vorstufe für in Plasma schwerlösliches $>$ Fibrin (Antithrombin-1).

Die folgende Abbildung zeigt die trinoduläre Struktur des Fibrinogens mit den globulären Domänen D und E, der C-terminalen Extension der $\alpha$-Ketten, Disulfidbrückenbindungen und den Fibrinopeptiden A und B.

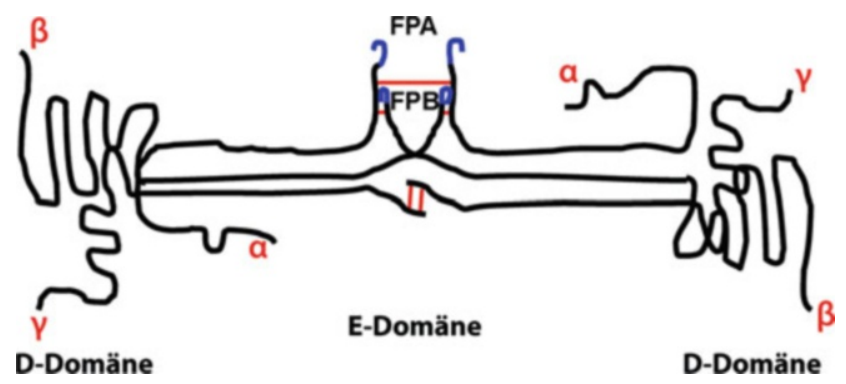

Synthese - Verteilung - Abbau - Elimination Jede Hälfte des symmetrischen dimeren Proteins besteht aus je 3 über Disulfidbrücken verknüpften Polypeptidketten $(\mathrm{A} \alpha, \mathrm{B} \beta, \gamma)$. $\mathrm{A}$ und $\mathrm{B}$ beziehen sich auf die $\mathrm{N}$-terminalen 16 bzw. 14 Aminosäurereste (Fibrinopeptide $\mathrm{A}[\mathrm{FpA}]$ und $\mathrm{B}[\mathrm{FpB}]$ ), die durch - Thrombin zunächst von der $\alpha$-, dann von der $\beta$-Kette abgespalten werden. Es entsteht Fibrin-Monomer (bereits nach Abspaltung von FpA), das dann zu Fibrin-Polymer auspolymerisiert.

Die 3 Polypeptidketten des Fibrinogens werden koordiniert in Hepatozyten und möglicherweise auch in Megakaryozyten synthetisiert. Kodiert werden die 3 Ketten von verschiedenen, aber verwandten Genen, die auf dem langen Arm des Chromosoms 4 lokalisiert sind. Alternatives Spleißen der
Transkripte, die für die $\gamma$-Kette kodieren, resultiert in Polypetide geringer Längenunterschiede (411 Aminosäuren [AS] bzw. 427 AS). Hepatozyten exprimieren eine 610 AS lange $A \alpha-K e t t e$ und eine 461 AS lange B $\beta$-Kette. Nach Zusammenbau der 3 Polypeptidketten im endoplasmatischen Retikulum und nach Glykosylierung und Phosphorylierung sekretieren die Hepatozyten ein Molekül mit einer Molmasse von ca. $340 \mathrm{kDa}$ in die Zirkulation. Fibrinogen findet sich auch in anderen Zellen und wird in den $\alpha$-Granula der Plättchen gespeichert. Die Konzentration im Plasma beträgt ca. $8+-2 \mu \mathrm{M}(100 \%$ der Norm = ca. $2.8 \mathrm{~g} / \mathrm{l})$. Die Konzentrationen in der Lymphe oder in der Interstitialflüssigkeit liegen bei ca. 20-40 \% der des Plasmas. Im Plasma hat Fibrinogen eine $>$ Halbwertszeit von 3-5 Tagen. Fibrinogen bindet als Adhäsivprotein an Fibronectin, $>$ Von-WillebrandFaktor, Thrombin, Heparin und Calcium-Ionen.

Funktion - Pathophysiologie Fibrinogen ist ein AkutePhase-Protein (z. B. bei Entzündungen, Traumen, nach Operationen, Tumoren, Verbrennungen), dessen Konzentration im Plasma unter Einfluss von $\triangleright$ Tumornekrosefaktor- $\alpha($ TNF- $\alpha)$, - Interleukin-1 und $>$ Interleukin-6 um bis zu ca. 100-200 $\%$ der Ausgangskonzentrationen ansteigen kann (Hyperfibrinogenämie). Schwere Leberfunktionsstörungen mit Verlust von Parenchymzellen (fortgeschrittene Leberzirrhose, Intoxikationen) gehen mit verminderten Fibrinogenwerten (Hypofibrinogenämie) einher. Fibrinogenmangel findet sich bei einer disseminierten intravasalen Koagulopathie (DIC), wobei die Fibrinogenkonzentration infolge der $>$ Akute-Phase-Reaktion auch pseudonormal sein kann. Fibrinogenkonzentrationen sinken durch eine systemische fibrinolytische Therapie, Asparaginase-Therapie oder Therapien mit thrombinähnlichen Enzymen (Ancrod, Defibrase) induziert werden.

Die eher seltenen kongenitalen Dysfibrinogenämien gehen in der Regel mit einer eingeschränkten Funktion und erniedrigten Antigenkonzentrationen einher. Etwas mehr als die Hälfte der angeborenen Dysfibrinogenämien sind klinisch inapparent; ca. ein Viertel geht mit einer milden Blutungsneigung einher, während bei den Übrigen klinisch eine Thrombophilie vorliegt.

Untersuchungsmaterial - Entnahmebedingungen Citratplasma.

Präanalytik Die Plasmagewinnung sollte innerhalb von $2 \mathrm{~h}$ nach der Blutentnahme erfolgen. Die Probe ist bei Raumtemperatur ca. 2 h stabil.

\section{Analytik}

- Fibrinogenbestimmung nach Claus: Der Test ist eine Variation der Thrombinzeit, wobei das Probenplasma in den optimalen Messbereich zwischen $0,1-0,4 \mathrm{~g} / \mathrm{L}$ ver- 
dünnt wird und ein Überschuss an Thrombin zugegeben wird. Unter diesen Bedingungen ist die Fibrinogenkonzentration der geschwingkeitsbestimmende Reaktionspartner und die gemessene Gerinnungszeit der Fibrinogenkonzentration proportional. Heparin, Hirudin oder sehr hohe Konzentrationen an Fibrinogenspaltprodukten können die Bestimmung stören.

- Derived Fibrinogen: Wenn die Prothrombinzeit nephelometrisch oder turbidimetrisch durch Endpunktmessung bestimmt wird, dann ist die Gesamtzunahme der Trübung direkt proportional der Konzentration an gerinnbarem Fibrinogen (insbesondere verlässlich im Bereich 3-6 g/L).

- Kinetische Fibrinogenbestimmung: Der kinetische Assay benutzt Batroxobin, und die Fibrinbildung wird turbidometrisch gemessen. Diese Methode hat einen weiten Messbereich, eine gute Präzision und lässt sich leicht automatisieren.

- Methode nach Ratnoff-Menzie: Eine Methode, die ähnlich der Methode ist, die derzeit zur Erstellung des internationalen Standards eingesetzt wird. Fibrinogen wird quantitativ in Fibrin durch Thrombin und Calcium-Ionen umgesetzt, und das Fibringerinnsel wird gewaschen und hydrolysiert. Der Proteingehalt des Hydrolysats wird anschließend fotometrisch bestimmt.

- Immunologische Tests zur Bestimmung von Fibrinogen basieren auf Nephelometrie ( $\triangleright$ Immunnephelometrie) oder ELISA ( $\triangleright$ Enzyme-linked Immunosorbent Assay). Sie unterscheiden in der Regel nicht zwischen gerinnbarem Fibrinogen oder inaktivem Fibrinogen und erfassen auch Fibrinogenabbauprodukte. Daher kann mit solchen Methoden bei thrombolytischen Therapien oder bei einer Verbrauchskoagulopathie das Potenzial an gerinnbarem Fibrinogen überschätzt werden.

- Turbidimetrische Bestimmung der Fibrinogenfunktion: Ein neuer Test (FIFTA) inkubiert 1 Teil Plasma mit 2 Teilen 0,3 IE/mL Thrombin, $6 \%$ Humanalbumin, 0,4 mg/L Polybrene (Heparininhibitor). Die Extinktion (z. B. bei 405 $\mathrm{nm})$ wird nach 0 und 2 Minuten $\left(37^{\circ} \mathrm{C}\right)$ gemessen (z. B. am Mikrotiterplattenphotometer). Die entstehende Plasmatrübung ist direkt proportional zur Fibrinogenfunktion.

- Turbidimetrische Bestimmung der Fibrinogenkonzentration. Ein neuer Test (FIATA) inkubiert Plasma mit 4,4 mM Vancomycin- PBS-Reagenz. Die entstehende Plasmatrübung (z. B. bei $405 \mathrm{~nm}$, meßbar am Mikrotiterplattenphotometer) ist direkt proportional zur Fibrinogenkonzentration.

Referenzbereich - Erwachsene $2,8 \pm 0,6 \mathrm{~g} / \mathrm{L}$ (Mittelwert +- 1 Standardabweichung).

\section{Indikation}

- Verdacht auf kongenitale Hypo- oder Hyperfibrinogenämien oder Dysfibrinogen
- Verdacht auf erworbene Hypo- oder Hyperfibrinogenämien

Interpretation Bei akut entzündlichen Erkrankungen sind Fibrinogenwerte bis zu ca.10 g/L möglich. Erhöhte Konzentrationen gelten als Risikofaktor für koronare und zerebrale atherothrombotische Erkrankungen. Extrem niedrige Fibrinogenkonzentrationen $(0,1-0,5 \mathrm{~g} / \mathrm{L})$ werden selten beobachtet; sie sind zu finden bei Verbrauchskoagulopathien, Hyperfibrinolysen, Leberfunktionsstörungen und systemischen fibrinolytischen Therapien (cave: in vitro Hyperfibrinolyse, da das Citrat der Monovette die Fibrinolyse nicht hemmt). Kongenitale Hypofibrinogenämien führen selten zu spontanen Blutungsneigungen, müssen jedoch vor größeren Eingriffen ausgeglichen werden. Eine Fibrinogenfunktion unter $1 \mathrm{~g} / \mathrm{L}$ ist ein Risiko für zerebrale Blutung.

Diagnostische Wertigkeit Routineparameter der Gerinnungstestung.

\section{Literatur}

Mackie IJ, Kitchen S, Machin SJ, Lowe GD (2003) Guidelines on Fibrinogen Assay. Brit J Haematol 121:396-404

McDonagh (2001) Dysfibrinogenemia and other disorders of fibrinogen structure or function. In: Colman RW, Hirsh J, Marder VJ (Hrsg) Hemostasis and thrombosis. Lippincott Williams \& Wilkins, Philadelphia, S 855-892

Stief TW (2007) The fibrinogen antigenic turbidimetric assay (FIATA). The $\chi 2 \mathrm{x}$ test: the corrected chi-square comparison against the control-mean. Clin Appl Thrombosis/Hemostasis 13:73-100

Stief TW (2008) The fibrinogen functional turbidimetric assay. Clin Appl Thromb/Hemost 14:84-96

\section{Fibrinogen-Antigen- turbidimetrischer Test}

T. Stief

\section{Synonym(e) FIATA}

Englischer Begriff fibrinogen antigen turbidimetric assay

Definition Das Glykopeptidantibiotikum Vancomycin (aus 7 teilmodifizierten Aminosäuren) bindet an Fibrinogen und faltet es in eine wasserunlösliche Form. Das sofort entstehende Präzipitat wird turbidimetrisch bei $405 \mathrm{~nm}$ gemessen und ist ein direktes Maß für die Konzentration an FibrinogenAntigen im Plasma. Somit wird auch dysfunktionelles Fibrinogen oder Fibrin mitgemessen. 
Beschreibung Fibrinogen-Antigen über Enzymimmunoteste zu messen, ist kompliziert, zeitintensiv und teuer. Inkubation von einem Teil Plasma mit 2 Teilen 4,4 mM Vancomycin (eine supratherapeutische Dosis des vergleichsweise billigen Antibiotikums) in PBS führt augenblicklich zu einem weißlichen Präzipitat, dessen Trübungs-Intensität einfach gemessen werden kann. Jedes Photometer (insbesondere auch - Mikrotiterplatte-Photometer) kann den plötzlichen Trübungsanstieg z. B. bei $405 \mathrm{~nm}$ messen. Spezielle Gerinnungsanalyzer sind nicht notwendig. Das Fibrinogen-Antigen wird (vergleichbar der AT3-Funktion) in \% der Norm angegeben $(100 \%=2,8 \mathrm{~g} / \mathrm{L})$. Der Normbereich ist $100 \pm 20 \%$ (Mittelwert $= \pm 1$ Standardabweichung).

\section{Literatur}

Stief TW (2007) The fibrinogen antigenic turbidimetric assay (FIATA): the $\mathrm{X} 2 \mathrm{x}$ test - the corrected chi-square comparison against the control-mean. Clin Appl Thromb/Hemost 13:73-100

Stief TW, Ijagha O, Weiste B, Herzum I, Renz H, Max M (2007) Analysis of hemostasis alterations in sepsis. Blood Coagul Fibrinolysis 18:179-186

Stief TW, Ulbricht K, Max M (2010) Circulating plasmin activity in severe sepsis. Hemost Lab 3:105-120

\section{Fibrinogen-äquivalente Einheiten}

T. Stief

Englischer Begriff fibrinogen equivalent units; FEU

Definition Fibrinogenmenge in $\mathrm{mg}$, die für die industrielle Herstellung von $1 \mathrm{mg}$ eines D-Dimer-Standards benötigt werden.

Beschreibung D-Dimer-Standards werden industriell aus gereinigtem Humanfibrinogen (Faktor 1) hergestellt, das mit Thrombin, Faktor 13a und Plasmin inkubiert wird. Da das - Fibrinogen (Molmasse ca. $340 \mathrm{kDa}$ ) aus 2 großen Domänen $\mathrm{D}$ und einer kleinen zentralen Domäne $\mathrm{E}$ besteht, entspricht $1 \mathrm{mg}$ Fibrinogen in etwa $0,7 \mathrm{mg}$ der Domäne D. Die D-Dimer-Konzentration im Blut von Patienten (z. B. mit Sepsis oder Mikrothromben) kann bezogen werden auf reines D-Dimer oder eben auf Fibrinogen, der industriellen Quelle von D-Dimer.

\section{Literatur}

Knowlson L, Bacchu S, Paneesha S, McManus A, Randall K, Rose $\mathrm{P}$ (2010) Elevated D-dimers are also a marker of underlying malignancy and increased mortality in the absence of venous thromboembolism. J Clin Pathol 63:818-822
Page DA (2009) Change designation of clotting factors to Arabic numerals. J Thromb Haemost 7:1599

Stief TW, Ulbricht K, Max M (2009) Circulating thrombin activity in sepsis. Haemost Lab 2:293-306

\section{Fibrin(ogen)-Degradationsprodukte}

T. Stief und P. Kiefer

Synonym(e) Fibrin(ogen)-Spaltprodukte

Englischer Begriff fibrin(ogen) degradation products

Definition Plasmin baut quervernetztes Fibrin in lösliche Fibrin-Spaltprodukte ab:

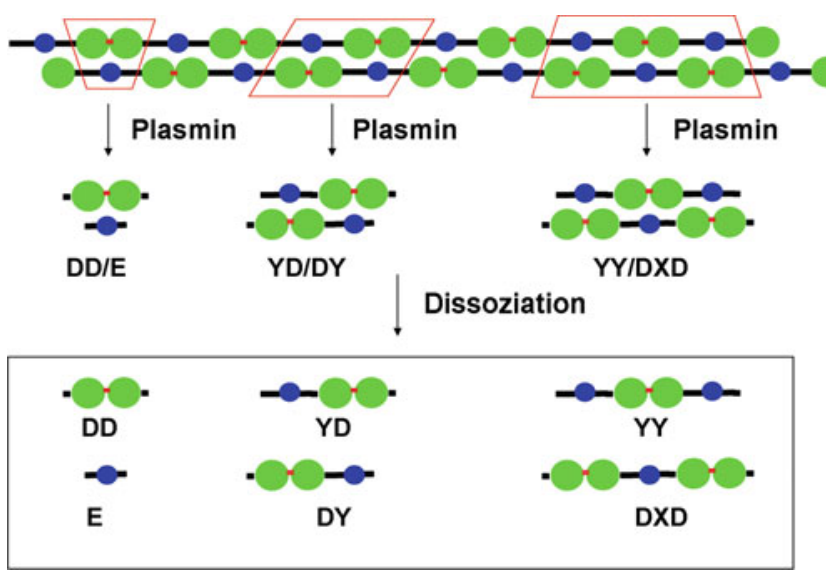

Plasmin baut auch Fibrinogen ab (wie die nachfolgende Abbildung darstellt), woraus ähnliche Fragmente entstehen, die Fibrinogen-Spaltprodukte.
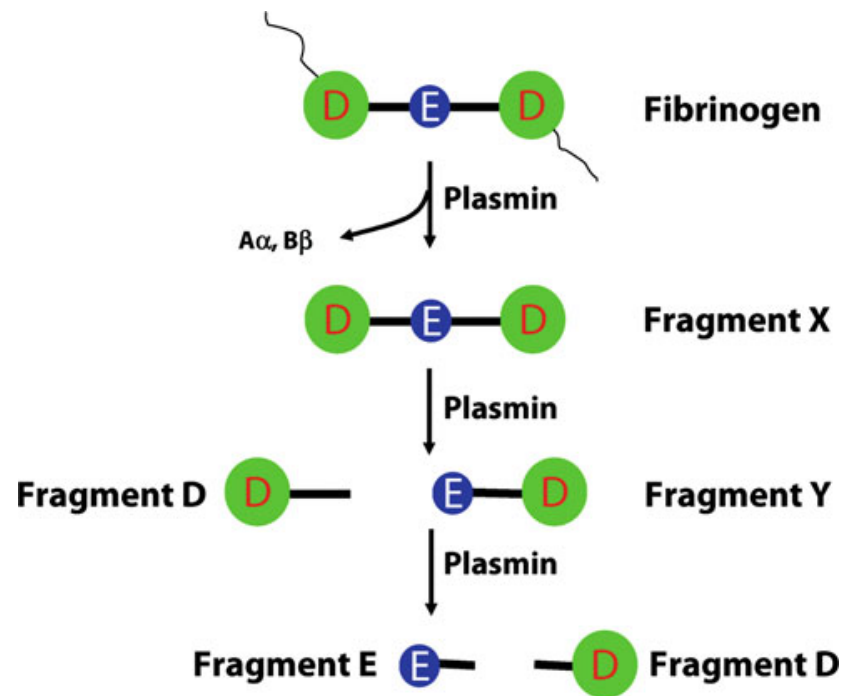
Gegebenenfalls können auch durch Elastase gespaltene Abbauprodukte des Fibrins bzw. Fibrinogens als Fibrin (ogen)-Degradationsprodukte bezeichnet werden.

Beschreibung Plasmin baut Fibrinogen über mehrere Schritte $a b$, wobei der erste die Spaltung der $A \alpha$ - und $B \beta-K e t t e$ ist, was zur Bildung des Fragments $\mathrm{X}$ führt, das noch gerinnbar ist (insbesondere durch Reptilase) und eine Molmasse von ca. $240 \mathrm{kDa}$ hat. Weitere Spaltung durch Plasmin führt zu den Fragmenten D (Molmasse: ca. $83 \mathrm{kDa}$ ) und Y (Molmasse: ca. $155 \mathrm{kDa}$ ). Fragment $\mathrm{Y}$ kann weiter in das Fragment E (Molmasse: ca. $50 \mathrm{kDa}$ ) und einem weiteren Fragment D gespalten werden. Der proteolytische Abbau von Fibrin durch Plasmin ergibt ähnliche Produkte (das aus Fibrin entstehende Fragment X-ähnliche Produkt entspricht allerdings in etwa einem Fibrin-Monomer und ist nicht mehr gerinnbar). Kompletter Plasmin-induzierter Abbau von quervernetztem Fibrin ergibt Fragment D, E und $>$ D-Dimer, das aus zwei (durch F13a) kovalent verknüpften D-Domänen besteht.

\section{Literatur}

Sidelmann JL, Gram J, Jespersen J, Kluft C (2000) Fibrin clot formation and lysis: basic mechanisms. SeminThromb Hemost 26:605-618

\section{Fibrinogen-Funktion- turbidimetrischer Test}

\section{T. Stief}

\section{Synonym(e) FIFTA}

Englischer Begriff fibrinogen function turbidimetric assay

Definition $>$ Thrombin in physiologischer/pathophysiologischer Plasmaaktivität (ca. 0,1-0,2 IE/ml) wandelt Fibrinogen in Fibrin um. Das bei der Polymerisation eingebaute Albumin trübt das entstehende Gerinnsel. Diese Trübung wird z. B. bei $405 \mathrm{~nm}$ gemessen und ist ein direktes Maß für die funktionelle Fibrinogen-Konzentration in vivo im Plasma.

Beschreibung Physiologische oder pathophysiologische plasmatische Thrombinaktivitäten im gerinnenden fließenden Blut sind nicht höher als $1 \mathrm{IE} / \mathrm{mL}$. Sie liegen um die $0,1 \mathrm{IE}$ Thrombin pro $\mathrm{mL}$ Blut. Fibrinogen als das Zielmolekül von Thrombin sollte folglich nicht mit unphysiologisch hohen Thrombinaktivitäten im Test konfrontiert werden; daneben sollte das Plasma nicht 10-fach verdünnt werden. Beides kann die In-vivo-Situation von plasmatischem Fibrinogen verzerrt reflektieren und zu artifiziellen (insbesondere falsch hohen) Ergebnissen führen. Der FIFTA misst im Gegensatz zu herkömmlichen Fibrinogen-Tests die Fibrinogen-Funktion in Anwesenheit von lediglich 0,2 IE Thrombin pro $\mathrm{mL}$ in Citratplasma, das lediglich 1+2 mit Thrombin-Albumin-PolybrenReagenz verdünnt wird. Jedes $>$ Photometer (insbesondere auch $>$ Mikrotiterplatten-Photometer) kann den Trübungsanstieg pro $2 \min \left(37^{\circ} \mathrm{C}\right)$ messen. Spezielle Gerinnungsanalyzer sind nicht notwendig. Die Fibrinogen-Funktion wird (vergleichbar der AT3-Funktion) in \% der Norm angegeben $(100 \%=2,8 \mathrm{~g} / \mathrm{L})$. Der Normbereich ist $100 \pm 20 \%$ (Mittelwert $= \pm 1$ Standardabweichung).

\section{Literatur}

Stief TW (2008) The fibrinogen functional turbidimetric assay. Clin Appl Thromb Hemost 14:84-96

Stief TW, Ulbricht K, Max M (2010) Circulating plasmin activity in severe sepsis. Hemost Lab 3:105-120

\section{Fibrin(ogen)-Spaltprodukte}

Fibrin(ogen)-Degradationsprodukte

\section{Fibrinoligase}

- Gerinnungsfaktor XIII

\section{Fibrinolyseinhibitor, Thrombin- aktivierbarer}

\section{T. Stief}

Synonym(e) TAFI; Thrombin-aktivierbarer Fibrinolyseinhibitor

Englischer Begriff thrombin-activatable fibrinolysis inhibitor

Definition TAFI ist eine durch $>$ Thrombin aktivierbare Pro-Carboxypeptidase-B, die die Fibrinolyse reguliert.

Beschreibung TAFI wird als 60-kDa-Proteoglykan in der Leber und in $>$ Megakaryozyten synthetisiert und findet sich in einer Konzentration von ca. $6 \mathrm{mg} / \mathrm{L}$ in der Zirkulation. Die Plasmakonzentration scheint im Wesentlichen transkriptio- 
nell reguliert zu werden. TAFI wird von freiem Thrombin aktiviert, wenn Thrombin in höheren Konzentrationen vorliegt. Geringe Mengen an Thrombin reichen jedoch schon aus, wenn Thrombin an $>$ Thrombomodulin als Kofaktor gebunden ist, um die Fibrinolyse zu regulieren. Neben Thrombin und dem Thrombin-Thrombomodulin-Komplex kann TAFI auch durch Plasmin aktiviert werden. Aktivierung bedeutet Abspaltung eines 92 Aminosäurereste großen Aktivierungsfragments, wobei der 309 Aminosäurereste umfassende C-terminale Teil (TAFIa, $35 \mathrm{kDa}$ ) generiert wird, eine $\mathrm{Zn}^{2+}$-abhängige Carboxypeptidase-B. TAFIa ist ein instabiles Protein, das im Blut eine Halbwertszeit von ca. 8 min hat.

Erhöhte TAFI-Antigenkonzentrationen könnten mit einem leicht erhöhten Thromboserisiko assoziiert sein und ein Risikofaktor für Angina pectoris sein. Während des fibrinolytischen Abbaus von $>$ Fibrin spaltet Plasmin Fibrin an spezifischen Arginin- und Lysinresten in den $\alpha$-, $\beta$ - und $\gamma$-Ketten, dies führt zu freien $\mathrm{C}$-terminalen Lysinresten, die die Bindung von t-PA und Plasminogen/Plasmin an Fibrin deutlich begünstigen. TAFIa entfernt diese freien Lysin- (und Arginin-) Reste. Diese Form hat eine deutlich niedrigere Kofaktoraktivität für die Aktivierung von Plasminogen. Allerdings könnte möglicherweise eine sehr hohe Aktivität an TAFIa Fibrin an den Lysinen abbauen, somit die Fibrinolyse verstärken.

\section{Literatur}

Nesheim M (2003) Thrombin and fibrinolysis. Chest 124:33S-39S

Stief TW, Fröhlich S, Renz H (2007) Determination of the global fibrinolytic state. Blood Coagul Fibrinolysis 18:479-487

\section{Fibrinopeptid A}

\section{T. Stief}

\section{Synonym(e) FPA}

Englischer Begriff fibrinopeptide A (FpA)

Definition Thrombin oder Thrombin-ähnliche Enzyme spalten die beiden Fibrinopeptide A von den beiden $\alpha$-Ketten des Fibrinogens ab. Die Messung des FPA könnte gegebenenfalls eine veränderte Thrombinbildung nachweisen.

Beschreibung Thrombin oder Enzyme aus Schlangengiften, wie das Batroxobin oder Arwin (Ancrod), spalten von der $\alpha$-Kette des Fibrinogens das Fibrinopeptid A ab. Dadurch entsteht das DesAA-Fibrin (Fibrin I). Während $\triangleright$ Thrombin dann auch die beiden Fibrinopeptide B von den beiden
$\beta$-Ketten abspalten kann, wodurch das DesAABB-Fibrin entsteht, fehlt diese Aktivität den beiden Schlangenenzymen. Der quantitative Nachweis des Fibrinopeptid A erfolgt mittels ELISA. Weil die Antikörper oft keine absolute Spezifität für die Fibrinopeptide besitzen, sollte vor dem Assay zunächst - Fibrinogen aus der Plasmaprobe entfernt werden. Erhöhte Konzentrationen werden bei der pathologischen disseminierten intravaskulären Gerinnung (PDIC), bei thromboembolischen Erkrankungen oder unter einer fibrinolytischen Therapie gemessen. Der Parameter FPA ist jedoch verglichen mit dem neuen Parameter systemisch zirkulierende amidolytische - Thrombinaktivität in Plasma ohne klinische Bedeutung.

Normbereich $<1,3 \mathrm{nmol} / \mathrm{L}$.

Messtechnik Enzymimmunoassay (EIA). Prä-analytisch ist darauf zu achten, dass Thrombin nicht in-vitro generiert wird, d. h. die EDTA-Blutprobe sollte nicht älter als $2 \mathrm{~h}$ sein, abzentrifugiert werden und das EDTA-Plasma $1+1$ mit $2.5 \mathrm{M}$ Arginin, $\mathrm{pH} 8.6$ stabilisiert werden.

\section{Literatur}

Soria J, Soria C, Ryckewaert JJ (1980) A solid phase immuno enzymological assay for the measurement of human fibrinopeptide A. Thromb Res 20:425-435

Stief TW (2009) Plasmin enhances thrombin generation. Hemost Lab 2:57-64

Zito F, Drummond F, Bujac SR, Esnouf MP, Morrissey JH, Humphries SE, Miller GJ (2000) Epidemiological and genetic associations of activated factor XII concentration with factor VII activity, fibrinopeptide A concentration, and risk of coronary heart disease in men. Circulation 102:2058-2062

Fibrinstabilisierender Faktor

- Gerinnungsfaktor XIII

\section{Fibroblasten-Wachstumsfaktor-23}

- Fibroblast Growth Factor 23

\section{Fibroblast Growth Factor 21}

- Hepatokine 


\section{Fibroblast Growth Factor 23}

H.-D. Haubeck

Synonym(e) Fibroblasten-Wachstumsfaktor-23; FGF-23

Englischer Begriff fibroblast growth factor 23

Definition Fibroblast Growth Factor 23 (FGF-23), ein Mitglied der FGF-Genfamilie, spielt eine wichtige Rolle bei der Regulation des $\triangleright$ Phosphat-Stoffwechsels.

Beschreibung Die Serumkonzentrationen von $>$ Calcium und $>$ Phosphat werden in einem engen Konzentrationsbereich konstant gehalten. Während die Regulation der Calcium-Konzentration über Parathormon und 1,25 $[\mathrm{OH}]_{2}$-Vitamin D ( $\triangleright$ Vitamin D) bereits seit Langem bekannt ist, zeichnet sich erst jetzt ein Verständnis der Mechanismen der Phosphatregulation ab. Die Bedeutung von Fibroblast Growth Factor 23 (FGF-23) für die Phosphatregulation ergab sich aus Untersuchungen bei Patienten mit X-chromosomal vererbter Osteomalazie (Rachitis) (XLH), autosomal dominant vererbter hypophosphatämischer Osteomalazie (Rachitis) (ADHR) und tumorinduzierter Osteomalazie (TIO). Diesen Krankheitsbildern gemeinsam sind eine Hypophosphatämie als Folge einer erhöhten Phosphatausscheidung in den Urin und Mineralisationsstörungen der Knochen. Die bei diesen Patienten in der Regel normalen Serumkonzentrationen von Calcium und Parathormon, aber auch die Normalisierung der Befunde bei Patienten mit TIO nach Entfernung des Tumors wiesen auf einen phosphaturischen Faktor (Phosphatonin) hin. FGF-23 wurde als verantwortlicher Faktor aus Tumoren von Patienten mit TIO identifiziert. Durch FGF-23 lassen sich eine erhöhte Phosphatausscheidung in den Urin und eine Hypophosphatämie auslösen. Außerdem wird über die Inhibition der $1-\alpha$-Hydroxylase der Niere durch FGF-23 auch die 1,25[OH $]_{2}$-Vitamin-DSerumkonzentration beeinflusst. Tierexperimentell lassen sich durch FGF-23 die Symptome der genannten Krankheiten auslösen. Darüber hinaus werden nicht nur bei Patienten mit TIO, sondern auch bei Patienten mit XLH erhöhte Konzentrationen von FGF-23 nachgewiesen. Bei Patienten mit ADHR führen Mutationen im FGF-23-Gen dazu, dass FGF23 nicht mehr proteolytisch abgebaut werden kann. Mit „secreted frizzled-related protein 4“ wurde aus Tumoren von Patienten mit TIO ein weiteres Phosphatonin identifiziert, das ebenfalls eine Phosphaturie und eine Hypophosphatämie verursacht.
Für die Messung der FGF-23-Konzentration im Serum steht ein Enzymimmunoassay zur Verfügung.

\section{Literatur}

Berndt T, Craig TA, Bowe AE et al (2003) Secreted frizzled-related protein 4 is a potent tumor-derived phosphaturic agent. J Clin Invest 112:785-794

Shimada T, Mizutani S, Muto T et al (2001) Cloning and characterization of FGF23 as a causative factor of tumor-induced osteomalacia. Proc Natl Acad Sci U S A 98:6500-6505

Shimada T, Kakitani M, Yamazaki Y et al (2004) Targeted ablation of FGF-23 demonstrates an essential physiological role of FGF-23 in phosphate and vitamin D metabolism. J Clin Invest 113:561-568

\section{Fibroglycan}

Syndecane

\section{Fibronectin}

H.-D. Haubeck

Synonym(e) Cold insoluble globulin; LETS-(large external transformation sensitive-)Protein; Opsonin

\section{Englischer Begriff fibronectin}

Definition Fibronectin ist ein Adhäsionsmolekül, das in mehreren Isoformen in der Extrazellulärmatrix und im Plasma vorkommt.

Beschreibung Fibronectine bilden eine Gruppe von nahe verwandten Glykoproteinen, die aus einem Gen durch alternatives Spleißen entstehen. Fibronectine sind wichtige Bestandteile der Extrazellulärmatrix und an der Kontrolle der Zelladhäsion, Zellausbreitung, Zellwanderung und Zytoskelettorganisation beteiligt. In der Embryogenese kommt ihnen eine entscheidende Bedeutung zu. Dementsprechend ist ein homozygoter Fibronectindefekt bereits in der frühen Embryonalentwicklung letal. Der Phänotyp der Fibronectin-defizienten Mäuseembryonen ist durch Defekte der Mesoderm- und Neuralrohrentwicklung und schwere Herz- und Gefäßdefekte gekennzeichnet. Auch im adulten Organismus weist Fibronectin ein breites Expressionsspektrum auf und ist an wichtigen physiologischen und pathologischen Prozessen, wie Tumorinvasion, Blutgerinnung, Wundheilung und Fibrose, beteiligt. 
Fibronectine sind große Glykoproteine $(440 \mathrm{kDa})$ und bestehen aus 2 fast identischen Untereinheiten, die durch Disulfidbrücken verknüpft sind. Fibronectine besitzen eine Domänenstruktur. Diese Domänen, die z. T. repetitiv auftreten, binden spezifisch an verschiedene Liganden, wie $>$ Kollagene, $>$ Fibrinogen/ $\triangleright$ Fibrin, Heparansulfat oder über sogenannte RGD-(Arg-Gly-Asp-)Sequenzen an > Integrine auf der Zelloberfläche. Diese niedrig-affine Bindung an die Integrine ermöglicht die Zelladhäsion an die Extrazellulärmatrix, aber auch die Zellmotilität.

Plasmafibronectin ist eine Fibronectinisoform, die überwiegend von Endothelzellen und Hepatozyten gebildet wird. Die Konzentration im Plasma beträgt $200-380 \mathrm{mg} / \mathrm{L}$, und die Halbwertszeit liegt bei 25 Stunden. Die Messung kann über Nephelometrie, Tubidimetrie und verschiedene Immunoassays erfolgen. Plasmafibronectin kommt auch im Liquor ( $\triangleright$ Liquor cerebrospinalis), in der Synovialflüssigkeit ( $\triangleright$ Synovia-Analyse) und im Aszites vor. Im Plasma wirkt Fibronectin vor allem als Opsonin und erlaubt die Clearance von Bakterien, Fibrinaggregaten, Gewebedebris etc. Erhöhte Plasmakonzentrationen von Fibronectin werden bei akuter, chronisch-aktiver und chronisch-persistierender Hepatitis, bei verschiedenen Tumoren und bei Hyperthyreose gefunden. Erniedrigte Konzentrationen treten bei Schockzuständen, Sepsis, disseminierter intravaskulärer Gerinnung, dekompensierter Leberzirrhose, akutem Leberversagen, posttraumatisch und postoperativ, aber auch bei Malnutrition auf. Die geringen bis mäßigen Konzentrationsänderungen bei diesen Erkrankungen schränken die diagnostische Wertigkeit der Fibronectinbestimmung stark ein. Bei der Sepsis stellt eine ausgeprägte Erniedrigung der Fibronectinkonzentration, als Ausdruck der RES-Insuffizienz, einen negativen prognostischen Faktor dar. Beim Aszites erlaubt Fibronectin die Unterscheidung zwischen malignen und nicht malignen Grunderkrankungen recht zuverlässig.

\section{Literatur}

George EL, George-Labouesse EN, Patel-King RS et al (1993) Defects in mesoderm, neural tube and vascular development in mouse embryos lacking fibronectin. Development 119:1079-1091

Gressner AM, Wallraff P (1980) Der Einsatz der Lasernephelometrie zur Bestimmung und rechnerunterstützten Auswertung der Fibronectinkonzentration in verschiedenen Körperflüssigkeiten. J Clin Chem Clin Biochem 18:797-805

\section{Fibrosekenngrößen}

A. M. Gressner und O. A. Gressner

Synonym(e) Fibrosemarker
Englischer Begriff markers of (liver) fibrosis

Definition Nicht invasive, in Serum oder Plasma gemessene klinisch-chemische Kenngrößen (Biomarker), die das Ausmaß der Fibrose (Zunahme des Bindegewebeanteils), die Aktivität der Fibrogenese (Neusynthese des Bindegewebes) und/oder Fibrolyse (Abbau des neu synthetisierten Bindegewebes) in der Leber zu diagnostizieren gestatten.

Synthese - Verteilung - Abbau - Elimination Ideale labormedizinische, im Vergleich zur histologischen Untersuchung einer Leberbiopsie nicht invasive Kenngrößen der Leberfibrose/-fibrogenese, die ein hohes $\mathrm{Ma}$ an diagnostischer Spezifität ( $\triangleright$ Spezifität, diagnostische) und Sensitivität (॰ Sensitivität, diagnostische) aufweisen, analytisch standardisiert sind und damit zu reproduzierbaren Ergebnissen führen, fehlen gegenwärtig. Einzelkenngrößen des erhöhten Kollagen-, Glykoprotein- und/oder Glykosaminoglykan- bzw. Proteoglykanstoffwechsels haben sich in der Labordiagnostik der Fibrose nicht durchsetzen können (Abb. 1). Stattdessen sind über 20 multiparametrische Testverfahren (Scores) vorgeschlagen worden (s. nachfolgende Tabelle), die auf überwiegend gängigen Kenngrößen ( $\triangleright$ Kenngröße, klinischchemische) beruhen, die in jeweilige Algorithmen Eingang finden. Sensitivitäten und Spezifitäten zwischen 60 und $99 \%$ sind für diese Biomarkerkombinationen berichtet worden.

Pathophysiologie Fibrose der chronisch geschädigten Leber (Hepatitis C, B, nicht alkoholische und alkoholische Leberschädigungen, genetische Erkrankungen) ist definiert durch eine

- 3- bis 10-fache Konzentrationszunahme der extrazellulären Matrix ( $\triangleright$ Kollagene, \ Glykosaminoglykane/ $\triangleright$ Proteoglykane, strukturelle $\triangleright$ Glykoproteine, $\triangleright$ Hyaluronan).

- veränderte molekulare Zusammensetzung,

- Verschiebung der molekularen Mikroheterogenität der einzelnen Matrixkomponenten und

- histologische Umverteilung mit Einengung der Lebersinusoide (Blutstrombahn).

Die Zunahme der extrazellulären Matrix ist überwiegend auf eine Neusynthese in hepatischen Sternzellen (Itozellen) zurückzuführen, die unter dem Einfluss von ,॰ transforming growth factor $\beta^{\prime \prime}$ (TGF- $\beta$ ) und ,connective tissue growth factor" (CTGF) ein breites Spektrum der genannten Bindegewebskomponenten nach Umwandlung in Myofibroblasten in der chronisch geschädigten Leber synthetisieren. Auch Leberparenchymzellen (Hepatozyten) können sich in 


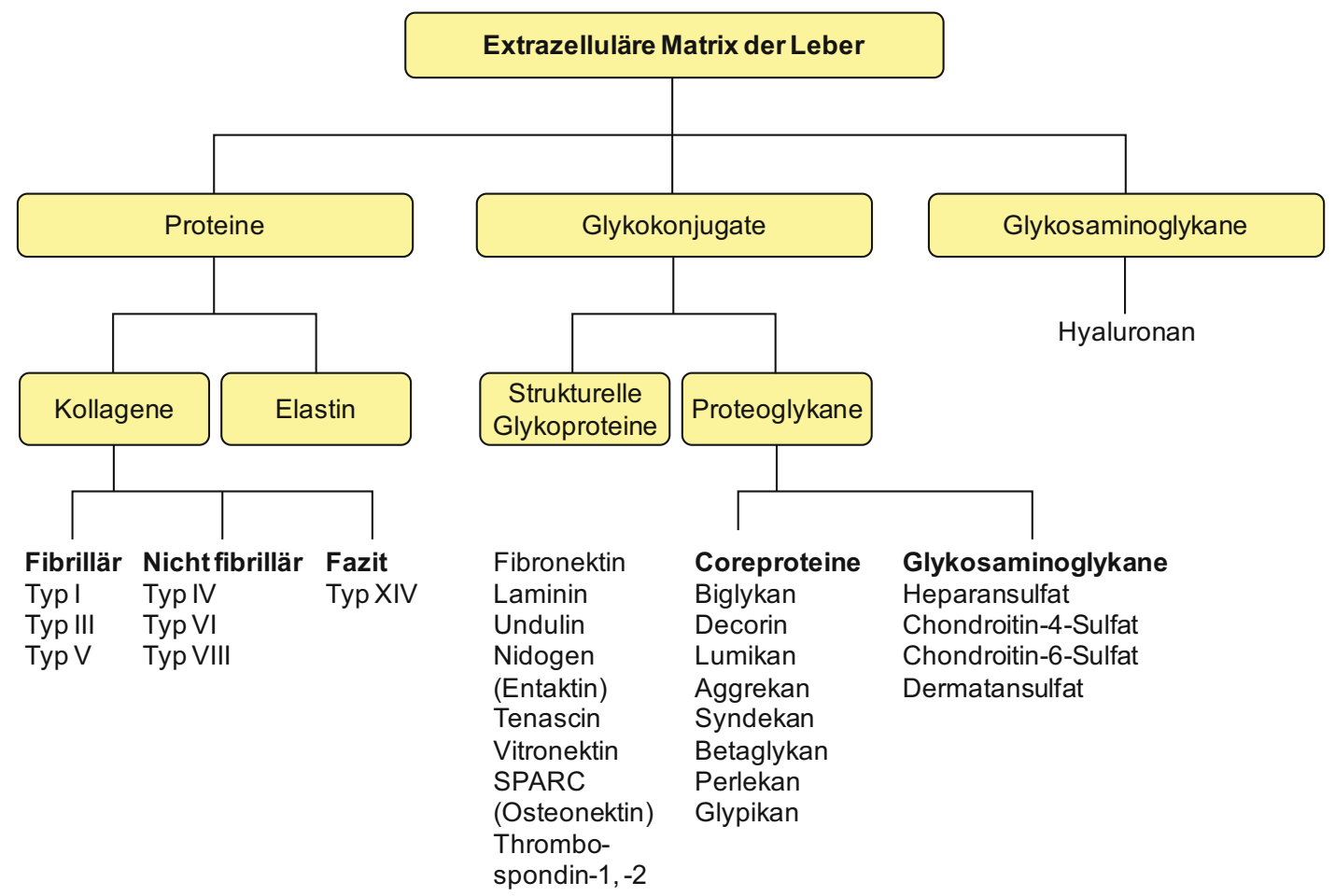

Fibrosekenngrößen, Abb. 1 Komponenten der extrazellulären Matrix der gesunden und fibrotischen Leber

Bindegewebe-synthetisierende Fibroblasten im Rahmen einer chronischen Leberschädigung umwandeln (epitheliale mesenchymale Transition EMT)

Untersuchungsmaterial Serum, Plasma.

Analytik Für die nicht invasive, serumbasierte Diagnostik der Fibrogenese sind in umfangreichen klinischen Studien Einzelkenngrößen, Parameterkombinationen und teilweise komplexe, bis zu 10 Einzelparameter umfassende multiparametrische Algorithmen empfohlen worden. Dabei reflektieren Biomarker der Klasse I vorzugweise den Grad der fibrogenen Aktivität und die der Klasse II das Stadium der Fibrose.

Folgende Biomarker sind für die Leberfibrose empfohlen worden (s. a. Tabelle):

- Hyaluronan, > Prokollagenpeptid Typ III, N-terminales, Typ-VI-Kollagen, Typ-IV-Kollagen, NC1-Fragment, $>$ Prolyl4-Hydroxylase, Monoaminooxidase ( $>$ Monoaminooxidase im Serum), Xylosyltransferase, ,connective tissue growth factor" (CTGF), > YKL-40, Undulin, Laminin-P1-Fragment ( Laminine), „ $>$ tissue inhibitor of metalloproteinase-1“ (TIMP-1, TIMP-2), Matrix-Metalloproteinase (MMP) 7, $\gamma$-Glutamyltransferase/Thrombozyten-(GPR-)Ratio, $>$ Enhanced-Liver-Fibrosis-Test (ELF-Test), > Forns-Index, $>$ WaiIndex, Fibrotest, Actitest, AST/Thrombozyten-(APRI-)Index, PGA-Index, Pohl-Index, Sud-Index, Rosenberg-Score, FIB-4, Hepascore, LOK-Score, FibroSpect, Fibrometer-Test, Fibroindex, u. a.
Auswahl komplexer multivariater Leberfibrose-Scores und deren Messgrößen:

\begin{tabular}{|c|c|}
\hline Score/Index & Einzelmessgrößen \\
\hline $\begin{array}{l}\text { PGAA- } \\
\text { Index }\end{array}$ & $\begin{array}{l}\text { Prothrombinzeit, } \gamma \text {-GT, Apolipoprotein A1, } \alpha 2 \text { - } \\
\text { Makroglobulin }\end{array}$ \\
\hline $\begin{array}{l}\text { Fortunato- } \\
\text { Score }\end{array}$ & $\begin{array}{l}\text { Fibronektin, Prothrombinzeit, PCHE, ALT, Mn-SOD, } \\
\beta \text {-NAG }\end{array}$ \\
\hline Fibrotest & $\begin{array}{l}\text { Haptoglobin, } \alpha 2 \text {-Makroglobulin, Apolipoprotein A1, } \\
\gamma \text {-GT, Bilirubin }\end{array}$ \\
\hline Pohl-Score & AST, ALT, Thrombozytenzahl \\
\hline Forns-Index & Thrombozytenzahl, $\gamma$-GT, Cholesterin, Alter \\
\hline Sud-Index & $\begin{array}{l}\text { AST, Cholesterin, Insulinresistenz (HOMA), } \\
\text { anamnestisch Alkoholaufnahme, Alter }\end{array}$ \\
\hline Fibrometer & $\begin{array}{l}\text { Thrombozytenzahl, Prothrombinindex, AST, } \\
\text { } 2 \text {-Makroglobulin, Hyaluronan, Harnstoff, Alter }\end{array}$ \\
\hline FIB-4 & Thrombozytenzahl, AST, ALT, Alter \\
\hline HUI-Score & Bilirubin, Albumin, Thrombozytenzahl, BMI \\
\hline Hepascore & $\begin{array}{l}\alpha 2-\text { Makroglobulin, Hyaluronan, Bilirubin, } \gamma \text {-GT, } \\
\text { Alter, Geschlecht }\end{array}$ \\
\hline Leroy-Score & PIIINP, MMP-1 \\
\hline $\begin{array}{l}\text { Rosenberg- } \\
\text { Score }\end{array}$ & PIIINP, Hyaluronan,TIMP-1 \\
\hline
\end{tabular}

Vergleichende standardisierte Evaluationen ihrer diagnostischen Leistungsfähigkeit sind im Gange und deuten auf Hyaluronan, Matrix-Metalloproteinasen 1 und 7 und APRI (AST/Thromobozyten-Verhältnis) als geeignete Kenngrößen hin (Irvine et al. 2016). Oft ist die histologische Graduierung der Fibrose (METAVIR-Leberfibrose-Score der histologischen Stadien F0 bis F4) und Entzündung einer Biopsieprobe des 
Lebergewebes als Bezug ungeeignet, da die kleine histologische Bezugsgröße von ca. $30 \mathrm{mg}$ bei einem Organ von ca. 1,5 kg Feuchtgewicht nur 1/50.000 der Lebermasse entspricht und somit einem erheblichen Probennahmefehler unterliegen kann. Das Ergebnis der Biopsie muss somit nicht immer repräsentativ für das gesamte Lebergewebe sein.

Die zur Anwendung kommenden analytischen Methoden sind neben (radioaktiven) Enzymaktivitätsbestimmungen, Radioimmunoassay, FIA, EIA, ELISA.

\section{Indikation}

- Verlaufskontrolle chronisch entzündlicher Lebererkrankungen wie Hepatitis $\mathrm{C}$ und Delta-Hepatitis, (HCV), nicht alkoholische Fettlebererkrankungen (NAFLD)

- Alkoholtoxische chronische Lebererkrankungen, alkoholinduzierte Hepatitis, Steatohepatitis (ASH)

- Selten: Leberreaktion bei einigen genetischen Stoffwechselerkrankungen wie Hämochromatose, $\alpha 1$-Antitrypsinmangel, Morbus Wilson

- Autoimmunhepatitis, primär biliäre Zirrhose (PBC), primär sklerosierende Cholangitis

- Parasitäre Infektionen (Schistosomiasis)

Referenzbereich Abhängig vom gewählten Verfahren.

Interpretation und Diagnostische Wertigkeit Die diagnostischen Sensitivitäten für Klasse I der Fibrosemarker bewegen sich zwischen 76-78 \%, die der Spezifität zwischen $71-81 \%$, etwas höhere diagnostische Sensitivitäten von bis zu $90 \%$ bei Spezifitäten um $80 \%$ sind bei Klasse-IIParametern berichtet.

Eine abschließende Bewertung der zahlreich zur Verfügung stehenden Scores zur nicht invasiven Fibrose-/ Zirrhosediagnostik ist noch nicht möglich. Bei den multiparametrischen Testverfahren ist die Präzision durch den Einsatz von mehreren analytischen Kenngrößen beeinträchtigt, da jeder Parameter seine analytische Unpräzision besitzt. Einige Kenngrößen, wie Fibrotest, Actitest und ELF-Test werden kommerziell angeboten, andere Testverfahren sind wenig standardisierte In-house-Verfahren. Ein Wechsel der Methode bei längerer Verlaufskontrolle ist daher zu vermeiden. Unter den Einzelparametern hat sich $>$ Hyaluronan mit einer Sensitivität von $97 \%$ und Spezifität von $73 \%$ für Zirrhose als die relativ zuverlässigste Kenngröße erwiesen. CTGF in Serum oder Plasma könnte sich nach Abschluss laufender Studien als ein zuverlässiger Parameter der Leberfibrogenese erweisen.

Alternativen zum biochemischen Verfahren der Fibrosediagnostik und -verlaufskontrolle sind transiente Elastographie (Fibroscan), akustische Strukturquantifizierung (ASQ, Messung der Echogenität) und hochauflösende röntgenologische und Ultraschall-(ARFI-)Techniken.

\section{Literatur}

Gressner AM, Rizk M, Gao C, Gressner OA (2010) Potential novel biomarkers for monitoring the fibrogenic process in liver. Arab J Gastroenterol 10:S12-S16

Irvine K, Wockner LF, Hoffmann I et al (2016) Multiple serum protein analysis identifies novel biomarkers of advanced fibrosis in patients with chronic liver disease with potential to improve diagnostic accuracy of established biomarkers. PLoS One 11(11):e0167001

Lee YA, Wallace MC, Friedman SL (2015) Pathobiology of liver fibrosis: a translational success story. Gut 64(5):830-841

Stasi C, Milani S (2016) Non-invasive assessment of liver fibrosis: between prediction/prevention of outcomes and cost-effectiveness. World J Gastroenterol 22(4):1711-1720

\section{Fibrosemarker}

> Fibrosekenngrößen

\section{Ficintest}

Enzymtest

\section{Ficoll-Gradiententrennung}

Gradiententrennung

\section{Ficoll-Hypaque-Röhrchen}

\section{W. G. Guder}

\section{Synonym(e) Zell-Trennröhrchen}

Englischer Begriff cell preparation tube (CPT); cell separation tube

Definition Röhrchen, in dem Blut ohne Abgießen durch Zentrifugation im Dichtegradienten in zelluläre und Plasmaphasen getrennt werden kann.

Beschreibung Die zunehmende Zahl analytischer Verfahren, die definierte Zellen des Blutes benötigen, machten die Entwicklung eines Trennverfahrens der Zellen aus dem Blut notwendig, bei dem nicht wie früher durch Dekantieren und Waschungen die gewonnenen Zellen kontaminiert wurden. Dies wurde ermöglicht durch ein geschlossenes Röhrchen- 
system, in dem eine Gelschicht mit einem Ficoll-Dichtegradienten kombiniert wurde. Bei der Zentrifugation werden Erythrozyten unter dem Gel abgetrennt, während Granulozyten oder Lymphozyten im Dichtegradienten darüber liegen und vom darüber liegenden Plasma getrennt werden können. Das Röhrchen erlaubt den Transport nach der ersten Zentrifugation über 40 Minuten bei $400 \mathrm{~g}$. Durch Zentrifugation bei $1500 \mathrm{~g}$ über 20 Minuten kann dann eine Schicht mit mononukleären Blutzellen ( $>$ Lymphozyt) abgetrennt werden. Die Granulozyten finden sich unterhalb der Gelschicht wieder.

Die Mischung besteht aus 10 Teilen 33,9\%igem HypaqueGel mit einer Dichte von 1,2 kg/L und $24 \%$ einer $9 \%$ igen Lösung von Ficoll in Wasser. Die Zentrifugation erfolgt bei Raumtemperatur.

\section{Literatur}

Boyum A (1968) Separation of lymphocytes from blood and bone marrow. Scand J Clin Lab Invest 21(Suppl 97):77-106

Guder WG, Narayanan S, Wisser H, Zawta B (2009) Blood cells can provide important information. Special aspects in cellular analysis. In: Diagnostic samples: from the patient to the laboratory, 4. Aufl. Wiley-Blackwell, Weinheim, S 62-63

\section{Field Desorption}

- Ionisationsmethoden (Massenspektrometrie)

\section{Field Ionization}

- Ionisationsmethoden (Massenspektrometrie)

\section{FIFTA}

- Fibrinogen-Funktion-turbidimetrischer Test

\section{FIGLU-Test}

\section{A. M. Gressner und O. A. Gressner}

Synonym(e) Formiminoglutaminsäure-Test; Histidinbelastungstest

Englischer Begriff histidine test
Definition Zum Nachweis eines Folsäuremangels eingesetzter oraler Belastungstest mit L-Histidin, der bei Folatmangel eine vermehrte Ausscheidung von N-Formiminoglutaminsäure (FIGLU) im Urin nachweist.

Beschreibung Der früher zum Nachweis einer Unterversorgung des Körpers mit $>$ Folsäure durchgeführte Belastungstest basiert auf der zwischen 3-8 Stunden nach oraler Aufnahme von 15 oder $20 \mathrm{~g}$ Histidin (L-Histidin-HCL) im Sammelurin messbaren, stark erhöhten Ausscheidung von N-Formiminoglutaminsäure (-glutamat). Als Folge der Abbauhemmung von Histidin (zu Glutamat und Ketoglutarat) aufgrund einer gestörten Übertragung der Formiminogruppe kommt es zur Akkumulation von FIGLU, deren vermehrte Ausscheidung im Sammelurin elektrophoretisch ( $\triangleright$ Elektrophorese), chromatographisch ( $\triangleright$ Chromatographie), enzymatisch-optisch bei 350-380 nm oder massenspektrometrisch ( $\triangleright$ Massenspektrometrie) quantifiziert werden kann. Außer einer stark erhöhten Ausscheidung bei manifestem Folsäuremangel sind erhöhte Ausscheidungsmengen auch bei einigen Lebererkrankungen, Glutenenteropathie (Spruesyndrome) und Vitamin B12-Mangel feststellbar. Durch die direkte Messung von Folsäure in Serum oder Hämolysat hat dieser Test heute seine Bedeutung weitgehend verloren.

\section{Literatur}

Cooperman JM, Lopez R (2002) The role of histidine in the anemia of folate deficiency. Exp Biol Med 227(11):998-1000

\section{File Transfer Protocol}

\section{O. Colhoun}

\section{Synonym(e) FTP}

Englischer Begriff file transfer protocol

Definition Übertragungsprotokoll im Internet zur Festlegung des Dateiübertrags von Computer zu Computer.

Beschreibung Für die Übertragung von Dateien ist das auf den Computern verwendete Betriebssystem (z. B. UNIX, Windows) und die Art der Internetverbindung ohne Belang. Neben der Dateiübertragung erlaubt FTP die Anzeige von Dateiverzeichnissen auf dem Host, das Wechseln, Anlegen und Umbenennen von Verzeichnissen sowie das Umbenennen und Löschen von Dateien auf dem Host. Wegen der weitreichenden Rechte, die der Benutzer erhält, muss dieser 
beim jeweiligen Host ein Benutzerkonto besitzen, sich mit einem Benutzernamen anmelden und mit Passwort ausweisen. Viele Hosts bieten die Möglichkeit, Dateien via Anonymous FTP abzurufen. Hierzu wird als Benutzername ,anonymous" eingegeben, das Passwort ist in diesem Falle beliebig. Für den FTP-Zugriff wird ein spezielles Programm verwendet, ein FTP-Client.

\section{Literatur}

Irlbeck T, Langenau F, Mayer F (2002) Beck EDV-Berater im dtv: Computer-Lexikon. Deutscher Taschenbuch-Verlag $\mathrm{GmbH} \& \mathrm{Co}$ $\mathrm{KG}$, München

\section{Filter}

\section{T. Arndt}

Synonym(e) Wellenlängenfilter

\section{Englischer Begriff filter}

Definition Optische Filter sondern den größten Wellenlängenbereich einfallenden Lichts selektiv aus und lassen nur Licht eines möglichst eng begrenzten Wellenlängenbereichs passieren.

Beschreibung Im einfachsten Fall besteht ein Filter aus gefärbtem Glas, das Licht mit den der Glasfarbe entsprechenden Wellenlängen absorbiert und nur Licht mit den Wellenlängen der Komplementärfarben passieren lässt. Auch Farbstofflösungen wurden als optische Filter eingesetzt. Neben diesen Absorptionsfiltern gibt es auch Interferenzfilter, deren Wirkung nicht auf Absorption oder Dispersion, sondern auf Interferenzeffekten beruht. Die wichtigste Anwendung im klinischchemischen Labor liegt in der $\gg$ Spektrometrie/Spektroskopie. Zum sog. \ Molfilter siehe dort.

\section{Literatur}

Kortüm G (1962) Kolorimetrie, Photometrie und Spektrometrie. Eine Anleitung zur Ausführung von Absorptions-, Emissions-, Fluoreszenz-, Streuungs-, Trübungs- und Reflexionsmessungen. SpringerVerlag, Berlin/Göttingen/Heidelberg

\section{Filter-Array}

- Makroarray

\section{Filtration, glomeruläre}

W. G. Guder

Synonym(e) Glomeruläre Clearance; Glomeruläre Filtrationsrate; GFR

Englischer Begriff glomerular filtration rate

Definition Die glomeruläre Filtration ( $\triangleright$ Clearance, glomeruläre) beschreibt den Prozess der Entstehung des Primärfiltrats in der Niere durch die Filtration aus dem kapillären Plasma in den proximalen Tubulus der Niere. Die Gesamtmenge der pro Minute filtrierten Flüssigkeitsmenge wird als glomeruläre Filtrationsrate bezeichnet.

Beschreibung Die glomeruläre Filtration findet in der Basalmembran des Glomerulums statt, einer extrazellulären Matrix, die eine Filtration nach Molekülgröße und Ladung erlaubt. Sie wird durch physikalische Eigenschaften wie Kapillardruck in glomerulären Kapillaren sowie physikalisch-chemischen Eigenschaften der filtrierten Moleküle wie der Oberfläche der Membran und der benachbarten Podozyten beeinflusst. Durch Heparansulfatreste an der den Kapillaren zugewandten Seite kommt es zu negativen Ladungen der Oberfläche, die negativ geladene Proteine von der Filtration abhalten. Dieser Mechanismus ist für Moleküle einer molekularen Größe $>10 \mathrm{kDa}$ bis $<45 \mathrm{kDa}$ relevant (z. B. > Albumin).

Die glomeruläre Clearance wird durch Messung frei filtrierbarer Moleküle im Plasma und im Sammelurin bestimmt (endogen durch Kreatinin [ $>$ Kreatinin-Clearance] und $\triangleright \mathrm{Cy}-$ statin $\mathrm{C}$, exogen durch Inulin [ $>$ Inulin-Clearance] und Iohexol). Neben der Bestimmung der Menge wird zunehmend die Qualität der glomerulären Clearance Gegenstand der diagnostischen Analytik. So wird eine selektive glomeruläre Proteinurie mit Vermehrung ausschließlich von Proteinen $<50 \mathrm{kDa}$ (z. B. Albumin) als Ausdruck einer Störung der Ladungsselektivität der glomerulären Filtration gesehen mit meist guter Prognose, d. h. ohne Verminderung der Filtrationsmenge (z. B. Minimal-change-Nephropathie, IgA-Nephropathie). Eine unselektive glomeruläre Proteinurie mit Ausscheidung von Molekülen $>120 \mathrm{kDa}$ (z. B. IgG, > Transferrin, bis $\mathrm{zu} \triangleright \alpha_{2}-$ Makroglobulin) hat demgegenüber eine schlechte Prognose bezüglich der Nierenfunktion (s. a. $>$ Proteinuriediagnostik).

\section{Literatur}

Anders Grubb (2010) Non-invasive estimation of glomerular filtration rate (GFR). The Lund model: Simultaneous use of cystatin C- and creatinine-based GFR-prediction equations, clinical data and an internal quality check. Scandinavian Journal of Clinical and Laboratory Investigation 70(2):65-70 
Guder WG, Hofmann W (1991) Glomeruläre Filtration. In: Thomas L, Fateh-Moghadam A, Guder WG et al (Hrsg) Proteindiagnostik. Behring Diagnostika, S 112-123

Hofmann W, Ehrich JHH, Guder WG, Keller F, Scherberich J (2014) Niere und ableitende Harnwege. In: Hofmann W, Aufenanger J, Hoffmann G. Klinikhandbuch Labordiagnostische Pfade, 2. Aufl. Walter de Gruyter, Berlin/Boston, S 130-150

Schleicher E, Nerlich A, Gerbitz KDA (1989) Struktur, Funktion und Pathobiochemie der glomerulären Basalmembran. In: Guder WG, Lang H (Hrsg) Pathobiochemie und Funktionsdiagnostik der Niere. Springer, Berlin/Heidelberg/New York, S 25-44

\section{Fingerprint}

- Variable number of tandem repeats (VNTRs)

\section{Finger-Schweißtest (nach Shwachman und Gahm)}

- Schweißanalytik

\section{First-Pass-Effekt}

\section{T. Arndt}

Synonym(e) Effekt der ersten Passage

\section{Englischer Begriff first pass effect}

Definition Bezeichnet gewöhnlich jenen Prozess, der bei der ersten Leberpassage eines endogenen oder exogenen Stoffs zu einer signifikanten Konzentrationsabnahme zwischen in die Leber einströmendem (Pfortader) und aus ihr heraustretendem (V. hepatica) Blut führt.

Beschreibung Nahezu das gesamte venöse Blut aus dem Magen-Darm-Kanal wird über die Pfortader in die Leber transportiert. Darin gelöste Stoffe werden z. T. erheblich durch Resorption und Metabolisierung in der Leber zurückgehalten und damit der Blutzirkulation entzogen. Nur der verbleibende Rest gelangt über die V. hepatica (erneut) in den großen Blutkreislauf und kann am Erfolgsorgan entsprechende Wirkungen auslösen.

Der First-Pass-Effekt hat große Bedeutung für die Bioverfügbarkeit von nicht wenigen oral applizierten Pharmaka, z. B. Propranolol oder Lidocain. So kann durch einen ausgeprägten First-Pass-Effekt ein Großteil der Dosis schon bei der ersten Leberpassage dem Kreislauf entzogen werden, z. B. bis $90 \%$ oral applizierter Sexualhormone. Ein Großteil der Ursprungsdosis steht dann für die pharmakologische Wirkung am
Zielort nicht mehr zur Verfügung. Medikamente mit großem First-Pass-Effekt und Metabolisierung zu inaktiven Metaboliten werden deshalb gewöhnlich höher dosiert als solche ohne ausgeprägten First-Pass-Effekt. Unter chronischem Einfluss eines Xenobiotikums (Pharmakons; - Xenobiotika) können hepatische Enzymsysteme induziert werden. Dies kann zu einem verstärkten First-Pass-Effekt mit schnellerer Metabolisierung und schlechterer Bioverfügbarkeit des Pharmakons führen. Ein unerwünschter ausgeprägter hepatischer First-PassEffekt kann durch z. B. sublinguale, transdermale oder intravenöse Darreichungsformen umgangen werden.

Nicht nur exogene Stoffe wie Pharmaka können einem starken First-Pass-Effekt unterliegen, sondern auch endogene Stoffe, wie z. B. - Insulin. Nach Sekretion des Insulins aus den $\beta$-Zellen des Pankreas in die Pfortader werden ca. $50 \%$ des Insulins direkt in der Leber abgefangen und treten damit nicht in die Blutzirkulation ein. Asialoglykoproteine haben einen starken First-Pass-Effekt und werden nahezu vollständig über den hepatozytären Asialoglykoproteinrezeptor aus der Zirkulation entfernt.

Ein gewöhnlich im Vergleich zum hepatischen First-PassEffekt weniger ausgeprägter First-Pass-Effekt kann auch aus der Metabolisierung von Substanzen im Lumen oder der Wand des Gastrointestinaltraktes resultieren.

\section{Literatur}

Mutschler E, Schäfer-Korting (1996) Arzneimittelwirkungen. Lehrbuch der Pharmakologie und Toxikologie, 7. Aufl. Wissenschaftliche Verlagsgesellschaft, Stuttgart

\section{Fischer, Hans}

W. Hubl

Lebensdaten Deutscher Chemiker und Mediziner, geboren am 21. Juli 1881 in Hoechst am Main; am 31. März 1945 Freitod nach der kriegsbedingten Zerstörung des Instituts.

1899-1904 Chemie- und Medizinstudium in Lausanne, München und Marburg. Im Jahr 1904 Promotion zum Dr. phil. in Marburg über das Thema „Beiträge zur Kenntnis der 4-Oxy-1,2-toluylsäure“. 1908 Promotion zum Dr. med. in München über das Thema „Zur Kenntnis des Karzinomatösen Mageninhalts“. 1912 Habilitation für das Fach Innere Medizin in München über das Thema „Urobilin und Bilirubin“. 1915 Ernennung zum Professor an der Medizinischen Fakultät der Universität München. 1916-1918 Lehrstuhlinhaber für Medizinische Chemie in Innsbruck und 1918-1921 in Wien. 1921-1945 Lehrstuhlinhaber für Organische Chemie an der TH München als Nachfolger von Heinrich Wieland. Im Jahr 1935 Eheschließung mit Wiltrud Fischer (geb. Haufe). 
Verdienste Das Lebenswerk widmete er der Chemie und Konstitutionsaufklärung der Pyrrolfarbstoffe. Er arbeitete über die Gallenfarbstoffe Urobilin, Biliverdin und Bilirubin, das er im Jahr 1942 erfolgreich synthetisierte. 1928 gelang Fischer die Synthese des Farbstoffs Hämin. Fischer nahm auch die von Richard Willstätter begonnenen Forschungen über Chlorophyll wieder auf, 1940 konnte er die Struktur des Moleküls aufklären. Seine Forschungsergebnisse wurden 1960 durch Robert B. Woodwards Chlorophyllsynthese bestätigt. 1929 Verleihung der Liebig-Gedenkmünze der Gesellschaft Deutscher Chemiker, 1930 Verleihung des Chemie-Nobelpreises für seine Arbeiten über den strukturellen Aufbau der Blut- und Pflanzenfarbstoffe und für die Synthese des Hämins, 1936 Verleihung der Ehrendoktorwürde der Harvard-Universität.

\section{Literatur}

Nobel Lectures (1966) Chemistry 1922-1941. Elsevier Publishing Company, Amsterdam. http://www.hans-fischer-gesellschaft.de/wp-content/ uploads/pdfs/Das_Leben_und_Wirken_Hans_Fischers.pdf. zugegriffen am 06.10.2017

Treibs A (1971, digitale Ausgabe 2010) Das Leben und Wirken von Hans Fischer. Hans-Fischer-Gesellschaft München

\section{Fischer-Quotient}

A. C. Sewell

Englischer Begriff Fischer ratio; Fischer quotient

Definition Plasmaquotient aus verzweigtkettigen $>$ Aminosäuren zu aromatischen Aminosäuren.

$$
\frac{\mathrm{Val}+\mathrm{Leu}+\mathrm{Ile}}{\text { Phe }+ \text { Tyr }}
$$

Beschreibung Der Fischer-Quotient ist ein wichtiger Parameter zur Beurteilung des Ernährungszustands, insbesondere von Patienten mit Lebererkrankung. Ein Quotient $<2$ ist Zeichen für eine hepatische Enzephalopathie. Im erweiterten Neugeborenenscreening mittels Tandem-((Verweis)) Massenspektrometrie (LC-MS/MS) wird der Fischer-Quotient zur Diagnose der Tyrosinämie mit herangezogen.

\section{Literatur}

Fischer JE, Funovics JM, Aguirre A et al (1975) The role of plasma amino acids in hepatic encephalopathy. Surgery 78:276-285

Kreuder J, Rauterberg EW (2005) Bedeutende Aminoazidopathien: Ahornsirupkrankheit, Tyrosinämie \& Co. Pädiatr Hautnah S2:12-15

\section{FISH}

- Fluoreszenz-in-Situ-Hybridisierung (FiSH)

\section{Fisher-Race-System}

- CDE-Nomenklatur

\section{Fitzgerald-Faktor}

- High-Molecular-Weight Kininogen

\section{FIX}

$\checkmark$ Gerinnungsfaktor IX

\section{FIZZ3}

$>$ Resistin

\section{FK-506}

- Tacrolimus

\section{Flachbett-Elektrophorese}

R. Westermeier

Synonym(e) Horizontalelektrophorese

Englischer Begriff flatbed electrophoresis 
Definition Im Gegensatz zur Vertikalelektrophorese ist bei der Flachbett-Elektrophorese die Trennmatrix, meist ein Agarose- oder ein Polyacrylamidgel, horizontal ausgerichtet.

Beschreibung Die bei der Flachbettelektrophorese verwendeten Trenngele sind in den meisten Fällen durch eine dünne Trägerglasplatte oder eine Trägerfolie gestützt. Sie werden mit offener Oberfläche verwendet. Meist werden diese Gele auf eine Kühlplatte gelegt, die Pufferbehälter sind seitlich angeordnet. Der Kontakt zwischen Laufpuffer und Trenngel erfolgt über puffergetränkte Papierbrücken. Alternativ hierzu gibt für manche Systeme auch Pufferstreifen aus Polyacrylamid- oder Agarosegel oder dickem Filterkarton, die auf die Gelkanten aufgelegt werden. Die Proben werden entweder in kleine, beim Gelgießen erzeugte Probenwannen einpipettiert, direkt auf die Oberfläche appliziert, oder mit Probenapplikatoren aufgegeben.

Manche Flachbett-Elektrophoreseapparaturen eignen sich auch für eine Trennmethode, die bei sehr hohen Spannungen durchgeführt wird: die $>$ Isoelektrische Fokussierung. Dann kann man sogar beide Trennungen der hochauflösenden Zweidimensional-Elektrophorese ( $\triangleright$ Elektrophorese, zweidimensionale) auf einer solchen Flachbettkammer laufen lassen.

\section{Fläche unter der Kurve}

C. Vidal und W.-R. Külpmann

$\operatorname{Synonym(e)~AUC~}$

Englischer Begriff area under the curve; AUC

Definition In der Pharmakokinetik Fläche im Plasmakonzentrations-Zeit-Diagramm.

Beschreibung Die Fläche kann für die verschiedenen Zeitabschnitte nach der Trapezregel berechnet werden. Die AUC ist ein Maß für die Menge an Pharmakon, die in die systemische Zirkulation gelangt und im Organismus verbleibt. Dementsprechend ist bei $100 \%$ Bioverfügbarkeit und langsamer Elimination die AUC besonders groß. Das Verhältnis der AUC bei oraler Applikation im Vergleich zur AUC bei i.v. Gabe spiegelt die $>$ Bioverfügbarkeit wider.

\section{Querverweise $\rightarrow$ AUC}

\section{Literatur}

Taylor WJ, Diers Caviness MH (1986) A textbook for the clinical application of therapeutic drug monitoring. Abbott, Irving

\section{Flags}

O. Colhoun

Synonym(e) Kennzeichnungen

\section{Englischer Begriff flags}

Definition Folgen mehrerer Bits, die innerhalb des Ergebnisübertrags vom Analysegerät zur Labor-EDV einen bestimmten Zustand eines Werts kennzeichnen.

Beschreibung So zeigen Flags in der Übertragung zu einem Wert z. B. die Zustände „lipämisch“, ,hämolytisch“, „wiederholt“, „verdünnt“ oder „oberhalb des Messbereichs“ an.

\section{Flame atomic absorption spectrometry (FAAS)}

- Flammenatomabsorptionsspektrometrie/-spektroskopie

\section{Flammen-AAS}

- Flammenatomabsorptionsspektrometrie/-spektroskopie

\section{Flammenatomabsorptionsspektro- metrie/-spektroskopie}

\section{J. Knecht}

Synonym(e) Flammenatomabsorptionsspektroskopie; Flammen-AAS

Englischer Begriff flame atomic absorption spectrometry

Definition Bei der Flammenatomabsorptionsspektrometrie werden die $\mathrm{zu}$ bestimmenden Atome mit einer heißen Flamme erzeugt.

Beschreibung Bei der Flammen-AAS wird eine Lösung (z. B. Patientenprobe) des zu bestimmenden Elements als Aerosol in die Flamme (entweder Luft-Acetylen $\left[\mathrm{C}_{2} \mathrm{H}_{2}\right]$ $\left[2400{ }^{\circ} \mathrm{C}\right]$ oder Lachgas- $\left[\mathrm{N}_{2} \mathrm{O}-\right]$ Acetylen $\left.\left[2800{ }^{\circ} \mathrm{C}\right]\right)$ gesaugt und dort versprüht. Hierbei laufen folgende Schritte ab: 
1. Desolvatation des Aerosols (das Wasser der Lösung wird verdampft, zurück bleiben feste Teilchen)

2. Verdampfung der festen Teilchen zu Molekülen

3. Dissoziation der Moleküle in Atome

4. Teilweise Ionisation der Atome (unerwünscht, da nur die Konzentration der Atome in der Flamme gemessen werden kann)

5. Reaktion der Atome mit anderen Teilchen, die in der Flamme sind (unerwünscht, da die Konzentration an freien Atomen in der Flamme verringert wird).

Das von der elementspezifischen $>$ Hohlkathodenlampe oder elektrodenlosen Entladungslampe ausgehende Licht wird nicht nur von den Atomen des zu bestimmenden Elements sondern auch unspezifisch durch den kontinuierlichen Untergrund geschwächt. Um die das Messsignal störende unspezifische Untergrundabsorption zu beseitigen, wird diese entweder mit einem Kontinuumstrahler (meist mit einer $>$ Deuteriumlampe) oder mit der sog. Zeeman-Untergrundkompensation (s. - Untergrundkompensation) korrigiert.

In neuerer Zeit wird manchmal die Fließinjektionsanalyse mit der Flammen-AAS gekoppelt, um diese gerade im Routinebetrieb noch vielseitiger einzusetzen. Damit ermöglicht man

- Online-Aufkonzentrierung des zu bestimmenden Elements, um die Nachweisgrenzen zu erniedrigen,

- Verdünnungen, um den linearen Bereich zu erweitern, und

- die teilweise Entfernung der Matrix, um deren Störungen zu verringern. Details unter Atomabsorptionsspektrometrie.

\section{Literatur}

Van Loon JA (2012) Analytical atomic absorption spectroscopy: selected methods, Elsevier, Amsterdam

Welz B, Sperling M (1997) Atomabsorptionsspektrometrie, 4. Aufl. Wiley-VCH, Weinheim

\section{Flammenatomabsorptionsspektro- skopie}

> Flammenatomabsorptionsspektrometrie/-spektroskopie

\section{Flammenatomemissionsspektrometrie}

- Flammenatomabsorptionsspektrometrie/-spektroskopie

- Flammenemissionsspektrometrie

\section{Flammenatomfluoreszenz- spektroskopie/-spektrometrie (FAFS)}

- Fluoreszenzspektrometrie/-spektroskopie

\section{Flammenemissionsspektrometrie}

J. Knecht

Synonym(e) Flammenatomemissionsspektrometrie; Flammenphotometrie; FES

Englischer Begriff flame emission spectrometry; flame photometry

Definition Bei der Flammenemissionspektrometrie wird eine Lösung (z. B. aufbereitende Patientenprobe) in eine Flamme (Propan, Acetylen) gesprüht und die thermisch angeregten Atome oder Moleküle senden ein für sie charakteristisches Licht aus.

Physikalisch-chemisches Prinzip Die aufbereitende Patientenprobe wird in eine heiße (Propan-, Acetylen-) Flamme gesprüht. Durch die hohe Temperatur werden die feinen Tröpfchen verdampft, die entstehenden Partikel thermisch in Moleküle und dann in Atome dissoziiert. Die Außenelektronen der Atome oder auch der Moleküle werden thermisch in einen höheren Energiezustand gehoben. Beim Zurückfallen in den Grundzustand wird Energie frei, die in Form von elektromagnetischer Strahlung (Licht) abgegeben wird. Diese Strahlung ist für das Element oder Molekül charakteristisch und kann zur qualitativen und/oder quantitativen Analyse verwendet werden.

Einsatzgebiet Die Flammenemissionsspektrometrie wird heute oft noch als kostengünstige Methode zur Bestimmung von Alkali- (z. B. Na, K) und Erdalkalimetallen (z. B. Ca, $\mathrm{Mg}$ ) eingesetzt. Die Verbindungen dieser Elemente sind im Allgemeinen so leicht in Atome spaltbar, dass hierzu die Temperatur der Flamme ausreicht.

Untersuchungsmaterial Mit der Flammenemissionsspektrometrie lassen sich grundsätzlich nur Lösungen untersuchen. Normalerweise müssen die zu untersuchenden Lösungen aufgeschlossen werden.

Feststoffe, aber auch die meisten Flüssigkeiten, werden durch oxidierende Säureaufschlüsse, manchmal auch durch eine Trockenveraschung mit anschließender Säurebehandlung, zersetzt. Bei der Messung ist besonders darauf zu ach- 
ten, dass die Matrixeffekte weitgehend eliminiert werden, indem man bei der Kalibrierung die Matrix berücksichtigt.

Instrumentierung Ein Flammenemissionsspektrometer ähnelt im Aufbau einem Atomemissionsspektrometer mit ICPAnregung (s. a. - Inductively coupled plasma), nur dass bei der FES die Anregung durch eine heiße Flamme erfolgt. Die optischen Komponenten sind im Flammenemissionsspektrometer weniger aufwendig als beim ICP-AES-Gerät, da mit einer Flamme nur ein Bruchteil der Emissionslinien im Vergleich zum ICP-AES-Spektrometer auftreten kann. Oft kann man auch Atomabsorptionsspektrometer durch einfaches Umschalten als Flammenemissionsspektrometer verwenden. Natürlich wird dann keine Lampe zur Emission der Atomlinien benötigt.

Spezifität Die Spezifität ( $\triangleright$ Spezifität, analytische) ist bei der Flammenemissionsspektrometrie geringer als bei der - Atomabsorptionsspektrometrie, weil die Optik der Geräte alle Fremdlinien ausblenden muss. Bei der AAS reicht diese einfachere Optik vollständig aus, da die aus der Hohlkathoden- oder EDL-Lampe kommenden Atomemissionslinien sehr schmalbandig sind. Die ICP-AES-Spektrometer haben wegen ihres höheren Preises auch eine wesentlich aufwendigere Optik als die Flammenemissionsspektrometer und haben auch deshalb eine bessere Spezifität.

Sensitivität Die Sensitivität ( $\vee$ Sensitivität, diagnostische) ist bei der Flammenemissionsspektrometrie etwa genauso groß wie bei der Flammenatomabsorptionsspektrometrie und geringer als die der Graphitrohr-AAS oder der ICP-Massenspektrometrie.

Fehlermöglichkeit Wenn man die unspezifische Untergrundstrahlung der Flamme optisch nicht genügend von den Atomemissionslinien abtrennt oder abtrennen kann, erhält man zu hohe Elementgehalte. Dies muss man durch eine geeignete Kalibrierung kompensieren. Auch durch die gegenseitige Beeinflussung der Intensität der Emissionslinien durch die Alkali- oder Erdalkalimetalle kann man sowohl zu hohe als auch zu niedrige Elementgehalte messen. Um richtige Messwerte zu erhalten, ist eine gewisse Erfahrung des Anwenders notwendig.

Praktikabilität - Automatisierung - Kosten Die Flammenemissionsspektrometrie eignet sich als kostengünstige Methode für Messungen der Alkali- und Erdalkalielemente in einer gut bekannten Matrix wie Blut, Serum usw. Bei einer unbekannten Probe sollte man diese Methode nicht ohne Vorversuche anwenden.

Wenn man einen Messroboter einsetzt, können in den zu untersuchenden Proben nacheinander die zu bestimmenden Elemente vermessen werden. Da das Gerät in der Anschaf- fung sehr kostengünstig ist und bei der laufenden Messung nur die verhältnismäßig geringen Kosten für das Flammengas anfallen, ist die Flammenemissionsspektrometrie sicher die kostengünstigste atomspektrometrische Methode.

Bewertung - Methodenhierarchie Die Flammenemissionsspektrometrie wird aus Kostengründen noch oft für die Bestimmung der Alkali- und Erdalkalimetalle mit allerdings abnehmender Tendenz eingesetzt. Bei der Bestimmung dieser Elemente in kompliziert oder unbekannt zusammengesetzten Proben sollte man zur Bestimmung andere atomspektrometrische Methoden anwenden.

\section{Literatur}

Broekaert JAC (2002) Analytical atomic spectrometry with flames and plasmas. Wiley-VCH, Weinheim

Kellner R et al (Hrsg) (2004) Analytical chemistry, 2. Aufl. Wiley-VCH, Weinheim

Welz B, Sperling M (1997) Atomabsorptionsspektrometrie, 4. Aufl. Wiley-VCH, Weinheim

\section{Flammenfluoreszenzspektroskopie/- spektrometrie (FFS)}

> Fluoreszenzspektrometrie/-spektroskopie

\section{Flammenphotometrie}

- Flammenatomabsorptionsspektrometrie/-spektroskopie

- Flammenemissionsspektrometrie

\section{Flavinmononukleotid}

- Vitamin $\mathrm{B}_{2}$

\section{Fletcher factor}

> Präkallikrein

\section{Fletcherfaktor}

> Präkallikrein 


\section{FLI}

\section{- Fettleber-Index}

\section{Fließgleichgewicht}

C. Vidal und W.-R. Külpmann

Englischer Begriff steady state

Definition Zustand, bei dem Zufuhr und Elimination z. B. eines Pharmakons gleich groß sind.

Beschreibung Im Fließgleichgewicht ist die Plasmakonzentration z. B. eines Arzneistoffs konstant, was sich durch eine Dauerinfusion erreichen lässt. Bei oraler, diskontinuierlicher Applikation ist ein Fließgleichgewicht bei langsamer Elimination gut anzunähern, bei rascher Elimination schwierig und lediglich durch Zufuhr in kurzen Zeitintervallen erreichbar.

Die aktuelle Konzentration eines Pharmakons im Plasma ist insgesamt die Resultante aus den Einflussgrößen Freisetzung (,liberation“), Absorption (,,absorption“), Verteilung (,distribution“), Metabolismus (,metabolism“) und Ausscheidung (,excretion"); LADME.

\section{Literatur}

Külpmann WR (1991) Drug monitoring. Diagnose und Labor 41:55-62

\section{Fließmittel}

D Mobile Phase

\section{Flocculations-Test}

- Serumprotein-Labilitätsreaktionen

\section{Florinef-Test}

Fludrokortison-Suppressionstest

\section{Flotillin-Autoantikörper}

- Autoantikörper gegen Flotillin

\section{Flow-Zytometrie}

- Durchflusszytometrie

Flucytosin

C. Vidal und W.-R. Külpmann

Englischer Begriff flucytosine

Definition Antimykotikum.

Strukturformel:<smiles>Nc1nc(O)ncc1F</smiles>

Molmasse $129,09 \mathrm{~g}$.

Synthese - Verteilung - Abbau - Elimination Bei oraler Applikation beträgt die $>$ Bioverfügbarkeit $84 \%$. Flucytosin wird unverändert renal eliminiert.

Halbwertszeit 3-5 Stunden (Plasma).

Funktion - Pathophysiologie Flucytosin wird mittels Cytosinpermease in die Zelle transportiert und dort $\mathrm{zu}$ 5-Fluorouracil (5 FU) metabolisiert, was durch Kompetition zu Thymidylatmangel führt.

Untersuchungsmaterial - Entnahmebedingungen Plasma (P), Serum (S).

Analytik HPLC ( $\triangleright$ Hochleistungs-Flüssigkeitschromatographie), LC-MS/MS.

Indikation Therapeutisches Drug Monitoring.

Interpretation Therapeutischer Bereich (S, P): 35-70 (20-50) $\mathrm{mg} / \mathrm{L}$; toxisch: $>100 \mathrm{mg} / \mathrm{L}$; komatös-letal: unbekannt (Schulz et al. 2012). Unter der Therapie sollten 
$25 \mathrm{mg} / \mathrm{L}$ nicht unterschritten werden, um das Auftreten resistenter Stämme zu vermeiden. Üblicherweise wird Flucytosin in Verbindung mit Amphotericin B verwendet.

\section{Literatur}

Bircher J, Sommer W (1999) Klinisch-pharmakologische Datensammlung, 2. Aufl. Wissenschaftliche Verlagsgesellschaft, Stuttgart

Schulz M, Iwersen-Bergmann S, Andresen H, Schmoldt A (2012) Therapeutic and toxic blood concentrations of nearly 1000 drugs and other xenobiotics. Crit Care 16:R136

\section{Fludrokortison-Suppressionstest}

W. Hubl

$\operatorname{Synonym(e)~} 9 \alpha$-Fluorocortisol-Test; $9 \alpha$-Fluorohydrocortison-Test; Florinef-Test

Englischer Begriff Fludrocortisone; $9 \alpha$-fluorohydrocortisone

Definition Der Fludrokortison-Suppressionstest dient zur Bestätigungsdiagnostik eines Hyperaldosteronismus nach klinischen Zeichen sowie einem pathologischen AldosteronRenin-Quotienten ( $\triangleright$ Aldosteron-Renin-Quotient).

\section{Durchführung}

- Erste Blutentnahme für die Bestimmung von Aldosteron und Kalium

- 4-mal täglich orale Gabe von $0,1 \mathrm{mg}$ Fludrokortison (Astonin H, Florinef), d. h. alle 6 Stunden: $4 \mathrm{Uhr}$, $10 \mathrm{Uhr}, 16 \mathrm{Uhr}, 22 \mathrm{Uhr}$ über 4 Tage

- Blutdruckmessungen 4-mal täglich

- Kaliumbestimmungen im Serum 4-mal täglich

- Tägliche Kaliumgabe mit einem Zielwert von 4,0 mmol/L im Serum

- 3-mal tägliche Natriumchloridgabe (jeweils $30 \mathrm{mmol}$ ) in Kombination mit einer Natriumchlorid-reichen Kost

- Am 4. Tag Blutentnahme um 7 Uhr für Kortisol und um $10 \mathrm{Uhr}$ bei sitzendem Patienten für Aldosteron und Kortisol. Die Kortisolbestimmungen dienen zum Ausschluss eines ACTH-Effektes auf die Aldosteronkonzentration.

Nebenwirkungen: arterieller Hypertonus, Hypokaliämie, Hypervolämie mit Ödemneigung, Dekompensation einer Herzinsuffizienz.

Folgende Kontraindikationen für die Verabreichung von Fludrokortison: hypertensive Entgleisungen, Hypokaliämie,
Schwangerschaft, Stillzeit, schwere periphere Ödeme, Überempfindlichkeit gegenüber Fludrokortison.

Medikamenteneinflüsse durch vorheriges Absetzen vermeiden: Diuretika und Antihypertensiva möglichst eine Woche vor dem Test absetzen.

Struktur $\mathrm{C}_{21} \mathrm{H}_{29} \mathrm{FO}_{5}$.

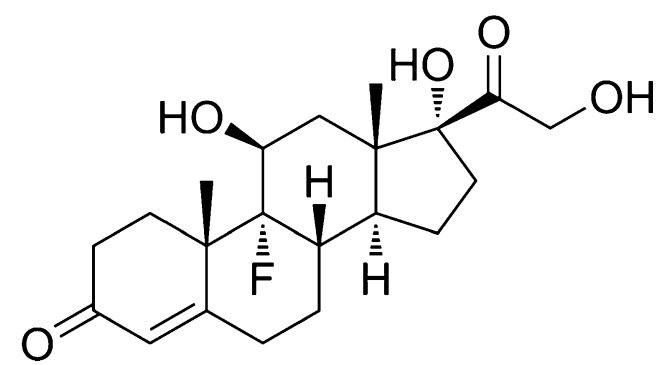

Molmasse $380,45 \mathrm{~g} / \mathrm{mol}$.

Pathophysiologie Eine mehrtätige Verabreichung von Mineralokortikoiden, wie z. B. Fludrokortison, bewirkt bei Gesunden und Patienten ohne primären Hyperaldosteronismus einen Abfall der Aldosteronkonzentration. Im Gegensatz hierzu wird bei Patienten mit einem primären Hyperaldosteronismus (Conn-Syndrom) die autonome Aldosteronproduktion nicht gehemmt. Diese Reaktion wird zur Bestätigungsdiagnostik des Conn-Syndroms verwendet.

Untersuchungsmaterial $>$ Aldosteron und $>$ Kalium.

Präanalytik $\triangleright$ Aldosteron und $\triangleright$ Kalium.

Analytik $>$ Aldosteron und $\gg$ Kalium.

Probenstabilität $\gg$ Aldosteron und $\gg$ Kalium.

Konventionelle Einheit $>$ Aldosteron und $\triangleright$ Kalium.

Internationale Einheit $>$ Aldosteron und $>$ Kalium.

Umrechnungsfaktor zw. konv. u. int. Einheit $\rightarrow$ Aldosteron und $>$ Kalium.

Referenzbereich - Erwachsene S. Interpretation.

\section{Indikation}

- Verdacht auf einen primären Hyperaldosteronismus (ConnSyndrom)

- Differenzialdiagnostik des primären Hyperaldosteronismus von der essenziellen Hypertonie 
Interpretation Aldosteron am 4. Tag oberhalb von $166 \mathrm{pmol} / \mathrm{L}$ (60 ng/L bzw. kein Abfall auf unter $90 \%$ des Ausgangswertes bedeutet: Bestätigung eines primären Hyperaldosteronismus. Als Voraussetzung gilt ein Abfall des 10-Uhr-Kortisolwertes auf unter $90 \%$ des 7-Uhr-Kortisolwertes (Ausschluss einer ACTH-Stimulation).

Diagnostische Wertigkeit Der Fludrokortison-Suppressionstest dient neben dem $>$ Kochsalz-Belastungstest sowie dem $>$ Captopril-Test als Bestätigungstest des primären Hyperaldosteronismus.

Der Test gilt als aufwendig und muss deshalb in der Regel stationär durchgeführt werden. Allerdings belegen einige Autoren eine höhere diagnostische Sensitivität im Vergleich zu den anderen alternativen Funktionstests.

\section{Literatur}

Funder J, Carey R, Fardella C, Gomez-Sanchez C, Matero F, Stowasser M et al (2008) Case detection, diagnosis, and treatment of patients with primary aldosteronism: an endocrine society clinical practice guideline. J Clin Endocrinol Metabol 93:3266-3281

Mönig H, Harbeck B, Domm C et al (2014) Dynamische Funktionstests in der Endokrinolgie und Diabetologie. Fludrokortison-Suppressionstest. In: Lehnert H (Hrsg) Rationelle Diagnostik und Therapie in Endokrinologie, Diabetologie und Stoffwechsel. Thieme-Verlag, Stuttgart, S 670-671

Schäffler A, Bollheimer C, Büttner R (2015) Nebennierenrinde. In: Schäffler A (Hrsg) Funktionsdiagnostik in Endokrinologie, Diabetologie und Stoffwechsel. Indikation, Testvorbereitung und -durchführung, Interpretation. Springer-Verlag/GmbH \& Co., Berlin/Heidelberg, S 79-102/S 93-94

\section{Fluor}

D. Meißner und T. Arndt

\section{Englischer Begriff fluorine}

Definition Fluor (chemisches Symbol: F) ist ein gasförmiges Halogen mit der Ordnungszahl 9. Es gehört zu den essenziellen $>$ Ultraspurenelemente.

Struktur Fluor liegt im Plasma als Fluorid vor, im Skelett und in den Zähnen ist es als schwer löslicher Fluorapatit gebunden, indem es Hydroxylgruppen im Apatit ersetzt.

Molmasse Relative Atommasse: 18,9984.
Synthese - Verteilung - Abbau - Elimination Fluor liegt im Organismus in der Oxidationsstufe -1 vor. Es wird mit Nahrungsmitteln, Getränken und Medikamenten aufgenommen und zu 80-100 \% resorbiert. Aus dem Plasma wird es sehr rasch an die Speicher abgegeben oder über die Nieren ausgeschieden. Auf diese Weise wird die Plasmakonzentration konstant gehalten. $99 \%$ des Gesamtfluors sind im Skelett und in den Zähnen gespeichert.

Körperbestand: 2-3 g. Bedarf: 0,7 mg/Tag. Empfohlene Zufuhr: Kinder 0,1-2,5 mg/Tag, Erwachsene 2-4 mg/Tag. Kleinkinder: zusätzlich $0,25 \mathrm{mg} / \mathrm{Tag}$ (als Tablette), wenn Trinkwasserkonzentration $<0,3 \mathrm{mg} / \mathrm{L}$ ist. Fluorreich sind Fische, Meeresfrüchte, Tee.

Funktion - Pathophysiologie Im Tierversuch wurde die Essenzialität des Fluors bestätigt. Für den Menschen ist seine hohe Affinität zum Zahnhartgewebe und Knochen von Bedeutung. Fluorid wird wegen seiner kariesprotektiven Wirkung zur Kariesprophylaxe und wegen seines Einflusses auf die Synthese und die Stabilität der Knochenmatrix zur Behandlung der Osteoporose therapeutisch angewendet. Hohe Dosen an Fluor können zu toxischen Erscheinungen (Verätzungen, Atemnot, Hautnekrosen, Hypokalzämie und Hypomagnesämie durch Bildung von $\mathrm{CaF}_{2}$ bzw. $\mathrm{MgF}_{2}$ ) sowie zur Beeinträchtigung der Schilddrüsenfunktion (Strumabildung) und im chronischen Stadium zu Zahn- oder Knochenfluorose (Fluorosteosklerose durch Stimulation der Osteoblasten) mit erheblichen Knochendefornationen führen.

Fluoridverbindungen finden Anwendung zum Ätzen von Glas, in der Halbleiterherstellung, Petrochemie, Textilindustrie, in Rostentfernern und Holzkonservierungsmitteln. Toxische Dosen führen zu lokaler Verätzung und starken Schmerzen. Die Zelltoxizität beruht auf der Hemmung verschiedener Enzyme, wie der Na-K-ATPase und der Adenylatzyklase.

Untersuchungsmaterial-Entnahmebedingungen Serum, Plasma, Urin.

Probenstabilität $4-8{ }^{\circ} \mathrm{C} 30$ Tage, $-20^{\circ} \mathrm{C} 1 \mathrm{Jahr}$.

Präanalytik Abnahme- und Aufbewahrungsgefäße für die Spurenelementbestimmung verwenden und Kontakt mit fluoridhaltigen Medikamenten und Kosmetika vermeiden.

Analytik Ionensensitive Elektroden.

Konventionelle Einheit $\mu \mathrm{g} / \mathrm{L}, \mathrm{mg} / \mathrm{L}, \mathrm{mg} / \mathrm{g}$ Kreatinin.

Internationale Einheit $\mu \mathrm{mol} / \mathrm{L}$.

Umrechnungsfaktor zw. konv. u. int. Einheit $\mu \mathrm{mol} /$ $\mathrm{L}=0,05264 \times \mu \mathrm{g} / \mathrm{L}, \mu \mathrm{g} / \mathrm{L}=18,9984 \times \mu \mathrm{mol} / \mathrm{L}$. 
Referenzbereich - Erwachsene Serum, Plasma: 5-20 $\mu \mathrm{g} / \mathrm{L}$ $(0,26-1,05 \mu \mathrm{mol} / \mathrm{L})$. Urin: $<0,5 \quad \mathrm{mg} / \mathrm{L} \quad(<26 \mu \mathrm{mol} / \mathrm{L})$ (Brätter 1992).

Referenzbereich - Kinder s. Erwachsene.

Indikation Verdacht auf übermäßige Aufnahme oder Intoxikation, Überwachung fluorexponierter Personen, Überwachung der Fluoridtherapie.

\section{Interpretation}

- Als unbedenklich gelten bis $100 \mu \mathrm{g}$ Fluorid/L Serum oder Plasma und $1 \mathrm{mg}$ Fluorid/L Urin.

- Serum oder Plasma: therapeutischer Bereich 95-190 $\mu \mathrm{g}$ Fluorid/L (bis $285 \mu \mathrm{g} / \mathrm{L}$ bei Osteoporosetherapie), toxisch $>500-2000 \mu \mathrm{g} / \mathrm{L}$, komatös-letal $>3000 \mathrm{mg} / \mathrm{L}$ (Schulz et al. 2012).

- BAT-Wert (Urin): 4 mg Fluorid/L (BAT-Liste in DFG 2016).

- Grenzwert im Trinkwasser: 1,5 mg Fluorid/L (TrinkwasserVO 2016).

Diagnostische Wertigkeit Erkennung einer übermäßigen Aufnahme oder Vergiftung, Kontrolle der Therapie mit Fluorid.

\section{Literatur}

Brätter P, Beirat W (1992) Mineralstoffe und Spurenelemente. Bertelsmann Stiftung, Gütersloh

DFG (2016) Senatskommission zur Prüfung gesundheitsschädlicher Arbeitsstoffe. Mitteilung 52. MAK- und BAT-Werte-Liste 2016. Wiley-VCH, Weinheim

Löffler G, Petrides PE (Hrsg) (2003) Biochemie und Pathobiochemie. Springer-Verlag, Berlin/Heidelberg/New York, S 714-716

Schulz M, Iwersen-Bergmann S, Andresen H, Schmoldt A (2012) Therapeutic and toxic blood concentrations of nearly 1,000 drugs and other xenobiotics. Crit Care 16:R136

Trinkwasser-VO (2016) Trinkwasserverordnung in der Fassung der Bekanntmachung vom 10. März 2016. https://www.gesetze-iminternet.de/bundesrecht/trinkwv_2001/gesamt.pdf. Zugegriffen am 11.08 .2017

\section{Fluoreszein}

T. Arndt

Synonym(e) Resorcinolphthalein

Englischer Begriff fluorescein
Definition Fluoreszein $\left(\mathrm{C}_{20} \mathrm{H}_{12} \mathrm{O}_{5}\right.$; Molmasse: $\left.332,32 \mathrm{~g}\right)$ ist eine polyzyklische Verbindung, die zu den Xanthinfarbstoffen gehört. Strukturformel:<smiles>O=C(O)c1ccccc1-c1c2ccc(=O)cc-2oc2cc(O)ccc12</smiles>

Beschreibung Fluoreszein wird gewöhnlich in Form seines Dinatriumsalzes (Uranin) gehandelt. Es zeigt eine intensive gelbgrüne > Fluoreszenz, die noch in einer Verdünnung von $10^{-11} \mathrm{~mol} / \mathrm{L}$ deutlich erkennbar ist. Fluoreszein eignet sich deshalb zur Verfolgung des Stofftransports in lebenden Organismen. In der klinisch-chemischen Diagnostik wird Fluoreszein u. a. im > Fluoreszenzpolarisations-Immunoassay (FPIA) und als Fluoreszeindilaureat (Salz der Laurinsäure) im sog. > Pankreolauryltest (Fluoreszeindilaurat-Test) zur Überprüfung der exokrinen Pankreasfunktion eingesetzt.

\section{Literatur}

Falbe J, Regitz M (Hrsg) (1996) Römpp Chemie Lexikon, 10. Aufl. Georg Thieme Verlag, Stuttgart/New York

\section{Fluoreszeindilaurat-Test}

- Pankreolauryltest

\section{Fluoreszenz}

T. Arndt

Englischer Begriff fluorescence

Definition Form der $\triangleright$ Lumineszenz, die sich durch eine kurze Verweildauer der Elektronen von ca. $10^{-8} \mathrm{~s}$ im angeregten Zustand auszeichnet.

Beschreibung Die schnelle Rückkehr der angeregten Elektronen auf niedrigere Energieniveaus führt dazu, dass das emittierte Licht schon unmittelbar nach Abklingen der Anregung nicht mehr zu beobachten ist. Das Ausmaß der Fluoreszenz hängt von der Intensität der Erregerstrahlung, der Schichtdicke (z. B. der Messküvette) und der Konzentration 
der fluoreszenzfähigen Moleküle in der zu analysierenden Probe ab. Hält man Erregerstrahlung und Schichtdicke konstant, kann die Fluoreszenz somit zur Konzentrationsbestimmung genutzt werden (Fluorometrie).

\section{Literatur}

Kortüm G (1962) Kolorimetrie Photometrie und Spektrometrie. Eine Anleitung zur Ausführung von Absorptions-, Emissions-, Fluoreszenz-, Streuungs-, Trübungs- und Reflexionsmessungen. SpringerVerlag, Berlin/Göttingen/Heidelberg

Latscha HP, Linti GW, Klein HA (2004) Analytische Chemie. ChemieBasiswissen III. Springer-Verlag, Berlin/Heidelberg/New York

\section{Fluoreszenz, zeitaufgelöste}

T. Arndt

\section{Synonym(e) TrFIA}

Englischer Begriff time-resolved fluorescence immunoassay

Definition Variante der $>$ Fluoreszenzspektrometrie/-spektroskopie, bei der durch Einsatz von Chelaten ( $\triangleright$ Chelate) seltener Erden (z. B. Europium) besonders langlebige Fluoreszenzen erzeugt und zeitaufgelöst ausgewertet werden.

Beschreibung Die emittierte Fluoreszenz zeichnet sich durch eine relativ lange Relaxationszeit von 10-1000 $\mu \mathrm{s}$ aus. Dies ermöglicht die Abtrennung des Zeitfensters der vom biologischen Material ausgehenden unspezifischen und kurzlebigen Fluoreszenz mit 1-20 ns vom Zeitfenster des eigentlichen Messvorgangs (400-800 $\mu$ s) und daraus resultierend eine signifikante Erhöhung der analytischen Spezifität. Europiumchelate zeigen eine große Stokes-Verschiebung ( $\triangleright$ Lumineszenz) von ca. $270 \mathrm{~nm}$; die Anregung erfolgt also durch blaues Licht, die Fluoreszenz wird als rotes Licht abgegeben. Damit liegt die Anregungswellenlänge weit von der Emissionswellenlänge entfernt, was gegenseitige Störungen ausschließt, infolge dessen eine hohe Anregungsenergie zulässt und schließlich zu einer signifikanten Sensitivitätsund Spezifitätssteigerung im Vergleich zu herkömmlichen Fluoreszenzmessungen führt. (Bei herkömmlichen Fluoreszenzmessungen mit z. B. \ Fluoreszein beträgt die StokesVerschiebung nur $30 \mathrm{~nm}$ ).

\section{Literatur}

Greiling H, Gressner AM (Hrsg) (1995) Lehrbuch der Klinischen Chemie und Pathobiochemie, 3. Aufl. Schattauer-Verlag, Stuttgart/New York
Yifeng Shen, Shaohan Xu, Donghua He, Sabato D'Auria (2015) A Novel Europium Chelate Coated Nanosphere for Time-Resolved Fluorescence Immunoassay. PLOS ONE 10 (6):e0129689

\section{Fluoreszenzemissionsspektrometrie}

> Fluoreszenz-Scan

\section{Fluoreszenzfärbung}

R. Westermeier

Englischer Begriff fluorescence staining

Definition Dient in der Elektrophorese dem Nachweis von Proteinen in Polyacrylamidgelen mithilfe von Fluoreszenzfarbstoffen bei hoher Empfindlichkeit und zeichnet sich durch einen weiten linearen Bereich aus. Sie ist daher besonders gut geeignet für quantitative Bestimmungen.

Beschreibung Fluoreszenzfarbstoffe haben eine hohe Empfindlichkeit und zeichnen sich durch einen weiten linearen Bereich aus. Sie sind daher besonders gut geeignet für quantitative Bestimmungen. Das zugrunde liegende Prinzip ist die Anregung der Fluoreszenzfarbstoffe ( $\downarrow$ Fluorophor) mit Licht niedriger Wellenlänge und die Messung des emittierten Lichtsignals mit höherer Wellenlänge ( $\triangleright$ Fluoreszenz). Die Intensität der emittierten Strahlung ist der Proteinmenge in der Elektrophoresefraktion proportional. Die Detektionsgrenze liegt im oberen Picogramm- bis Nanogrammbereich. Der lineare dynamische Messbereich erstreckt sich über 4 Größenordnungen.

Für Nukleinsäuren verwendet man Ethidiumbromid oder SYBRgreen, bei Proteinen Nilrot, SYPRO-Red, -Orange, -Tangerine und -Ruby sowie den neueren Farbstoff ServaPurple. Zur Visualisierung von Fluoreszenzfärbungen benötigt man entweder einen UV-Leuchttisch mit Kamerasystem, ein Video-Imaging-System oder ein Fluoreszenzdensitometer (s. - Densitometer).

\section{Literatur}

Westermeier R (2016) Elektrophorese leicht gemacht. Wiley-VCH, Weinheim 


\section{Fluoreszenz-in-Situ-Hybridisierung (FiSH)}

\section{J. Arnemann}

Synonym(e) DNA-/RNA-Nachweis mittels fluoreszenzmarkierter Sonden

Englischer Begriff fluorescence in-situ hybridization

Definition Fluoreszenz-in-Situ-Hybridisierung (FiSH) ist eine Methode zum Nachweis und zur Charakterisierung von mRNA- und DNA-Molekülen in situ, nämlich in Geweben, in Zellen oder auf Chromosomen mittels fluoreszenzmarkierter DNA-oder RNA-Sonden.

Beschreibung Die eingesetzten DNA-Sonden werden i. d. R. aus klonierten und sequenzspezifischen DNAAbschnitten durch direkte Markierung mittels Nicktranslation oder PCR unter Einsatz eines fluoreszenzmarkierten Nukleotids oder durch indirekte Markierung unter Einbau eines biotin- oder digoxigeninmarkierten Nukleotids erstellt. Bei den indirekt markierten Sonden wird zur Detektion ein fluoreszenmarkiertes Konjugat (Biotin-Streptavidin + Fluoreszenzfarbstoff) oder ein fluoreszenzmarkierter Antikörper (Digoxigenin-anti-Digoxigenin + Fluoreszenzfarbstoff) eingesetzt. Die RNA-Sonden werden durch reverse Transkription der Plasmide mittels T3-, T7- oder SP-Polymerase unter direktem Einsatz eines fluoreszenmarkierten Nukleotids oder indirekt unter Einbau von biotin- oder digoxigeneinmarkierten Nukleotiden generiert, wobei der Nachweis wie bei den indirekt markierten DNA-Sonden abläuft.

Vom Prinzip werden die vorbereiteten Objektträger mit den ausgestrichenen Zellen oder den vorbehandelten FFPEGewebeschnitten (FFPE = ,formaldehyde-fixed paraffinembedded") für eine DNA-Hybridisierung zunächst denaturiert, um die Interphase-DNA einzelsträngig vorliegen $\mathrm{zu}$ haben, was bei RNA-Sonden entfällt. Anschließend werden die Präparate mit einer zugegebenen einzelsträngigen fluoreszenzmarkierten oder indirekt markierten Hybridisierungssonde über mehrere Stunden inkubiert (hybridisiert). Nach abgeschlossener Hybridisierung erfolgen mehrere Waschungen der Objektträger mit unterschiedlicher Stringenz und die anschließende Einbettung mit Deckgläschen. Bei einer indirekten Markierung erfolgt vorher noch eine Inkubation mit dem Konjugat bzw. Antikörper. Eine Auswertung erfolgt am Fluoreszenzmikroskop. Während die Hybridisierung der DNA als Ergebnis immer eine Aussage zu Vorhandensein oder Abwesenheit der durch die DNA-Sonde definierten DNA-Abschnitte im Zellkern ergibt, vermag die RNA-Hybridisierung mit RNA-
Sonden am Gewebe nicht nur semiquantitativ die Expression des Gens, sondern auch die gewebespezifische Verteilung darzustellen.

\section{Literatur}

Alberts et al (2002) Molecular biology of the cell, 4. Aufl. Garland Science, New York

\section{Fluoreszenzmarkierte Hybridisierungssonde}

Taqman-Sonden

\section{Fluoreszenzmarkierung}

R. Westermeier

Synonym(e) Markierung mit Fluoreszenzfarbstoffen

Englischer Begriff fluorescence labeling

Definition Fluoreszenzfarbstoffe werden vor der Analyse oder Auftrennung kovalent an Nukleinsäuren oder Proteine gebunden, wodurch - unter anderem - Online-Detektionsmethoden ermöglicht werden.

Physikalisch-chemisches Prinzip Wie bei den Fluoreszenzfärbungen werden bei der Fluoreszenzmarkierung die Fluorophore mit Licht niedriger Wellenlänge angeregt und das emittierte Lichtsignal gemessen, das eine höhere Wellenlänge hat. Der lineare dynamische Messbereich erstreckt sich über 4 Größenordnungen. Quantitative Analysen sind deutlich exakter, wegen des weiten linearen Detektionsbereichs wie bei der Fluoreszenzfärbung. Meist werden hierzu Cyaninfarbstoffe (wie Cy2, Cy3 und Cy5) verwendet, wobei für die Bindung an das Lysin N-Hydroxysuccinimidyl-(NHS-)Ester verwendet werden, für die Bindung an die Cysteine reaktive Maleimidgruppen. Als Alternative eignen sich fluorogene Pyryliumfarbstoffe, die sowohl an das Lysin als auch an den N-Terminus von Proteinen binden. Während bei der NHSEster-Reaktion keine Reduktionsmittel und/oder Trägerampholyten in der Probe enthalten sein dürfen, werden diese Reagenzien bei der zweiten Methode ohne weiteres toleriert.

Fluoreszenzmarkierungen von Nukleinsäuren und Proteinen ermöglichen Multiplexanalysen. Für die Differenzgelelektrophorese (DIGE) bei der Zweidimensional-Elektrophorese ( $>$ Elektro- 
phorese, Elektrophorese, zweidimensionale) von Proteinen werden die Cyaninfarbstoffe chemisch in der Weise modifiziert, dass die gleichen Molekulargewichte angefügt und die isoelektrischen Punkte der Proteine nicht verändert werden. Auf diese Weise erreicht man, dass die gleichen Proteine aus den verschiedenen Proben zu den exakt gleichen Positionen im Gel wandern. Die Differenzgelelektrophorese ermöglicht die Verwendung eines inneren Standards für jedes einzelne Protein, wodurch Gel-zuGel-Variationen ausgeschaltet werden. Dies ist neben einigen neuen Markierungsmethoden für die Massenspektrometrie, die auf unterschiedlich schweren Isotopenmarkern beruht, eine sehr verlässliche quantitative Analysenmethode in der Proteomik.

Einsatzgebiet Bei Nukleinsäuren wird die Fluoreszenzmarkierung für die DNA-Sequenzierung und DNA-Fragmentanalyse eingesetzt. Für denaturierende Proteinelektrophoresen wie die SDS-Polyacrylamidgel-Elektrophorese und die isoelektrische Fokussierung in Gegenwart von mindestens 8 M Harnstoff kann die Fluoreszenzmarkierung die aufwändigen mehrschrittigen Färbemethoden ersetzen und bietet zudem eine deutlich verbesserte Quantifizierbarkeit. DIGE für die Proteomik.

Untersuchungsmaterial Nukleinsäuren, Proteingemische.

Instrumentalisierung Ausrüstung für PolyacrylamidgelElektrophorese bestehend aus Horizontal- oder Minivertikalkammer, Stromversorger, Umlaufthermostat; Fluoreszenzscanner oder Fluoreszenz-CCD-Kamerasystem.

Sensitivität Die Detektionsempfindlichkeitsgrenze liegt im höheren Picogramm- bis Nanogrammbereich.

Fehlermöglichkeit Die Proteinprobe muss mit SDS oder Harnstoff denaturiert sein. Der $\mathrm{pH}-$ Wert der Probe darf nicht unter 8 sein.

Praktikabilität - Automatisierung - Kosten Die Kosten für Fluoreszenzfarbstoffe für die Markierung von Proteinen sind auf dem Niveau der gängigen Färbemethoden (wie Coomassie-Brilliant-Blau- und Silberfärbung) angelangt. Ein Fluoreszenzdetektionsgerät (CCD-Kamera oder Fluoreszenzscanner) wird benötigt; seit kurzem sind gute Kamerasysteme für ca. 5000 Euro erhältlich.

Bewertung - Methodenhierarchie (allg.) Fluoreszenzmarkierung ist eine Methode für biochemisch arbeitende Labors, aber auch sehr gut geeignet für die Urinprotein-Elektrophorese.

\section{Literatur}

Westermeier R (2016) Elektrophorese leicht gemacht, 2. Aufl. WileyVCH, Weinheim, S 129-136

\section{Fluoreszenzpolarisation}

W. Stöcker und C. Krüger

Englischer Begriff fluorescence polarisation

Definition Fluoreszenzpolarisation beschreibt die Eigenschaft fluoreszierender Moleküle, die Polarisation absorbierten Lichts in Abhängigkeit von der Molekülgröße bei der Emission zu verändern.

Beschreibung Fluoreszierende Moleküle absorbieren polarisiertes Licht entsprechend ihrer Orientierung relativ zur Richtung und Polarisation der Lichtquelle. Das emittierte Licht ist in der Regel ebenfalls polarisiert. Eine Rotation der Moleküle in der wenige Nanosekunden langen Zeitspanne zwischen Absorption und Emission verringert die Polarisation, da sich die Orientierung der Fluorophore nach dem Zufallsprinzip ändert. Kleine Moleküle sind beweglicher und tragen stärker zur Aufhebung der Polarisation bei als große oder an Teilchen oder feste Phasen gebundene Moleküle.

Dieses Prinzip dient im $>$ Fluoreszenzpolarisations-Immunoassay der Konzentrationsbestimmung von Antigenen: Einer Antigen-/Antikörper-Mischung wird fluoreszenzmarkiertes Antigen zugegeben, das mit dem gesuchten Antigen um die Bindung an den Antikörper konkurriert. Je mehr Antigen die Probe enthält, umso mehr ungebundener Marker bleibt übrig, der zur (messbaren) Abnahme der Polarisation beiträgt, sodass sich die Konzentration des Antigens unter Anwendung einer Kalibrationskurve bestimmen lässt.

\section{Literatur}

Valeur B (2002) Molecular fluorescence. Wiley-VCH, Weinheim

\section{Fluoreszenzpolarisations- Immunoassay}

G. Töpfer

Synonym(e) FPIA

Englischer Begriff fluorescence polarization immunoassay

Definition Immunoassay, der auf der Veränderung der Polarisationsebene von monochromatischem Licht durch Antigen-Antikörper-Komplexe beruht. 
Physikalisch-chemisches Prinzip Die Polarisationsebene von monochromatischem Licht, das auf fluoreszierende Moleküle trifft, wird umso mehr gedreht, je kleiner die fluoreszierenden Moleküle sind.

Das von Dandliker und Feigen im Jahr 1961 erstmals für Immunreaktionen beschriebene Phänomen wurde von Abbott als FPIA mithilfe des Fluoreszenz-Polarisations-Fotometers TDx für eine breite Palette von Immunoassays (s. - Immunoassay) angewendet. Tracermoleküle, die in Immunkomplexen gebunden sind, drehen die Polarisationsebene des Lichts in der Messzeit praktisch nicht, während die nicht im Immunkomplex gebundenen (freien) Tracer-Antigene die Polarisationsebene des Lichtes so drehen, dass ein hohes Signal des polarisierten Lichtes entsteht und das Messsignal in der ursprünglichen Polarisationsebene geschwächt wird (Abb. 1).

Die Polarisation wird ausgelöst durch die schnellere Rotation der kleineren Antigen/Tracer-Moleküle im Vergleich zu dem Antigen/Antikörpertracer-Komplex. Hohe Probenanalytkonzentrationen zeigen hohe Konzentrationen an freiem Antigen/Tracer und dadurch Signalabschwächung (indirekte Proportionalität zwischen Analytkonzentration und Messsignal).

Einsatzgebiet Bis 2016 Analytik von Haptenen (Arzneimittel, Drogen, Hormone).
Untersuchungsmaterial Urin, Speichel, Serum, Plasma.

Instrumentalisierung Analysenmesssysteme TDx, IMx und AxSYM der Firma Abbott (Abb. 2) (seit 2016 historische Geräte, die nicht mehr betrieben werden).

Spezifität Unspezifische Fluoreszenzen werden im Messsystem weitgehend ausgeschaltet. Problematisch ist eine eventuell vorhandene Kreuzreaktivität der Antikörper, weshalb die Kenntnis dieser Unspezifität z. B. bei Arzneimittelbestimmungen erforderlich ist. Wichtig ist bei Drogenbestimmungen, dass häufig Abbauprodukte kreuzreagieren, die biologisch inaktiv sind, sodass eine Bestimmung der wirksamen Substanz allein nicht möglich ist.

Sensitivität $10^{14}-10^{15-} \mathrm{mol} / \mathrm{L}$ (Devlin et al. 1993).

Fehlermöglichkeit S. Spezifität.

Praktikabilität - Automatisierung - Kosten Abgesehen von manueller Beschickung des Analysensystems mit Probe und Reagenz arbeiteten die Systeme TDx, IMx und AxSYM halb- bis vollautomatisch.

Bewertung - Methodenhierarchie Vor allem wichtig für Arzneimittel- und Drogenbestimmungen, wobei die Unspe-
FluoreszenzpolarisationsImmunoassay, Abb. 1 FPIAMessprinzip: wenig Antigen in der Probe - starke Bildung von Antikörper/AntigentracerKomplexen - hohes Messsignal. (Mit freundlicher Genehmigung von Abbott Diagnostics, Wiesbaden)
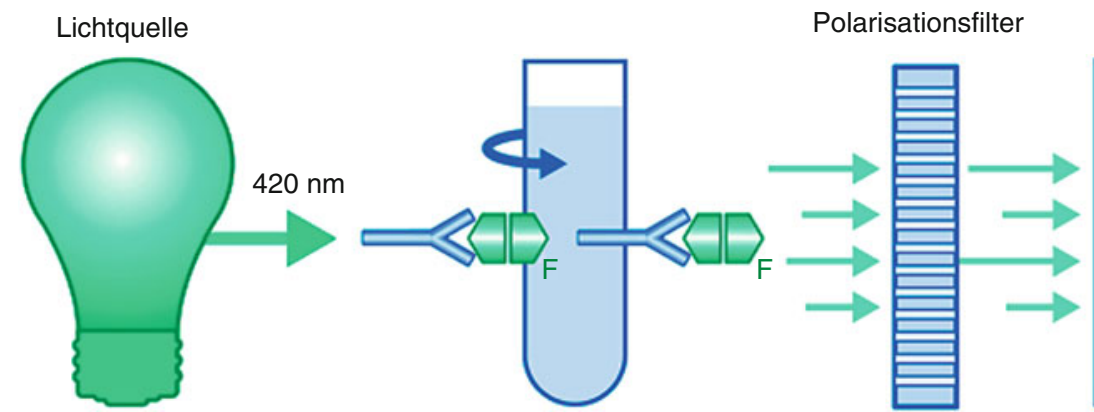

Lichtdetektor

Antikörper/Antigentracer rotieren langsam in der Lösung

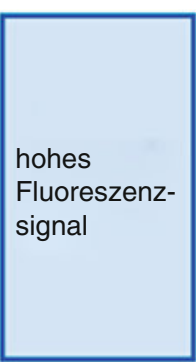

Fluoreszenz-

signal
FluoreszenzpolarisationsImmunoassay, Abb. 2 FPIAMessprinzip: viel Antigen in der Probe - hohe Konzentration von freiem Antigentracer - niedriges Messsignal. (Mit freundlicher Genehmigung von Abbott Diagnostics, Wiesbaden)
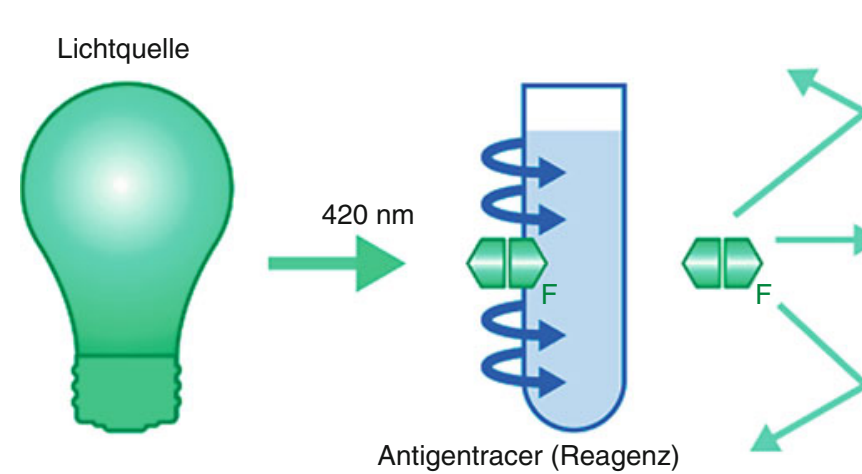

Polarisationsfilter

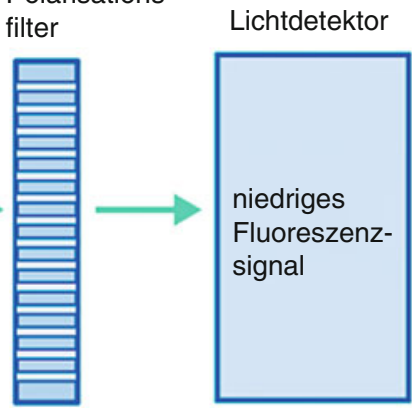


zifität und das Ausmaß der Kreuzreaktivität der Antikörper beachtet werden mussten, weshalb häufig spezifische Methoden (HPLC) nachgeschaltet wurden.

\section{Literatur}

Danliker WB, Feigen G (1961) Quantification of the antigen-antibody reaction by the polarization of fluorescence. BiochemBiophys Res Commun 5:299

Devlin R, Studholme RM, Dandliker WB, Fahy E, Blumeyer K, Gosh SS (1993) Homogenous detection of nucleic acids by transient-state polarized fluorescence. ClinChem 39:1939-1943. erratum 2343

\section{Fluoreszenz-Scan}

\section{T. Stauch}

Synonym(e) Fluoreszenzemissionsspektrometrie; Plasmafluoreszenzmessung

\section{Englischer Begriff plasma fluorescence scanning}

Definition Spektrometrischer Nachweis fluoreszierender Substanzen im Serum, Plasma oder auch anderen Körperflüssigkeiten.

Beschreibung Das Verfahren wird im Besonderen benutzt, um die Akkumulation endogener Fluorochrome bei Störungen der Porphyrinbiosynthese zu detektieren. Nicht zuletzt auch aufgrund der einfachen und schnellen Durchführbarkeit ausgezeichnete Screeningmethode zum Nachweis klinisch symptomatischer Porphyrien. Valide Alternative zu den weitgehend obsoleten Urinschnelltestverfahren wie $>$ HoeschTest oder $>$ Schwartz-Watson-Test.

Aufgrund der Abhängigkeit der Porphyrinfluoreszenz von pH-Wert und Ionenstärke wird die zu untersuchende Probe zunächst mit einer geeigneten Pufferlösung verdünnt und dann unter Einstrahlung von Licht der Wellenlänge $405 \mathrm{~nm}$ ein Emissionsspektrum im Bereich zwischen 580 und $650 \mathrm{~nm}$ aufgezeichnet. Bei unzureichender Empfindlichkeit (schwachem Emissionsspektrum) kann ggf. die Anregungswellenlänge durch Aufzeichnung eines Exzitationsspektrums bei feststehender Emissionswellenlänge optimiert werden. Sie liegt dann gewöhnlich im Bereich zwischen 398 und $409 \mathrm{~nm}$.

Normalproben ohne fluoreszierende Bestandteile ergeben im Bereich 580-650 nm kein Emissionssignal und weisen eine in dieser Richtung abnehmende Fluoreszenzintensität auf. Hingegen zeigen Positivproben einen Emissionspeak, dessen Lage von den hauptsächlich akkumulierten Porphyrinspezies abhängt und der daher eine gewisse Aussage hinsichtlich der Art der möglichen Porphyrinstoffwechselstörung erlaubt (s. Abbildung).
Die Abbildung zeigt Fluoreszenz-Emissionsspektren gepufferter Plasmaproben eines Normalprobanden (schwarz), eines Patienten mit akuter intermittierender Porphyrie (AIP, rot) sowie eines Patienten mit Porphyria variegata (VP, blau); Anregungswellenlänge $405 \mathrm{~nm}$ (Emissionsscan von $580-650 \mathrm{~nm}$ ):

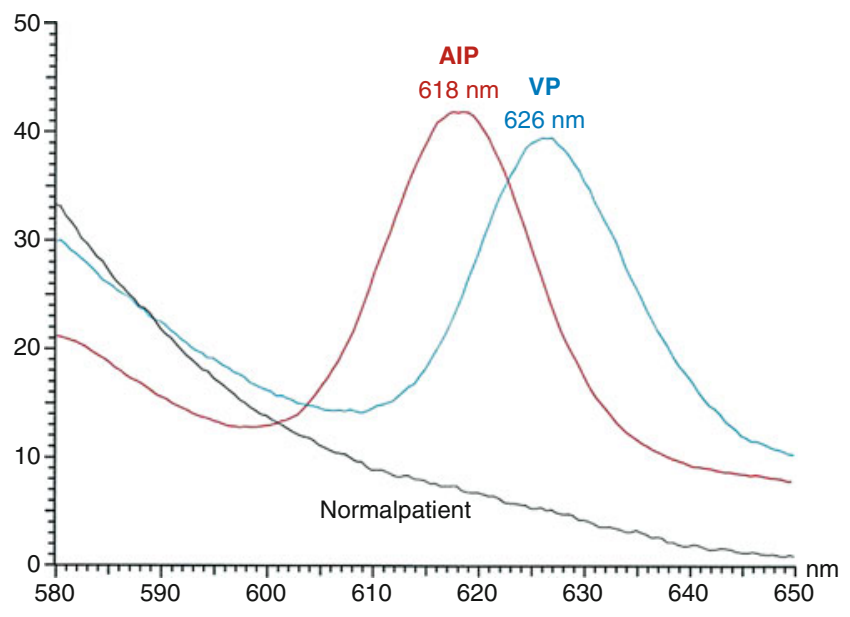

Geeignet sind Serum- oder Plasmaproben, die weitgehend dunkel verwahrt bzw. transportiert werden und keine signifikante Hämolyse und/oder Ikterie aufweisen. Die letztgenannten Probeneigenschaften verringern die Sensitivität der Messung aufgrund von Absorptions- und QuenchingEffekten.

Sofern die präanalytische Probenintegrität gewährleistet ist, werden alle zum Zeitpunkt der Materialgewinnung klinisch symptomatischen Porphyrien, und zwar sowohl hepatische als auch erythropoetische Formen, zuverlässig entdeckt (100 \% Sensitivität!). Die Spezifität des Verfahrens ist allerdings dementsprechend gering und nur im Falle der Porphyria variegata („Südafrikanische Porphyrie“) vollständig gegeben. Das hier erhaltene Fluoreszenzemissionsmaximum bei $626 \mathrm{~nm}$ ist charakteristisch für diese Form der Porphyrie. Die meisten anderen Porphyrinstoffwechselstörungen ergeben Emissionsmaxima zwischen 615 und $622 \mathrm{~nm}$ mit Ausnahme des typischerweise breiten Fluoreszenzsignals der erythropoetischen Protoporphyrie, das häufig zwischen 628 und $638 \mathrm{~nm}$ gefunden wird. Insofern sollte ein positives Ergebnis dieses Suchtestverfahrens immer die vollständige Analyse der renalen und fäkalen Exkretionsprofile nach sich ziehen.

Es handelt sich um einen qualitativen Suchtest, d. h. die Höhe/Intensität des Fluoreszenzsignals wird diagnostisch üblicherweise nicht verwertet.

Indikationen sind:

- Suchtest/Schnelltest bei Verdacht auf symptomatische Porphyrie

- Differenzialdiagnose der akuten hepatischen Porphyrien (Porphyria variegata versus akute intermittierende Porphyrie und hereditäre Koproporphyrie) 


\section{Literatur}

Enriquez de Salamanca R, Sepulveda P, Moran MJ, Santos JL et al (1993) Clinical utility of fluorometric scanning of plasma porphyrins for the diagnosis an typing of porphyrias. Clin Exp Dermatol 18:128-130

Poh-Fitzpatrick MB, Lamola AA (1976) Direct spectrofluometry of diluted erythrocytes and plasma: a rapid diagnostic method in primary and secondary porphyrinemias. J Lab Clin Med 87:362-370

\section{Fluoreszenzspektrometrie/- spektroskopie}

\section{T. Arndt}

Synonym(e) Atomfluoreszenzspektroskopie/-spektrometrie (AFS); Flammenfluoreszenzspektroskopie/-spektrometrie (FFS); Fluoreszenzspektroskopie

Englischer Begriff fluorescence spectroscopy; fluorescence spectrometry; atom fluorescence spectroscopy/-spectrometry; flame fluorescence spectroscopy/-spectrometry; atom flame fluorescence spectroscopy/-spectrometry

Definition Eine Form der $>$ Spektrometrie/Spektroskopie, bei der Fluoreszenzerscheinungen zur qualitativen und quantitativen Analyse untersucht werden.

Beschreibung Die Begriffe Fluoreszenzspektroskopie und Fluoreszenzspektrometrie werden häufig vereinfachend synonym benutzt. Nach IUPAC wäre der Begriff Fluoreszenzspektrometrie zu verwenden, wenn Intensitäten von Fluoreszenzerscheinungen bei bestimmten Wellenlängen(bereichen) mit einem Detektor aufgezeichnet werden.

Man unterscheidet verschiedene Typen der Fluoreszenzspektrometrie. Werden Spektrallinien von Atomen beobachtet, spricht man von Atomfluoreszenzspektrometrie, bei Einsatz einer Flamme zur Verdampfung, Atomisierung und Anregung von Flammenfluoreszenzspektrometrie (FFS) und wenn beide Bedingungen erfüllt sind von Flammenatomfluoreszenzspektrometrie.

Zur Grundlage von Fluoreszenzerscheinungen s. unter > Lumineszenz und $>$ Fluoreszenz.

Im klinisch-chemischen Labor wird die Fluoreszenzspektrometrie u. a. im sog. Fluoreszenzpolarisations-Immunoassay (FPIA) und in der HPLC in Kombination mit einem Fluoreszenzdetektor eingesetzt. Eine Sonderform der Fluoreszenzspektrometrie, die auf Erscheinungen der $>$ Chemolumineszenz beruht, hat große Bedeutung, z. B. für die Hepatitisserologie und die Bestimmung von Tumormarkern ( $\triangleright$ Tumormarker).
Eine interessante Variante der Fluoreszenzspektrometrie ist die sog. zeitverzögerte Fluoreszenzmessung (auch zeitaufgelöste Fluoreszenzmessung), bei der durch Einsatz von Chelaten seltener Erden wie Europium mit $\beta$-Diketonen (z. B. 2-Naphthoyltrifluorazeton) eine Fluoreszenz mit vergleichsweise langer Relaxationszeit erzielt wird. Diese kann erhebliche Vorteile bzgl. Spezifität und Sensitivität im Vergleich zu herkömmlichen Fluoreszenzmessung aufweisen ( $\triangleright$ Fluoreszenz, zeitaufgelöste).

\section{Literatur}

Eleftherios P. Diamandis (1993) Fluorescence Spectroscopy. Analytical Chemistry 65(12):454-459

Greiling H, Gressner AM (Hrsg) (1995) Lehrbuch der Klinischen Chemie und Pathobiochemie. Schattauer-Verlag, Stuttgart/New York

IInczedy J, Lengyel T, Ure AM (1998) Compendium of analytical nomenclature (definitive rules 1997). 3rd edn. Blackwell Science, Oxford

\section{Fluoreszenzspektroskopie}

- Fluoreszenzspektrometrie/-spektroskopie

\section{Fluoreszenzträger}

- Fluorophor

\section{Fluoreszenz Western Blotting}

R. Westermeier

Englischer Begriff Fluorescent Western Blotting

Definition Immundetektion von Antigenen auf Blotmembranen mit fluoreszenzmarkierten Sekundärantikörpern.

Physikalisch-chemisches Prinzip Bei dieser Variante von Western Blotting benötigt man Blotmembranen mit niedriger Eigenfluoreszenz. Mit dieser Methode werden meist Multiplexbestimmungen durchgeführt: Nach dem Blockieren der unbesetzten Bindungsstellen wird die Blotmembran mit einem Gemisch der Primärantikörper gegen die zu bestimmenden Zielantigene inkubiert. Diese Primärantikörper stam- 
men von unterschiedlichen Wirtstieren, z. B. Maus und Kaninchen. Dann wird die Blotmembran mit PBS-TweenLösung gewaschen und mit einer geeigneten Mischung von Fluoreszenzfarbstoffen markierten Sekundärantikörpern inkubiert, z. B. Ziege-Anti-Maus markiert mit Cy3 (Anregung durch grünes Licht mit $532 \mathrm{~nm}$ Wellenlänge) und Ziege-AntiKaninchen markiert mit Cy5 (Anregung durch rotes Licht mit $633 \mathrm{~nm}$ Wellenlänge). Die Detektion kann entweder mit einem Multifluoreszenzscanner oder einem fluoreszenzfähigem CCD-Kamerasystem durchgeführt werden.

Einsatzgebiet Multiplexproteinbestimmungen.

Untersuchungsmaterial Biologische Flüssigkeiten, Gewebeextrakte, Zelllysate.

Instrumentalisierung Ausrüstung für Polyacrylamidgel-Elektrophorese bestehend aus Horizontal- oder Minivertikalkammer, Stromversorger, Umlaufthermostat; Fluoreszenzscanner oder Fluoreszenz-CCD-Kamerasystem.

Spezifizität Hoch, da die Methode auf Immunreaktion beruht.

Sensitivität Picomol- bis Nanomolbereich.

Fehlermöglichkeit Fehler bei der Elektrophorese können bei Verwendung von Fertiggelen minimiert werden. Für den Elektrotransfer bei Western Blotting können fertige Pufferkits eingesetzt werden.

Praktikabilität - Automatisierung - Kosten Aufwand wie bei normalem Western Blotting, aber ein Fluoreszenzdetektionsgerät (CCD-Kamera oder Fluoreszenzscanner) wird benötigt. Bei der Verwendung von Fertigprodukten ist mit höheren Kosten zu rechnen.

Bewertung - Methodenhierarchie (allg.) Fluoreszenz Western Blotting ist eine Methode für biochemisch arbeitende Labors.

\section{Literatur}

Fradelizi J, Friederich E, Beckerle MC, Golsteyn RM (1998) Quantitative measurement of proteins by western blotting with Cy5-coupled secondary antibodies. Biotechniques 26:484-494

\section{Fluorid als Antikoagulans}

$>$ Antikoagulanzien in vitro

\section{Fluorid-Hemmtest}

$>$ Fluorid-Zahl

\section{Fluorid-Zahl}

A. M. Gressner und O. A. Gressner

Synonym(e) FZ; Fluorid-Hemmtest

Englischer Begriff fluoride number

Definition FZ gibt wie die zu einem ähnlichen Zweck eingesetzte Dibucain-Zahl die prozentuale Hemmung der Aktivität der $>$ Pseudocholinesterase (PCHE, EC 3.1.1.8) durch Fluorid an und dient der Erkennung atypischer PCHEVarianten.

Synthese - Verteilung - Abbau - Elimination Pseudocholinesterase (PCHE) ist ein in den Hepatozyten synthetisiertes, sezerniertes, mit hoher Aktivität im Blut vorkommendes Glykoprotein unbekannter physiologischer Funktion, das spezifisch exogene Cholinester hydrolysiert, unter denen Succinylcholin, Procain und Kokain klinische Bedeutung haben. Das kodierende Gen ist auf dem E1-Locus des langen Armes des Chromosoms 3 lokalisiert, und $96 \%$ der Population ist homozygot für den normalen Pseudocholinesterasegenotyp (als EuEu bezeichnet).

Funktion - Pathophysiologie Atypische Varianten der PCHE sind gekennzeichnet durch eine stärkere (homozygote Form) oder geringere (heterozygote Form) Erniedrigung der PCHE-Aktivität, die u. a. zu einer deutlich reduzierten Hydrolyse des Muskelrelaxans Succinylcholin führt und damit zu einer verlängerten respiratorischen Paralyse. Sie treten bei etwa $4 \%$ der europäischen Population in heterozygoter oder homozygoter Form auf und sind selten bei Asiaten. Die atypischen Genallele beruhen auf Punkt- oder FrameshiftMutationen mit dem Ergebnis einer verminderten Synthese oder der Synthese einer funktionell inaktiven Form aufgrund veränderter Struktur. Die schwerste Form der atypischen PCHE tritt bei 1:100.000 Individuen auf, die homozygot für den sogenannten ,silent“ Es-Genotyp mit fehlender PCHEAktivität sind (Frameshift-Mutation). Punktmutationen führen zur Dibucain-resistenten (Ea-Genotyp) oder Fluorid-resistenten Variante (Ef-Genotyp) (s. Tabelle). Da die komplette DNA-Sequenz und Aminosäurestruktur sowohl der normalen als auch der atypischen PCHE bekannt sind, kann letztere auch molekulargenetisch identifiziert werden. 
Atypische Gen-Allele des PCHE-Genotyps (normales Allel: $\mathrm{Eu})$ :

\begin{tabular}{|l|l|l|l|}
\hline Allel & Eigenschaft & Molekularer Defekt & $\begin{array}{l}\text { Dibucain-Zahl } \\
\text { und PCHE- } \\
\text { Aktivität }\end{array}$ \\
\hline Ea & $\begin{array}{l}\text { Dibucain- } \\
\text { resistente } \\
\text { Variante }\end{array}$ & Punktmutation & $\begin{array}{l}\text { EaEa: } 35 \\
\text { EuEa: }>36-75\end{array}$ \\
\hline Ef & $\begin{array}{l}\text { Fluorid- } \\
\text { resistente }\end{array}$ & Punktmutation & $\begin{array}{l}\text { EfEf: } 36 \\
\text { EuEf: }>36\end{array}$ \\
\hline Es & $\begin{array}{l}\text { Siliante } \\
\text { Variante }\end{array}$ & $\begin{array}{l}\text { Frameshift-Mutation, } \\
\text { Stop-codon-Mutation }\end{array}$ & $\begin{array}{l}\text { Keine PCHE- } \\
\text { Aktivität bei EsEs } \\
\text { Prävalenz: } \\
1: 10.000\end{array}$ \\
\hline
\end{tabular}

Untersuchungsmaterial-Entnahmebedingungen Serum.

Probenstabilität PCHE-Aktivität ist stabil bis zu 1 Jahr bei $-20{ }^{\circ} \mathrm{C}$ und mehrere Wochen bei Raumtemperatur.

Analytik Die PCHE-Aktivität im Serum wird mit dem Substrat Butyrylthiocholin in einem Parallelansatz ohne und mit Fluorid $\left(5 \times 10^{-5} \mathrm{~mol} / \mathrm{L} \mathrm{NaF}\right)$ gemessen. Das Ausmaß der Hemmung, angegeben durch die Fluorid-Zahl (FZ), wird nach der Formel berechnet:

$$
\mathrm{FZ}=\left(1-\frac{\text { Fluorid }- \text { gehemmte PCHE }}{\text { ungehemmte PCHE }}\right) \times 100
$$

Referenzbereich - Erwachsene $>76$.

Indikation Differenzialdiagnostische Abgrenzung einer erworbenen Verminderung der PCHE-Aktivität von einer genetisch determinierten Ursache (atypische PCHE). OPVorbereitung bei Verdacht auf atypische PCHE.

Interpretation Erniedrigungen der FZ deuten wie die der Dibucain-Zahl auf atypische PCHE-Varianten hin: Heterozygote: $36-75$, Homozygote: $\leq 35$.

Es sind jedoch genetische Varianten der PCHE bekannt, die Fluorid-resistent, aber Dibucain-sensitiv sind. Erniedrigte Fluoridzahlen weisen auf zu erwartende Abbauverzögerungen kurz wirksamer Muskelrelaxanzien vom Typ des Succinylcholins hin, die zu einer verlängerten Apnoephase führen können. Der Bestimmung der $>$ Dibucain-Zahl kommt eine ähnliche klinische Bedeutung zu.

\section{Literatur}

Garry PJ (1971) Serum cholinesterase variants: examination of several differential inhibitors, salts and buffers used to measure enzyme activity. Clin Chem 17:183-191

\section{Fluorimetrie}

- Fluoreszenzspektrometrie/-spektroskopie

\section{$9 \alpha$-Fluorocortisol-Test}

- Fludrokortison-Suppressionstest

\section{$9 \alpha$-Fluorohydrocortison-Test}

- Fludrokortison-Suppressionstest

\section{Fluorophor}

T. Arndt

\section{Synonym(e) Fluoreszenzträger}

\section{Englischer Begriff fluorophor}

Definition Molekülgruppe, die einem Molekül die Fähigkeit zur Fluoreszenz verleiht.

Beschreibung Es handelt sich meist um Verbindungen mit ausgedehnten aromatischen Systemen. Im klinisch-chemischen Labor werden bei einigen Analyseverfahren nicht oder nur schwach fluoreszierende Analyte durch chemische Umsetzung mit Fluorophoren zu stärker fluoreszierenden Substanzen derivatisiert und damit der quantitativen Analyse mithilfe eines Fluoreszenzdetektors zugängig gemacht. Ein Beispiel hierfür ist die Umsetzung der $>$ Katecholamine (Adrenalin, Noradrenalin und Dopamin) mit $o$-Phtalaldehyd oder Trihydroxyindol zu ihren entsprechenden Derivaten.

Ein weiteres Einsatzgebiet von Fluorophoren bzw. fluoreszierenden Substanzen sind immunfluorimetrische Untersuchungen zur Darstellung bestimmter Zellstrukturen oder von Antikörpern in Blut- oder Gewebeproben (s. z. B. Stichwörter zu Autoimmunantikörpern).

\section{Literatur}

Falbe J, Regitz M (Hrsg) (1996) Römpp Chemie Lexikon, 10. Aufl. Georg Thieme Verlag, Stuttgart/New York 


\section{Flüssigchromatographie}

- Flüssigkeitschromatographie

\section{Flüssiges Ecstasy}

$>$ Liquid E

\section{Flüssigextraktion}

> Flüssig-Flüssig-Extraktion

\section{Flüssig-Flüssig-Extraktion}

T. Arndt

Synonym(e) Ausschütteln; Flüssigextraktion

Englischer Begriff liquid extraction; liquid-liquid extraction

Definition Extraktionsverfahren (lat. extrahere $=$ herausziehen), bei dem eine gelöste Substanz aus ihrem Lösungsmittel durch ein zweites, mit dem ersten nicht oder nur geringfügig mischbares Lösungsmittel herausgezogen (extrahiert) und dadurch in diesem angereichert wird.

Beschreibung Die Flüssig-Flüssig-Extraktion ist ein effizientes Verfahren der Probenvorbereitung auch im klinischchemischen Labor mit dem Ziel, den Analyt oder die Analyte aus einer zumeist komplexen Matrix wie Blut, Fäzes, Plasma, Serum oder Urin in ein möglichst reines Lösungsmittel oder Lösungsmittelgemisch zu überführen und dort anzureichern. Letzteres gelingt, indem beispielsweise das Volumen des Lösungsmittels geringer als jenes der flüssigen Probe gewählt wird.

Grundlage der Flüssig-Flüssig-Extraktion sind Verteilungsgleichgewichte zwischen zwei miteinander nicht mischbaren Lösungsmittelphasen und deren Phasengrenze (s. Lehrbücher der Chemie). Eine Flüssig-Flüssig-Extraktion gelingt nur dann (weitgehend vollständig), wenn ein geeignetes Lösungsmittel (z. B. ein hydrophobes [unpolares] für hydrophobe [unpolare] Substanzen) und Lösungsmittelvolumen gewählt wird.

Beispiele für Flüssig-Flüssig-Extraktionen im klinischchemischen Labor finden sich in der Stuhlfettbestimmung
(Extraktion der Fette aus der verflüssigten Stuhlprobe z. B. mit Petroleumbenzin) sowie der Flüssigextraktion von Pharmaka und Drogen aus Blut, Magensaft und Urin (z. B. mit Essigsäureethylester).

Von der Flüssigextraktion zu unterscheiden ist die $>$ Festphasenextraktion, die eine vergleichsweise größere Bedeutung im klinisch-chemischen Labor hat.

\section{Literatur}

Falbe J, Regitz M (Hrsg) (1996) Römpp Chemie Lexikon, 10. Aufl. Georg Thieme Verlag, Stuttgart/New York

\section{Flüssigkeitschromatographie}

T. Arndt

Synonym(e) Flüssigchromatographie; LC

Englischer Begriff liquid chromatography; LC

Definition Eine Form der $>$ Chromatographie, bei der die mobile Phase eine Flüssigkeit ist.

Beschreibung Flüssigchromatographie ist das umgangssprachlich häufiger benutzte, gleichwohl weniger exakte Synonym für Flüssigkeitschromatographie. Eine Variante der Flüssigkeitschromatographie ist die $>$ Hochleistungs-Flüssigkeitschromatographie (HPLC), die sich durch ein besonders hohes Trennvermögen auszeichnet. Sie ist die heute am häufigsten eingesetzte chromatografische Methode im klinisch-chemischen Labor.

\section{Literatur}

Unger KK (Hrsg) (1989) Handbuch der HPLC. Teil 1 Leitfaden für Anfänger und Praktiker. GIT Verlag GmbH, Darmstadt

\section{Flüssigkeitshaushalt}

- Wasserhaushalt

\section{Flüssigkeitsverbindung}

$\checkmark$ Ionenselektive Elektrode 


\section{Flüssigmembranelektrode}

\ Ionenselektive Elektrode

\section{FMN}

- Vitamin $\mathrm{B}_{2}$

\section{fms-like tyrosine kinase 1, lösliche}

H. Fiedler

Synonym(e) Löslicher vaskulärer endothelialer Wachstumsfaktor-Rezeptor-1; sVEGFR-1; sFlt-1

Englischer Begriff soluble fms-like tyrosine kinase 1; soluble vascular endothelial growth factor receptor-1

Definition „Soluble fms-like tyrosine kinase“ (sFlt-1) ist ein anti-angiogener Faktor, der an Rezeptor-bindende Domänen von plazentarem Wachstumsfaktor (PlGF; s. \ Plazentarer Wachstumsfaktor) und vaskulärem endothelialen Wachstumsfaktor (VEGF; s. > Vaskulärer endothelialer Wachstumsfaktor) bindet. SFlt-1 wird vom extrazellulären Teil des VEGFR-1 (Flk-1) abgespalten, gelangt in extrazelluläre Flüssigkeiten und blockiert die pro-angiogenen Faktoren.

Beschreibung sFlt-1 wird hauptsächlich in Endothelzellen Trophoblasten und Makrophagen gebildet. Bei Schwangeren steigen die sFlt-1-Konzentrationen (15. SSW ca. $1500 \mathrm{ng} / \mathrm{L}$ ) etwa 2-3 Monate vor der Entbindung an (30. SSW ca. $3000 \mathrm{ng} / \mathrm{L}$ ). Der Anstieg erfolgt eher und stärker mindestens 5 Wochen vor den Symptomen einer Präeklampsie und ist am stärksten bei Frauen mit Präeklampsie vor dem Termin bzw. bei Kombination mit einem „small-for-date baby“ oder Diabetes mellitus (Werte um $10 \mu \mathrm{g} / \mathrm{L}$ ). Die Konzentrationen von freiem PIGF und VEGF werden durch die Bindung an das erhöhte sFlt-1 erniedrigt. Parallel zu sFlt-1 verhält sich das in der Plazenta gebildete Endoglin, ein Korezeptor von TGF- $\beta$ (s. a. D Plazentarer Wachstumsfaktor).

Die Präeklampsie (PE, früher auch Gestose genannt) hat eine Prävalenz von $2-5 \%$ und eine 5 -fach erhöhte perinatale Mortalität (ca. 16.000 Tote weltweit). Bisher beruhte die Diagnose auf Blutdruckanstieg, Proteinurie ( $>300 \mathrm{mg} / \mathrm{Tag}$ ),
Ödemen und Durchblutungsstörungen der uterinen Arterien. Die Laborwerte waren wenig sensitiv und unspezifisch: Harnsäure $>5 \mathrm{mg} / \mathrm{dL}$, Kreatinin $>0,9 \mathrm{mg} / \mathrm{dL}$, erhöhte Transaminasen und erniedrigte Thrombozytenzahlen. Die Deutsche Gesellschaft für Gynäkologie und Geburtshilfe hat 2014 in den Leitlinien den Quotienten sFlt-1/PIGF (automatisierte Elecsys-Teste) für die PE-Diagnostik empfohlen. Der Quotient sollte nicht als generelles Screening, sondern bei Patientinnen mit hohem Risiko eingesetzt werden (Anamnese, vorbestehende Hypertonie, Erstlings- und Mehrlingsschwangerschaft, Nierenerkrankung, Diabetes, Antiphospholipidsyndrom). Ein sFlt-1/PlGF-Quotient $<38$ schließt mit hoher Wahrscheinlichkeit in nächster Zeit eine PE aus. Vor der 34. SSW (,early-onset PE") verweist ein Quotient von $>85$ und nach der 34. SSW (,late-onset PE“) von $>110$ auf eine PE und/oder eine andere Form von Plazentadysfunktion. In der Grauzone (38-85) sollte nach 1-2 Wochen der Test wiederholt werden. Extrem hohe Quotienten weisen auf eine kurzfristig notwendige stationäre Aufnahme und Entbindung. Die gleichzeitige Wirkung stark erhöhter Konzentrationen von sFlt-1 und sEndoglin können das schwere HELLP(,haemolysis, elevated liver enzyme levels, low platelet")-Syndrom auslösen. Neue Untersuchungen haben bei PE erhöhte Konzentrationen von anti-angiogenen miR-195-5p und miR-885$5 \mathrm{p}$ gefunden. Eine Arbeitsgruppe unter C.S. Buhimschi vermutet, dass bei Präeklampsie vermehrt falsch gefaltete Proteine sich in der Niere anreichern und prüfen einen in Entwicklungsländern anwendbaren „Congo Red Dot urine (retention)“-Test.

\section{Literatur}

Acestor N, Goett J, Lee A et al (2016) Towards biomarker-based tests that can facilitate decisions about prevention and management of preeclampsia in low-resource settings. Clin Chem Lab Med $54: 17-27$

Buhimschi IA, Nayeri UA, Zhao G, Shook LL, Pensalfini A, Funai EF, Bernstein IM, Glabe CG, Buhimschi CS (2014) Protein misfolding, congophilia, oligomerization, and defective amyloid processing in preeclampsia. Sci Transl Med 6 (245):245ra92

$\mathrm{Gu}$ Y, Lewis DF, Wang Y (2008) Placental productions and expressions of soluble endoglin, soluble fms-like tyrosine kinase receptor-1, and placental growth factor in normal and preeclamptic pregnancies. J Clin Endocrinol Metab 93:260-266

Sandrim VC, Luizon MR, Palei AC, Tanus-Santos JE, Cavalli RC (2016) Circulating microRNA expression profiles in pre-eclampsia: evidence of increased miR-885-5p levels. BJOG 123 (13): 2120-2128

Schoofs K, Grittner U, Engels T et al (2014) The importance of repeated measurements of the sFlt-1/PlGF ratio for the prediction of preeclampsia and intrauterine growth restriction. J Perinat Med 42:61-68

Shah DA, Khalil RA (2015) Bioactive factors in uteroplacental and systemic circulation link placental ischemia to generalized vascular dysfunction in hypertensive pregnancy and preeclampsia. Biochem Pharmacol 95:211-226 


\section{$\alpha$-Fodrin-Antikörper}

Autoantikörper gegen $\alpha$-Fodrin

\section{Fokussierung, isoelektrische}

$>$ Isoelektrische Fokussierung

\section{Folacin}

$>$ Folsäure

\section{Folat}

> Folsäure

\section{Folin-Ciocalteu-Methode}

\author{
G. Töpfer
}

Synonym(e) Lowry-Methode der Proteinbestimmung

\section{Englischer Begriff Lowry method}

Definition Die $>$ Biuretmethode wird ohne Kaliumiodid im Reagens durchgeführt, so dass $\mathrm{Cu}^{2+}$ im Biuretkomplex in $\mathrm{Cu}^{+}$ übergeht. Parallel dazu findet die Reaktion (Oxidation) von Tyrosin-, Tryptophan- und Cysteinresten mit dem zusätzlichen Folin-Ciocalteu-Reagens (besteht aus Phenol- und Natronlauge sowie Phosphorwolframsäure und Phosphormolybdänsäure) statt. Durch Reduktion dieser beiden Säuren wächst die Empfindlichkeit 100-fach gegenüber der klassischen Biuretreaktion.

Beschreibung Die von Hartree (1972) und Lowry (1951) modifizierte Methode nach Folin-Ciocalteu (1927) erreicht eine $>$ Nachweisgrenze von $0,1-1 \mathrm{mg} / \mathrm{L}$ Protein. Da die Eichkurve nicht linear verläuft, die Färbung nicht sehr stabil ist und Proteine infolge ihrer differenten Anteile an Tyrosin-, Tryptophan- und Cysteinresten unterschiedliche Extinktionskonzentrationskurven aufweisen, ist die Anwendung dieser Methode durch den besser standardisierbaren Bicinchonin- säureassay und teilweise durch Farbstoffbindungsmethoden (z. B. \& Bromkresolgrünmethode) ersetzt worden.

Methodik Frisches Lowry-Reagens wird durch Mischen folgender Lösungen hergestellt:

- $15 \mathrm{~mL}$ Stammlösung A $\left(100 \mathrm{~g} \mathrm{Na}_{2} \mathrm{CO}_{3}\right.$ in $1 \mathrm{~L} 0,5 \mathrm{M}$ $\mathrm{NaOH})$

- $0,75 \mathrm{~mL}$ Stammlösung $\mathrm{B}\left(1 \mathrm{~g} \mathrm{CuSO}_{4} \times 5 \mathrm{H}_{2} \mathrm{O}\right.$ in $100 \mathrm{~mL}$ $\mathrm{H}_{2} \mathrm{O}$ )

- 0,75 mL Stammlösung C (2 g K-Tartrat in $\left.100 \mathrm{~mL} \mathrm{H}_{2} \mathrm{O}\right)$

$1 \mathrm{~mL}$ Lowry-Reagens $+1 \mathrm{~mL}$ Proteinlösung 15 Minuten bei Raumtemperatur, $2 \mathrm{~N}$ Folin-Ciocalteu-Reagens mit $\mathrm{H}_{2} \mathrm{O}$ 1:10 verdünnen, davon $3 \mathrm{~mL}$ zusetzen, mischen und $45 \mathrm{Minu}-$ ten bei Raumtemperatur inkubieren. Fotometrie bei $650 \mathrm{~nm}$.

Kalibration Mit Rinderserumalbumin.

Störfaktoren EDTA, Ammoniumsulfat, Triton X-100.

Diagnostische Bedeutung Nur noch verwendet zur Messung von Proteinlösungen aus Fraktionierungen oder Biopsien.

\section{Literatur}

Hartree EF (1972) Determination of protein: a modification of the lowry method that gives a linear photometrie response. Anal Biochem $48: 422-427$

\section{Follikelhormone}

$>$ Estrogene

\section{Follikelstimulierendes Hormon}

M. Bidlingmaier

Synonym(e) FSH; Follitropin

Englischer Begriff FSH; follicle-stimulating hormone

Definition Eines der vom Hypophysenvorderlappen sezernierten Gonadotropine, reguliert zusammen mit dem luteinisierenden Hormon (LH, s. $>$ Luteinisierendes Hormon) die Follikel- bzw. Spermienreifung. 
Struktur Aus 2 nichtkovalent verbundenen Untereinheiten (Polypeptidketten) bestehendes Glykoprotein. Die $\alpha$-Untereinheit mit 92 Aminosäuren kommt auch in anderen Hormonen vor (Choriongonadotropin, $>$ Luteinisierendes Hormon, Thyreotropin), nur die aus 111 Aminosäuren bestehende $\beta$-Untereinheit ist spezifisch für das FSH. Die Gonadotropine weisen wegen unterschiedlich starker Glykosilierung eine große molekulare Heterogenität auf.

Molmasse Insgesamt ca. $35.000 \mathrm{Da}$, die FSH-spezifische $\beta$-Untereinheit ca. 12.500 Da.

Synthese - Verteilung - Abbau - Elimination Die pulsatile $>$ Gonadotropin-Releasing-Hormon-Sekretion des Hypothalamus stimuliert am Hypophysenvorderlappen die Synthese und Sekretion von FSH (und LH). Auf hypophysärer Ebene wird die FSH-Sekretion zudem durch die $>$ Peptidhormone Activin und Inhibin moduliert. FSH vermittelt seine Wirkung über Bindung an spezifische Rezeptoren auf den Sertoli-Zellen des Hodens beim Mann bzw. den follikulären Granulosazellen bei der Frau. Im Sinne eines negativen Feedback wird die FSH-Sekretion der Hypophyse dann durch in den Granulosa- bzw. Sertoli-Zellen gebildetes Inhibin gehemmt. Die Serumkonzentrationen des FSH folgen aufgrund der längeren Halbwertszeit weniger ausgeprägt der hypothalamischen GnRH-Pulsatilität als die des LH ( $\vee$ Luteinisierendes Hormon). FSH wird zum Teil proteolytisch degradiert, die Elimination erfolgt renal. Das im Urin gemessene FSH repräsentiert im Wesentlichen die freie $\beta$-Untereinheit.

Halbwertszeit Endogen 3-4 Stunden, nach subkutaner oder intramuskulärer Injektion 40-50 Stunden.

Pathophysiologie Vor der Pubertät sind die Gonadotropinkonzentrationen aufgrund der fehlenden Stimulation durch hypothalamisches GnRH niedrig, erst mit Einsetzen der pulsatilen GnRH-Sekretion steigen die FSH- (und LH-) Konzentrationen an. FSH stimuliert und reguliert bei der fertilen Frau die Reifung der präovulatorischen Follikel sowie die Östrogensynthese in den Granulosazellen. Nach einem weniger stark als beim LH erkennbaren ovulatorischen Peak fallen die FSH-Konzentrationen in der Lutealphase des Zyklus ab. Bei Mann stimuliert FSH über die Sertoli-Zellen die Spermatogenese.

Zusammen mit LH ist FSH zentraler Regulator der normalen Spermatogenese bzw. des Menstruationszyklus, Störungen der physiologischen Sekretion oder der Bindung und Wirkung des FSH führen zu Fertilitätsproblemen. Bei der primären Ovarialinsuffizienz wie beim primären Hypogonadismus des Mannes z. B. bei Hodenatrophie sind die FSH-Konzentrationen dauerhaft hoch. Niedrige FSH-Konzentrationen finden sich bei den sekundären Ovarial- bzw. Hodeninsuffizienzen. Neben Störungen auf hypophysärer Ebene kann auch eine Störung der regu- lären GnRH-Sekretion bei hypothalamischen Prozessen, Anorexie, chronischem Stress etc. Ursache einer insuffizienten FSH-Sekretion sein.

Therapeutisch kommt aus Urin aufgereinigtes oder rekombinant hergestelltes FSH bei unerfülltem Kinderwunsch bzw. bei der Vorbereitung der In-vitro-Fertilisation (IVF) zum Einsatz.

\section{Untersuchungsmaterial Serum.}

Probenstabilität 24 Stunden bei Raumtemperatur, mehrere Tage bei $4{ }^{\circ} \mathrm{C}$, mehrere Monate bei $-20^{\circ} \mathrm{C}$.

Präanalytik Bei der Blutentnahme sind der Zyklustag bzw. die Einnahme von Ovulationshemmern zu erfragen.

Analytik Immunoassays. Nach wie vor besteht keine Harmonisierung der verschiedenen FSH-Assays, Unterschiede bestehen vor allem in der Spezifität der Antikörper sowie der verwendeten Standardpräparation. Der Ersatz der mehr oder weniger aufgereinigten Hypophysenextrakte durch eine rekombinante Standardpräparation hat die Vergleichbarkeit der Messergebnisse nicht verbessert.

Konventionelle Einheit IU/L (die International Units beziehen sich auf die jeweilige Standardpräparation).

Referenzbereich - Erwachsene Aufgrund der Unterschiede der Assays sind jeweils methodenspezifische Referenzbereiche zu verwenden. Orientierend folgende Angaben:

Männer: 2-10 IU/L

Frauen:

- Follikelphase: 3-12 IU/L

- Periovulatorisch: 8-20 IU/L

- Lutealphase: 2-8 IU/L

- Postmenopausal: $>20 \mathrm{IU} / \mathrm{L}$

Referenzbereich - Kinder Aufgrund der Unterschiede der Assays sind jeweils methodenspezifische Referenzbereiche zu verwenden. Orientierend folgende Angaben:

\begin{tabular}{lll}
\hline Alter (Jahre) & Knaben (IU/L) & Mädchen (IU/L) \\
\hline$<3$ & $<5,5$ & $<3,5$ \\
\hline $4-9$ & $<1,9$ & $<1,6$ \\
\hline 10 & $0,2-4,5$ & $0,4-6,9$ \\
11 & $0,4-9$ & $0,4-9$ \\
$12-14$ & $0,5-10$ & $1-17$ \\
15 & $0,4-18,5$ & Zyklusabhängig
\end{tabular}

\section{Indikation}

- Beurteilung von Zyklusstörungen bei der Frau 
- Fertilitätsdiagnostik bei Mann und Frau

- Differenzialdiagnostik des Hypogonadismus bei Mann und Frau

- Hypophysenerkrankungen

Interpretation Erhöhte FSH-Konzentrationen sprechen für einen primären, erniedrigte für einen sekundären oder tertiären Hypogonadismus.

Diagnostische Wertigkeit Basal erhöhte FSH-Konzentrationen sind in aller Regel diagnostisch ausreichend. In Zweifelsfällen bzw. in der speziellen Differenzialdiagnostik kann jedoch der $>$ GnRH-Test hilfreich sein.

\section{Literatur}

Rose MP, Gaines Das RE, Balen AH (2000) Definition and measurement of follicle stimulating hormone. Endocr Rev 21(1):5-22

Stamatiades GA, Kaiser UB (2017) Gonadotropin regulation by pulsatile GnRH: signaling and gene expression. Mol Cell Endocrinol pii: S0303-7207(17)30552-X

Sturgeon CM, Ellis AR (2007) Standardization of FSH, LH and hCG - current position and future prospects. Mol Cell Endocrinol 260-262:301-309

\section{Follikelstimulierendes-Hormon-}

Releasing-Hormon

> Gonadotropin-Releasing-Hormon

\section{Follikulostatin}

$\triangleright$ Inhibin

\section{Follitropin}

> Follikelstimulierendes Hormon

\section{Folsäure}

H. Jomaa

Synonym(e) Folacin; Folat; Pteroylglutamat; Pteroylglutaminsäure; Vitamin $\mathrm{B}_{9}$; Vitamin B11; Vitamin Bc; Vitamin M
Englischer Begriff folate; folic acid

Definition Wasserlösliches Vitamin des B-Komplexes. Der Begriff Folat wird als Gruppenname für verschiedene Derivate des Tetrahydrofolats (THF) gebraucht. Der Begriff Folsäure steht für die synthetisch hergestellte Pteroylglutaminsäure, die im Organismus in THF-Derivate umgewandelt wird. Folat dient als Koenzym zur Übertragung von Ein-Kohlenstoff- $\left(\mathrm{C}_{1^{-}}\right)$Einheiten und ist beteiligt an der Synthese von Purinen, der Umwandlung von dUMP in den DNABaustein dTMP sowie der Remethylierung von Homocystein zu Methionin als Folgereaktion S-Adenosylmethionin(SAM-) abhängiger Methylierungsreaktionen.

Synthese - Verteilung - Abbau - Elimination Folsäure besteht aus einem Pterin-Ringsystem, das über eine Methylenbrücke mit dem N-Atom von $p$-Aminobenzoesäure verbunden ist, die wiederum über eine Amidbindung mit L-Glutaminsäure verknüpft ist (s. folgende Abbildung).

Strukturformel der Folsäure (Pteroylglutaminsäure):

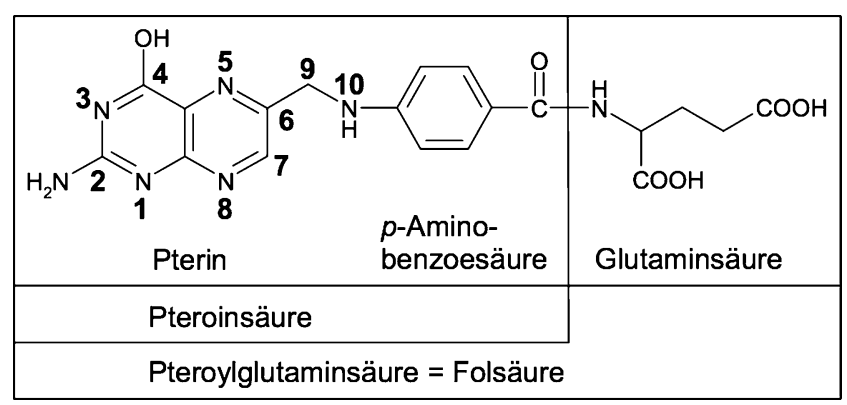

Reduktion des Pteridin-Ringsystems führt über Dihydrofolsäure zur Tetrahydrofolsäure (s. folgende Abbildung).

Dihydrofolat (DHF) und Tetrahydrofolat (THF) ( $R$, Glutamyl- oder Polyglutamylrest):<smiles>[R]C(=O)c1ccc(NCC2=Nc3c(O)nc(N)nc3NCC2CNc2ccc(C([R])=O)cc2)cc1</smiles>

Verschiedene als Koenzyme aktive THF-Derivate sind mit unterschiedlichen, durch enzymatische Reaktionen übertragbare $\mathrm{C}_{1}$-Einheiten modifiziert, die entweder als Substitution des N-Atoms in Position 5 oder 10 auftreten oder eine Brücke zwischen diesen N-Atomen bilden (s. folgende Abbildung).

Mit $\mathrm{C}_{1}$-Einheiten beladene Tetrahydrofolat-(THF-)Derivate: 


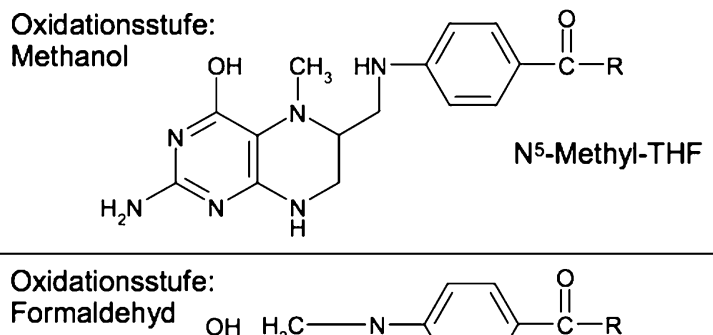<smiles>[R]C(=O)c1ccc(N=CN2c3c(O)nc(N)nc3NCC2CN2c3c(O)nc(N)nc3NCC2COCN2c3c(O)nc(N)nc3NC[C@@H]2CNc2ccc(C([R])=O)cc2)cc1</smiles>

Die $\mathrm{C}_{1}$-Einheiten können in unterschiedlichen Oxidationsstufen auftreten, die formal dem Formiat, Formaldehyd oder Methanol entsprechen. Intrazellulär vorliegende THF-Derivate sind überwiegend mit mehreren (bis zu 9) L-Glutaminsäureresten modifiziert, die durch $\gamma$-Peptidbindungen untereinander verknüpft sind. Im Blutplasma zirkulierendes Folat liegt hauptsächlich als $\mathrm{N}^{5}$-Methyl-THF-Monoglutamatform vor.

Folat ist in praktisch allen Lebensmitteln enthalten, besonders reichhaltig in Leber, Sojabohnen, Blattgemüse und Getreide. Es wird auch durch die Darmflora gebildet, jedoch ist die Resorption zu gering, um einen alimentären Folatmangel zu kompensieren. In der Nahrung vorkommendes Folat besteht überwiegend aus Polyglutamaten der Methyl- und Formyltetrahydrofolsäure. Die Resorption erfolgt hauptsächlich im Duodenum und Jejunum. Die Polyglutamate werden durch die in der Bürstensaummembran eingelagerte Glutamat-Carboxypeptidase II zu den Monoglutamaten hydroly- siert, die über den protonengekoppelten Folattransporter (PCFT) in die Enterozyten gelangen. In den Enterozyten werden verschiedene THF-Derivate in $\mathrm{N}^{5}$-Methyl-THF umgewandelt und basolateral sezerniert.

Synthetische Folsäure wird mit vergleichbarer Transportrate ebenfalls über PCFT resorbiert, gelangt jedoch unmodifiziert ins Pfortaderblut und wird erst in der Leber unter Beteiligung der Dihydrofolatreduktase in $\mathrm{N}^{5}$-Methyl-THF umgewandelt. Wegen der geringen Effizienz dieser Umwandlung tritt nach Folsäuregabe auch das unmodifizierte Molekül in der systemischen Zirkulation auf.

Periphere Zellen nehmen $\mathrm{N}^{5}$-Methyl-THF über den ubiquitären Carrier für reduziertes Folat (RFC) im Antiport mit organischen Phosphaten (v. a. Adeninnukleotiden) auf. Zusätzlich werden in Epithelzellen bestimmter Gewebe (proximaler Tubulus der Niere, Pigmentepithel der Retina, Plexus choroideus, Uterus und Plazenta) $\mathrm{N}^{5}$-Methyl-THF und Folsäure durch rezeptorvermittelte Endozytose über den Folatrezeptor $\alpha(\mathrm{FR} \alpha)$ aufgenommen. Durch die Aktivität der Folylpolyglutamat-Synthetase entstehen die Polyglutamatformen, die hohe Affinität zu den Enzymen des intrazellulären Folatstoffwechsels aufweisen, aber nicht über Membranen transportiert werden. Für den Export werden durch die lysosomale $\gamma$-Glutamylhydrolase die Monoglutamate gebildet. Essenzielle Reaktionen des $\mathrm{C}_{1}$-Stoffwechsels sind zwischen dem Zytoplasma und den Mitochondrien kompartimentiert. Nur THF-Monoglutamat ohne gebundene C1-Einheit kann die Mitochondrienmembran passieren. Für den Transport von $\mathrm{C}_{1}$-Einheiten über die Mitochondrienmembran spielt freies Formiat eine wichtige Rolle, das reversibel mit THF zu N ${ }^{10}$ Formyl-THF reagiert.

Der menschliche Körper enthält 5-20 mg Folat, davon sind ca. $50 \%$ in der Leber gespeichert. Folat wird mit der Galle ausgeschieden (10-90 $\mu \mathrm{g} / \mathrm{Tag})$ und unterliegt einer ausgeprägten enterohepatischen Zirkulation. Folat wird glomerulär filtriert und mit hoher Effizienz im proximalen Tubulus über FR $\alpha$ rückresorbiert; mit dem Harn ausgeschieden werden $1-12 \mu \mathrm{g} /$ Tag.

Die Plazenta wird wahrscheinlich hauptsächlich über FR $\alpha$ passiert, die Blut-Hirn-Schranke wahrscheinlich RFC- und PCFT-vermittelt, während beim Transport über die BlutLiquor-Schranke zusätzlich FR $\alpha$ beteiligt ist. Im Liquor ist Folat gegenüber dem Blutplasma 2- bis 3-fach angereichert.

Funktion - Pathophysiologie Quellen für die durch Folat transferierbaren $\mathrm{C}_{1}$-Einheiten sind Serin, Glycin, Formiat, Histidin und die aus dem Cholinabbau stammenden Substanzen Sarcosin und Dimethylglycin. In schnell proliferierenden Zellen ist Serin, das mit der Nahrung aufgenommen oder aus Glukose synthetisiert wird, die wichtigste $\mathrm{C}_{1}$-Quelle. Bei der Bildung von $\mathrm{N}^{5}, \mathrm{~N}^{10}$-Methylen-THF aus Serin und THF entsteht Glycin, sodass die Reaktion auch essenziell für die 
Glycin-de-novo-Synthese ist. Mitochondrial kann Glycin durch die Enzyme des Glycin-spaltenden Systems (GCS) unter Bildung eines weiteren Moleküls $\mathrm{N}^{5}, \mathrm{~N}^{10}$-MethylenTHF zu CO 2 und $\mathrm{NH}_{3}$ abgebaut werden. Freies Formiat, das mit der Nahrung aufgenommen wird und bei metabolischen Prozessen entsteht, liegt im Serum mit einer Konzentration von $20-50 \mu \mathrm{M}$ vor. Formiat gilt als Giftstoff, der bei Methanol- oder Formaldehydvergiftungen entsteht. Für die Entgiftung ist Folat notwendig. Als Zwischenprodukt des Histidinabbaus entsteht Formiminoglutamat (FIGLU), das mit THF zu Glutamat und $\mathrm{N}^{5}$-Formimino-THF reagiert. Beim Histidinbelastungstest weist eine erhöhte Ausscheidung von FIGLU mit dem Harn auf Folatmangel hin.

Von zentraler Bedeutung für den Folatstoffwechsel ist der Methioninzyklus, der in der folgenden Abbildung dargestellt ist. S-Adenosylmethionin überträgt Methylgruppen auf verschiedene Substrate (R). Die Methioninsynthase enthält Vitamin $B_{12}$ als prosthetische Gruppe:

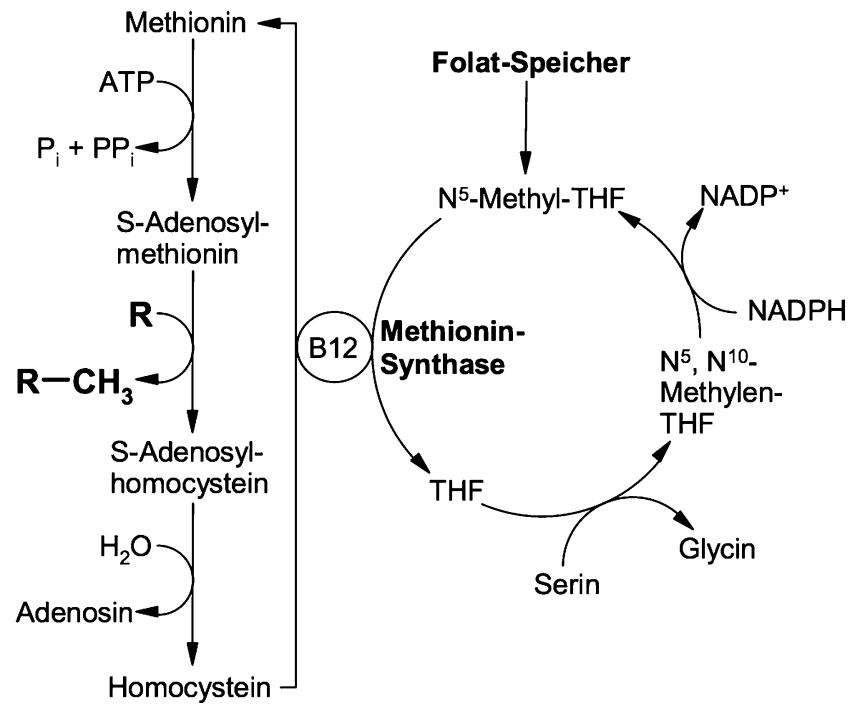

Dabei wird aus Methionin S-Adenosylmethionin (SAM) gebildet, das bei vielfältigen Reaktionen als Methylgruppendonator dient (z. B. Synthese von Phosphatidylcholin, Kreatin, Carnitin, Adrenalin, Melatonin; Methylierung von Cytosin in der DNA zur Genregulation). Nach Abgabe der Methylgruppe entsteht aus dem Methioningrundkörper Homocystein, das in der Vitamin- $\mathrm{B}_{12}$-abhängigen Methioninsynthasereaktion durch $\mathrm{N}^{5}$-Metyhl-THF zu Methionin remethyliert wird. Das entstandene THF kann zu N ${ }^{5}$-Metyhl-THF regeneriert oder für die Bereitstellung anderer THF-C ${ }_{1}$ Derivate genutzt werden. Die Umwandlung der verschiedenen THF-C $\mathrm{C}_{1}$-Derivate ineinander durch Redox- und Isomerisierungsreaktionen ist reversibel; eine Ausnahme ist die Reduktion von $\mathrm{N}^{5}, \mathrm{~N}^{10}$-Methylen-THF zu N ${ }^{5}$-Metyhl-THF. Deshalb ist die Erzeugung anderer THF-C ${ }_{1}$-Derivate aus $\mathrm{N}^{5}$-Metyhl-THF, das die Haupttransport- und Speicherform darstellt, nur über die Methioninsynthasereaktion möglich.
Folglich führt ein Vitamin- $\mathrm{B}_{12}$-Mangel zu einem funktionellen Folatmangel.

Bei der Synthese des Puringrundkörpers der Nukleotide AMP und GMP dient $\mathrm{N}^{10}$-Formyl-THF bei 2 Reaktionen als Formylgruppendonator (s. folgende Abbildung).

Die folgende Abbildung stellt die Synthese der Purinnukleotide AMP und GMP über Inosinmonophosphat (IMP) aus Phosphoribosyldiphosphat (PRPP) dar. Bei 2 der insgesamt 10 Reaktionen vom PRPP zum IMP werden Formylgruppen durch die Glycinamide-Ribonukleotide-Transformylase (GAR-TF) bzw. 5-Aminoimidazol-4-CarboxamidRibonukleotid-Transformylase (AICAR-TF) übertragen:

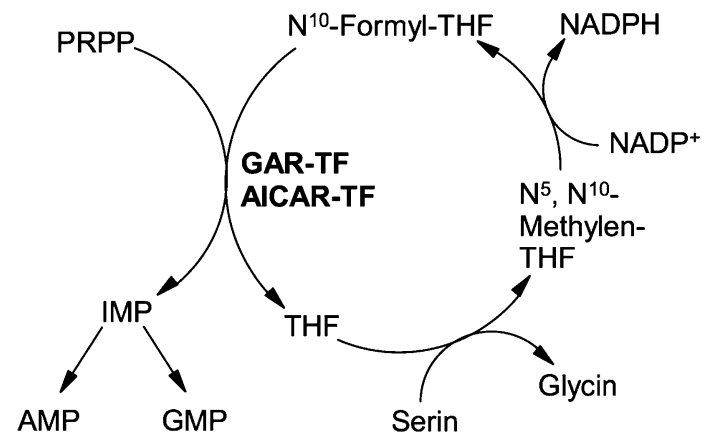

Die Synthese von dTMP erfolgt durch $\mathrm{N}^{5}, \mathrm{~N}^{10}$-MethylenTHF-abhängige Methylierung von dUMP. Das dabei entstehende DHF wird durch die DHF-Reduktase zu THF reduziert (s. folgende Abbildung).

Synthese von Desoxythymidinmonophosphat (dTMP) durch Methylierung von Desoxyuridinmonophosphat (dUMP):

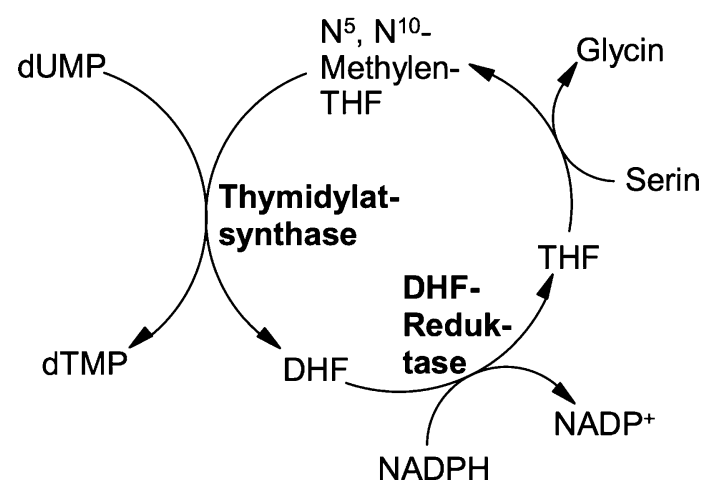

Als Zytostatika und Immunsuppressiva eingesetzte Folatanaloga (z. B. Methotrexat) hemmen dieses Enzym. Selektive Hemmstoffe der bakteriellen DHF-Reduktase (z. B. Trimethoprim) werden als Antibiotika verwendet und typischerweise mit einem Sulfonamid (z. B. Sulfamethoxazol) zur Hemmung der für die Folat-de-novo-Synthese essenziellen Dihydropteroat-Synthase kombiniert. In den Mitochondrien dient $\mathrm{N}^{10}$-Formyl-THF der Synthese der FormylmethionyltRNA, die zur Initiation der mitochondrialen Translation erforderlich ist. 
Folatmangel gilt als die häufigste Hypovitaminose in den Industrienationen. Erhöhter Bedarf besteht während der Schwangerschaft. Bei älteren Menschen und Alkoholikern ist die Folatversorgung oft unzureichend. Die Bioverfügbarkeit natürlichen Folats ist niedriger (ca. $50 \%$ ) als die synthetischer Folsäure (85-100 \%). Daher erfolgen Dosisempfehlungen als Folatäquivalente. $1 \mu \mathrm{g}$ Folatäquivalent entspricht $1 \mu \mathrm{g}$ Nahrungsfolat oder $0,5 \mu \mathrm{g}$ synthetischer Folsäure auf nüchternen Magen bzw. 0,6 $\mu$ g synthetischer Folsäure mit einer Mahlzeit. Die Tagesempfehlungen der Deutschen Gesellschaft für Ernährung liegen bei $300 \mu \mathrm{g}$ für Menschen ab 13 Jahren, $550 \mu \mathrm{g}$ für Schwangere und $450 \mu \mathrm{g}$ für Stillende. Bei geplanter und bestehender Schwangerschaft wird grundsätzlich eine Folatgabe empfohlen.

Folatmangel verursacht eine unzureichende DNA-Synthese, die vor allem Zellen mit hoher Teilungsrate beeinträchtigt. Außerdem bedingt er erhöhte Homocysteinplasmaspiegel, die als Risikofaktor für Gefäßerkrankungen gelten. Ein klarer Zusammenhang besteht zwischen Folatmangel und embryonalen Neuralrohrdefekten. Folatmangel manifestiert sich nach 10-12 Wochen als Übersegmentierung der Granulozyten und nach 4-5 Monaten als megaloblastäre (makrozytäre), hyperchrome Anämie.

Untersuchungsmaterial Serum für die Serumfolatbestimmung, EDTA-Vollblut und Heparin-Vollblut für die Erythrozytenfolatbestimmung.

Präanalytik Serumfolatbestimmung: Nüchternblutentnahme, Probe lichtgeschützt transportieren und lagern. Hämolytisches Material ist ungeeignet, da $95 \%$ des Blutfolats intraerythrozytär vorliegt. Probenstabilität bei lichtgeschützter Lagerung bei Raumtemperatur für 8 Stunden bei $2-8{ }^{\circ} \mathrm{C}$ für 48 Stunden und bei $-20^{\circ} \mathrm{C}$ für 30 Tage gegeben.

Erythrozytenfolatbestimmung: EDTA- oder Heparin-Blut ggf. vor Vitamingabe entnehmen, Probe lichtgeschützt transportieren und lagern. Hämatokrit bestimmen und anschließend das Vollbluthämolysat herstellen.

Analytik Kommerziellen Ligandenassays basierend auf der Bindung von Folat an spezifische Bindungsproteine; HPLC mit MS-Detektion; Radioimmuno- und mikrobiologische Assays.

Referenzbereich - Erwachsene Publizierte Referenzbereiche variieren sehr stark. Neben der Abhängigkeit vom Verfahren und der untersuchten Population ist zu berücksichtigen, dass zum Beispiel in Kanada und den USA eine gesetzlich verpflichtende Anreicherung von Lebensmitteln mit Folsäure vorgenommen wird. Die Ermittlung laboreigener Referenzbereiche wird empfohlen.

Referenzbereich - Kinder Referenzbereiche für Kinder wurden in Deutschland im Rahmen der KIGGS-, in Kanada im Rahmen der CALIPER-Studie erhoben. Siehe KIGGS-rki.de.

\section{Indikation}

- Megaloblastäre (makrozytäre) Anämie

- Chronischer Alkoholismus

- Malabsorptionssyndrom

- Therapie mit Folatantagonisten, Antiepileptika, Kontrazeptiva

- Neurologische und psychiatrische Störungen

Diagnostische Wertigkeit Die Konzentration des Serumfolats kann kurzzeitigen Schwankungen unterliegen. Das Erythrozytenfolat ist ein besserer Indikator für den Versorgungszustand.

Bei der Abklärung einer megaloblastären Anämie ist die zusätzliche Bestimmung der Vitamin- $\mathrm{B}_{12}$-Konzentration dringend empfohlen. Hämatologisch ist ein Folatmangel nicht von einem Vitamin- $\mathrm{B}_{12}$-Mangel unterscheidbar, bei Folatmangel fehlt aber meist die für einen Vitamin- $\mathrm{B}_{12}$-Mangel typische Neuropathie. Seltene genetische Formen des Folatmangels sollten v. a. bei Kindern in Erwägung gezogen werde. Bekannt sind Mutationen der Gene für PCFT-SLC46A1, FTCD, MTHFR, DHFR.

\section{Literatur}

Bässler KH, Golly I, Loew D et al (2007) Vitaminlexikon, 4. Aufl. Urban und Fischer, München

Biesalski HK (2016) Vitamine und Minerale. Thieme, Stuttgart

Ducker GS, Rabinowitz JD (2016) One-Carbon Metabolism in Health and Disease. Cell Metab 25:27-42

Patanwala I, King MJ, Barrett DA et al (2014) Folic acid handling by the human gut: implications for food fortification and supplementation. Am J Clin Nutr 100(2):593-599

\section{Folsäureantagonisten}

Folsäure

\section{Fondaparinux}

- Faktor-Xa-Inhibitoren

\section{Fonio-Methode}

- Thrombozytenzählung nach Fonio 


\section{Food and Drug Administration}

A. M. Gressner und O. A. Gressner

\section{Synonym(e) FDA}

Definition FDA ist eine von der US-Regierung eingerichtete und unterhaltene, breit gefächerte Institution innerhalb des Departments of Health and Human Sciences, die dem Gesundheitsschutz der amerikanischen Bevölkerung im weitesten Sinne dient.

Beschreibung Die Aufgaben der FDA wurden in dem FDA Modernization Act (FDAMA) von 1997 definiert und betreffen u. a.:

- Förderung öffentlicher Gesundheitsmaßnahmen durch schnelle und effiziente Evaluation klinischer Forschungen und Prüfung medizinisch-technischer und biologischer Gesundheitsprodukte kommerzieller Hersteller vor dessen Markteinführung

- Zulassung von verschreibungspflichtigen und nicht verschreibungspflichtigen Medikamenten, Blutprodukten und Vakzinen sowie von medizinischen Vorrichtungen und radiologischen Produkten

Die Aufgaben werden von 8 FDA-Zentren (Unterabteilungen) wahrgenommen, von denen für die Klinische Chemie und Laboratoriumsmedizin das Center for Biologics Evaluation and Research (CBER), das Center for Devices and Radiological Health (CDRH), das Center for Toxicological Research (NCTR) und das Center for Drug Evaluation and Research (CDER) am bedeutsamsten sind.

\section{Adresse:}

US Food and Drug Administration

5600 Fishers Lane

Rockville, MD 20857-0001

USA

\section{Literatur}

www.fda.gov

\section{Formatierung}

O. Colhoun

Synonym(e) Ausgabegestaltung

\section{Englischer Begriff formatting}

Definition Graphische Gestaltung der Ausgabe von Informationen des $>$ Labor-EDV-Systems.

Beschreibung Festlegung von u. a. Schriftart und -größe, Seitenrändern, Textfluss, Positionierung von Text und Grafiken (etwa Barcodes), Kopf- und Fußzeilen auf dem Bildschirm, im Ausgabebefund, für Arbeitslisten, Restelisten etc.

\section{Formeln}

- Aktionen

\section{Formiminoglutaminsäure-Test}

- FIGLU-Test

\section{Forns-Index}

A. M. Gressner und O. A. Gressner

Synonym(e) Leberfibrose-Index nach Forns

Englischer Begriff Forns index

Definition Beispiel eines nicht invasiven, aus den KenngröBen Alter, $>\gamma$-Glutamyltransferase, $\triangleright$ Cholesterin und - Thrombozytenzahl ermittelten Index zur Diagnose und Verlaufskontrolle einer signifikanten Leberfibrose.

Beschreibung Durch multivariate Analyse ermitteltes, als nicht invasive Fibrosekenngröße ( $\triangleright$ Fibrosekenngrößen) dienendes Score-System, das neben Patientenalter die Thrombozytenzahl und die Serumparameter $\gamma$-Glutamyltransferase(GGT-)Aktivität und Cholesterinkonzentration bestimmt und nach folgender Formel berechnet wird:

$$
\begin{aligned}
& \text { 7,811-3,131 } \times \ln (\text { Thrombozytenzahl })+0,781 \times \ln (\mathrm{GGT}) \\
& +3,467 \times \ln (\text { Alter })+0,014 \times \text { Cholesterin }
\end{aligned}
$$

Ein Wert $<4,2$ ist mit Abwesenheit, ein Wert $>6,9$ mit signifikanter Fibrose verbunden. Der negative prädiktive Wert ( $\triangleright$ Vorhersagewert, negativer) wird mit $96 \%$, der positive prädiktive Wert ( $\triangleright$ Vorhersagewert, positiver) mit $66 \%$ angegeben. Zwischenzeitlich sind ca. 20 nicht invasive, multiparametrische Scores zur Fibrosediagnostik vorgeschlagen worden. 


\section{Literatur}

Forns X, Ampurdanès S, Llovet JM et al (2002) Identification of chronic hepatitis $\mathrm{C}$ patients without hepatic fibrosis by a simple predictive model. Hepatology 36:986-992

Gressner AM, Gao CF, Gressner OA (2009) Non-invasive biomarkers for monitoring the fibrogenic process in liver: a short survey. World J Gastroenterol 15:2433-2440

\section{Forrest-Reaktion}

C. Vidal und W.-R. Külpmann

Definition Phenothiazin-Nachweis (Gruppenreaktion).

Bewertung Schwermetallsalze (z. B. Eisen(III)chlorid oder Kaliumdichromat) in konzentrierten Mineralsäuren (z. B. Schwefelsäure, Salpetersäure) reagieren mit Phenothiazinen und ihren Metaboliten unter Ausbildung von verschiedenen Farben, je nach Substanz und Reagenszusammensetzung. In praxi kann das Verfahren zum Urinscreening auf eine Intoxikation mit Phenothiazinen (z. B. Chlorpromazin, Promazin, Thioridazin, Imipramin) eingesetzt werden.

\section{Literatur}

Geldmacher-von Mallinckrodt M (2009) Neuroleptic drugs and antidepressants. Group assays: Color test. In: Külpmann WR (Hrsg) Clinical toxicological analysis. Wiley-VCH, Weinheim, S 394-396

\section{Forum of the European Societies of Clinical Chemistry and Laboratory Medicine}

\section{A. M. Gressner und O. A. Gressner}

\section{Synonym(e) FESCC}

Definition FESCC versteht sich als regionale Subgruppe der International Federation of Clinical Chemistry (IFCC), deren Mitglieder die europäischen wissenschaftlichen Fachgesellschaften für Klinische Chemie und Laboratoriumsmedizin sind.

Beschreibung Unter der Schirmherrschaft von IFCC $(\triangleright$ International Federation of Clinical Chemistry and Laboratory Medicine) agiert FESCC als europäische Task Force von IFCC, indem sie die Belange von Klinischer Chemie und Laboratoriumsmedizin sowohl global als auch auf einer regionalen europäischen Ebene vertritt. Im Einzelnen sind die Ziele:

- Fort- und Weiterbildung von Spezialisten in Klinischer Chemie und Laboratoriumsmedizin sowie Austausch von Studenten und Wissenschaftlern

- Förderung der Kooperation Klinisch-Chemischer und Laboratoriumsmedizinischer Fachgesellschaften zwischen den europäischen Ländern

- Unterstützung von Laboratoriumsakkreditierungen und -zertifizierungen und von Qualitätskontrollmaßnahmen auf europäischer Ebene

- Förderung der IFCC-Aktivitäten in Europa

- Vertretung von Klinischer Chemie und Laboratoriumsmedizin in der Diskussion mit anderen spezifischen medizinischen Laboratoriumsdisziplinen

Dem Executive Board gehören 5 Personen (ein Präsident), dem Council jeweils 2 delegierte Vertreter aller europäischen Mitgliedsgesellschaften an.

Das offizielle Publikationsorgan von FESCC ist „Clinical Chemistry and Laboratory Medicine".

FESCC und EC4 (European Communities Confederation of Clinical Chemistry) gingen 2007 in EFCC (European Federation of Clinical Chemistry and Laboratory Medicine) auf.

\section{Fotodiode}

- Photodiode

\section{Fotoelektrischer Detektor}

Photoelektrische Empfänger

\section{Fotoelement}

> Photoelement

\section{Fotometrie}

- Photometrie

\section{Fotomultiplier}

- Photomultiplier 


\section{Fotozelle}

Photozelle

\section{Fouchet-Probe}

$>$ Fouchet-Test

\section{Fouchet-Test}

\section{A. M. Gressner und O. A. Gressner}

Synonym(e) Bilirubinnachweis nach Fouchet; Fouchet-Probe

\section{Englischer Begriff Fouchet test}

Definition Heute obsoleter, qualitativer Nachweis von - Bilirubin in Urin oder Serum.

Beschreibung Nach Proteinfällung durch Trichloressigsäure wird Bilirubin mit Ferrichlorid zu einem blaugrün gefärbten oder rein grünen Produkt ( $\triangleright$ Biliverdin) oxidiert, positiver Ausfall ab 1,7 mg/dl Bilirubin. Nachweisverfahren nicht mehr in Gebrauch.

Eine Modifikation des Fouchet-Tests stellt der HarrisonTest dar: $10 \mathrm{ml}$ des angesäuerten Urins wird mit Bariumchlorid gefällt und auf Filterpapier aufgefangen, um bei Anwesenheit von Bilirubin eine blaugrüne Färbung nach Zugabe weniger Tropfen des Fouchet-Reagenz (Trichloressigsäure in einer Ferrichloridlösung) zu erzeugen. Die Methode ist mit einer Nachweisgrenze von $0,15-0,20 \mathrm{mg} / \mathrm{dl}$ Bilirubin im Urin sehr empfindlich.

\section{Literatur}

Gitter A, Heilmeyer L (1963) Taschenbuch klinischer Funktionsprüfungen, 8. Aufl. Gustav Fischer Verlag, Stuttgart

Hallmann L (1980) Klinische Chemie und Mikroskopie, 11. Aufl. Georg Thieme Verlag, Stuttgart/New York

\section{Founder effect}

J. Arnemann

Synonym(e) Gründereffekt
Englischer Begriff founder effect

Definition Der Gründereffekt oder „founder effect“ beschreibt die Manifestation einer genetischen Variation oder auch Neumutation aufgrund einer begrenzten Anzahl an Allelen in einer Gründerpopulation.

Beschreibung Gründerpopulationen fand man in Deutschland und Europa in relativ unzugänglichen Bergregionen oder nur dünn besiedelten Landstrichen, wo die Bevölkerung einen geringen Austausch mit anderen hatte und bei den Ehen oftmals ein hoher Anteil an Verwandtschaften vorlag. Dies war die Grundlage, dass sich meist rezessive, seltener auch dominante Mutationen im Genpool festigen konnten und teilweise neue Krankheitsbilder oder Fehlbildungen entstehen ließ, die in der übrigen Bevölkerung zunächst unbekannt waren. Beispiele für einen Gründereffekt findet sich in der rezessiven adulten Laktoseintoleranz in der ursprünglich nordeuropäischen, Milchwirtschaft betreibenden Bevölkerung oder die starke Vermehrung der dominanten ChoreaHuntington-Erkrankung am Maracaibo-See in Venezuela, ausgehend von einer Frau mit 10 Kindern vor über 200 Jahren.

\section{Literatur}

Claramunt $\mathrm{R}$ et al (2005) Genetics of Charcot-Marie-Tooth disease type 4A: mutations, inheritance, phenotypic variability, and founder effect. J Med Genet 242:358-365

\section{FPA}

- Fibrinopeptid A

FPIA

- Fluoreszenzpolarisations-Immunoassay

- Immunoassay, homogener

fPSA

- Prostataspezifisches Antigen, freies

Fragment $D, E, X, Y$

- Fibrin(ogen)-Degradationsprodukte 


\section{Fragmentierung}

- Massenspektrometrie

\section{Fragment-Ion}

\section{B. Güssregen}

\section{Englischer Begriff fragment ion}

Beschreibung Ein Fragment-Ion entsteht in der $>$ Massenspektrometrie durch Zerfall eines Molekülions. Fragment-Ionen liefern wertvolle Hinweise bei der Strukturaufklärung von unbekannten Metaboliten und dienen dem Spektrenvergleich bei Bibliothekssuchen.

\section{Fragmentlängenanalyse}

\section{J. Arnemann}

Synonym(e) DNA-Längenbestimmung

Englischer Begriff fragment length analysis

Definition Die Fragmentlängenanalyse ist eine Methode, über eine präzise Ermittlung der Länge eines DNAFragments qualitative oder quantitative Hinweise zu kleineren Insertionen oder Duplikationen in einem diagnostisch relevanten DNA-Abschnitt zu bekommen.

Beschreibung Zur Vorgehensweise der Fragmentlängenanalyse werden PCR-Rektionen zu den relevanten DNAAbschnitten mit einem fluoreszenzmarkierten Primer im Reaktionsansatz durchgeführt. Anschließend werden die denaturierten, einzelsträngigen PCR-Produkte mittels Kapillarelektrophorese detektiert und die Fragmentlängen anhand der eingesetzten Standards mit einem spezifischen SoftwareProgramm ermittelt.

Die Methode der Fragmentlängenanalyse wird zunehmend eingesetzt, wie beispielsweise bei Repeaterkrankungen (fragiles X-Syndrom oder Chorea Huntington), zur MLPAAnalyse zwecks Ausschluss von intragenischen Duplikationen oder Insertionen, zur Klonalitätstestung in der Hämatoonkologie oder zum DNA-Fingerprinting in der Forensik.

\section{Literatur}

Butler JM et al (2004) Forensic DNA typing by capillary electrophoresis using the ABI Prism 310 and 3100 genetic analyzers for STR analysis. Electrophoresis 25:1397-1412

De Bellis G et al (1997) Apolipoprotein E genotyping by capillary electrophoretic analysis of restriction fragments. Clin Chem 43:1321-1324

\section{Fragmentozyt}

H. Baum

Synonym(e) Schistozyten; Schizozyten

Englischer Begriff fragmentocyte

Definition Missgestalteter Erythrozyt, der sekundär aus einem normalen Erythrozyten entsteht.

Beschreibung Fragmentozyten sind stark missgebildete Erythrozyten mit unregelmäßigen Formen.

Sie entstehen sekundär aus normalen Erythrozyten. Morphologisch sind sie meist durch eine unveränderte konvexe Seite charakterisiert, die Risskante erscheint jedoch gerade oder konkav. Dabei zeigen sie an der Risskante scharfe Endigungen. Selten können aber auch mehr dreieckige Formen gefunden werden.

Die Abbildung zeigt einen Fragmentozyten mit typischer normaler konvexer Seite und scharfkantiger Risskante $(1000 \times$, May-Grünwald-Giemsa-Färbung):

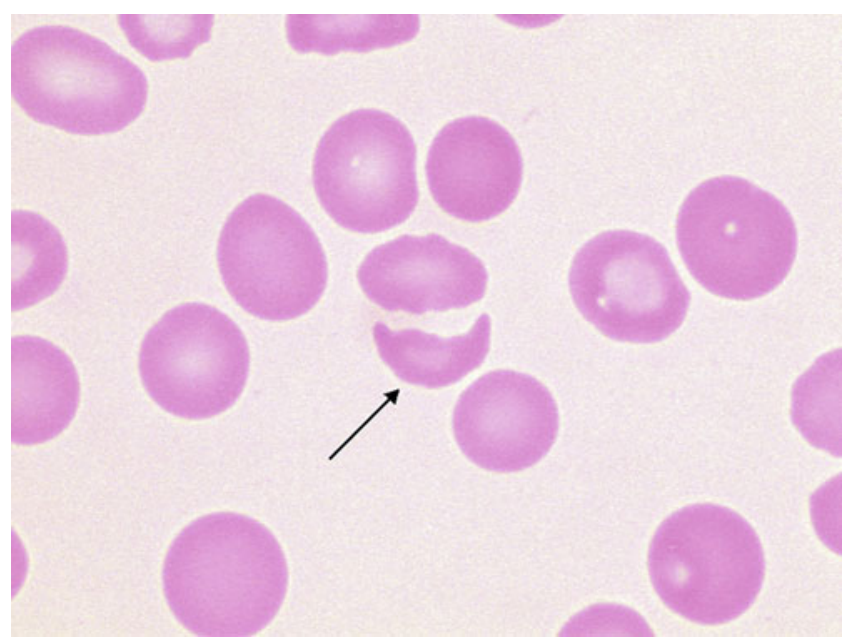

Fragmentozyten können in erster Linie nachgewiesen werden bei

- Mikroangiopathischen hämolytischen Anämien 
- Mechanischer Schädigung der Erythrozyten (künstliche Herzklappen)

- Thalassämie-Syndromen

Normalerweise werden im Blutausstrich 0-1 Fragmentozyten pro Gesichtsfeld gefunden. Werte über 5 Fragmentozyten pro Gesichtsfeld gelten als pathologisch ( $\triangleright$ Helmzellen).

\section{Literatur}

Kaboth W (1993) Erythrozyten im gefärbten Blutausstrich. In: Begemann H, Rastetter J (Hrsg) Klinische Hämatologie, 4. Aufl. Georg Thieme Verlag, Stuttgart, S 241

\section{Fragmentozyten (Sonderform)}

$>$ Helmzellen

\section{Fraktion}

C. Vidal und W.-R. Külpmann

Synonym(e) Anteil

Englischer Begriff fraction

Definition Verhältnis eines Bestandteils (oder eines Teiles) zu sämtlichen Bestandteilen (oder allen Teilen) eines Systems, unter der Voraussetzung gleicher Größen.

Beschreibung Beispiele:

- Volumenfraktion: Volumenanteil der Erythrozyten bezogen auf das Gesamtblutvolumen $(\mathrm{L} / \mathrm{L})$

- Numerische Fraktion: Anzahl der Retikulozyten bezogen auf die Gesamtzahl der Erythrozyten

- Substanzfraktion: Stoffmengenanteil von Methämoglobin am Gesamthämoglobin $(\mathrm{mol} / \mathrm{mol})$

- Massenfraktion: Lipidanteil im Stuhl (g/g)

- Katalytischer Aktivitätsanteil: CKMB-Aktivitätsanteil an der gesamten CK-Aktivität (kat/kat)

\section{Fraktionierte Magensekretionsanalyse}

- Magensekretionsanalyse

\section{Fraktioniertes Heparin}

- Heparin und Heparinoide

\section{Frameshift Mutation}

- Leseraster-Mutation

Fredrickson, Donald S.

K. J. Lackner und D. Peetz

Lebensdaten Amerikanischer Physiologe, geboren am 8. August 1924 in Canon City, Colorado, USA, gestorben am 7. Juni 2002 in Bethesda, Maryland, USA.

Verdienste Fredrickson hat sich wissenschaftlich mit Erkrankungen des Fettstoffwechsels und deren Beziehung zur Atherosklerose beschäftigt. Er entwickelte in den 1960er-Jahren des letzten Jahrhunderts eine Klassifikation der Hyperlipidämien, die inzwischen weitgehend durch eine stärker pathophysiologisch orientierte Betrachtung abgelöst wurde ( $\triangleright$ Fredrickson-Klassifikation).

\section{Fredrickson-Klassifikation}

K. J. Lackner und D. Peetz

Synonym(e) Fredrickson-Phänotypen

Englischer Begriff Fredrickson classification; Fredrickson phenotypes

Definition Phänotypische Beschreibung der Hyperlipoproteinämien.

Beschreibung Von D.S. Fredrickson ( $\triangleright$ Fredrickson, Donald S.) in den 1960er-Jahren beschriebene Einteilung von Hyperlipoproteinämien auf der methodischen Basis der - Lipoprotein-Elektrophorese, die rein phänomenologisch ist und die Pathobiochemie der verschiedenen Störungen nicht oder nur partiell berücksichtigt. Sie ist in der folgenden Tabelle zusammengefasst: 


\begin{tabular}{|l|l|l|} 
Typ & $\begin{array}{l}\text { Erhöhter/pathologischer } \\
\text { Lipoproteinpartikel }\end{array}$ & Phänotyp \\
\hline I & Chylomikronen & Hypertriglyzeridämie (schwer) \\
IIa & LDL & Hypercholesterinämie \\
\hline IIb & LDL, VLDL & Gemischte Hyperlipidämie \\
\hline III & Beta-VLDL & Gemischte Hyperlipidämie \\
IV & VLDL & Hypertriglyzeridämie \\
\hline V & VLDL, Chylomikronen & $\begin{array}{l}\text { Hypertriglyzeridämie und } \\
\text { Hypercholesterinämie }\end{array}$ \\
\hline
\end{tabular}

Die Einteilung wird deshalb heute von vielen Fachleuten als überholt betrachtet.

\section{Literatur}

Beaumont JL, Carlson LA, Cooper GR et al (1970) Classification of hyperlipidaemias and hyperlipoproteinaemias. Bull World Health Organ 43:891-915

\section{Fredrickson-Phänotypen}

- Fredrickson-Klassifikation

\section{Frei fließender Urin}

$>$ Spontanurin

\section{Freie (Kappa- oder Lambda-)}

\section{Leichtketten der Immunglobuline}

Bence-Jones-Protein

\section{Freier Androgenindex}

- Androgenindex, freier

\section{Freier Testosteronindex}

- Androgenindex, freier

\section{Freier T4-Index}

- Thyroxin-Index, freier

\section{Freies Erythrozyten-Protoporphyrin}

Freies Protoporphyrin

\section{Freies Protoporphyrin}

T. Stauch

Synonym(e) Freies Erythrozyten-Protoporphyrin; Protoporphyrin IX

Englischer Begriff free protoporphyrin

Definition Als Dicarboxyporphyrin letztes Intermediat vor Bildung des Häms durch Einbau von Eisen.

Struktur Strukturformel:<smiles></smiles>

Molmasse $562,67 \mathrm{~g}$.

Synthese - Verteilung - Abbau - Elimination Protoporphyrin entsteht durch oxidative Decarboxylierung (2 Schritte) aus dem Tetracarboxyporphyrin Koproporphyrin III. Das katalysierende Enzym ist die $>$ Koproporphyrinogenoxidase in der Mitochondrienmembran. Es werden keine Kofaktoren benötigt.

Das Substrat muss jedoch aus dem Zytosol in den Raum zwischen innerer und äußerer Mitochondrienmembran transportiert werden. Die Weiterverwertung des Protoporphyrins erfolgt intramitochondrial durch Einbau von Eisen. Katalysiert wird die Reaktion durch das Enzym $>$ Ferrochelatase. Bei einem signifikanten Mangel dieses Enzyms (Restaktivität $<30 \%$ ) kommt es zur Anflutung von Protoporphyrin in erythropoetischen Zellen und damit zur Ausprägung des Krankheitsbildes der erythropoetischen Protoporphyrie (EPP).

$\mathrm{Zu}$ klinisch relevanten Erhöhungen des Protoporphyrins kommt es auch, wenn die 5-Aminolävulinsäuresynthase $2 \mathrm{im}$ 
Knochenmark unreguliert, d. h. mit maximaler Syntheseleistung, exprimiert wird. Für die dergestalt maximierte Porphyrinsynthese wird die Verfügbarkeit von Eisen leistungsbegrenzend, sodass auf diesem Wege hohe Mengen an freiem Protoporphyrin generiert werden. Es handelt sich bei dieser X-chromosomale Protoporphyrie (XLPP) genannten Störung bis dato um die einzige Form einer Porphyrie, die durch Hyperaktivität (und nicht durch Aktivitätsminderung) eines der beteiligten Enzyme bedingt ist.

Protoporphyrin gehört aufgrund seiner Struktur zu den lipophilen Porphyrinen. Seine Ausscheidung erfolgt daher nicht renal, sondern nahezu ausschließlich biliär in den Darm. Störungen, die zur Akkumulation von Protoporphyrin führen, können folglich labordiagnostisch nur über Analysen im Blut und im Stuhl entdeckt bzw. diagnostiziert werden. Sie gehen hauptsächlich mit erhöhter kutaner Lichtempfindlichkeit einher, die durch Einlagerung überschüssigen Protoporphyrins in der Haut verursacht wird.

Funktion - Pathophysiologie Protoporphyrin IX ist in allen Geweben letzte Vorstufe des Häms, das als prosthetische Gruppe in zahlreichen Enzymen und Proteinen (Hämoglobin, Myoglobin, Cytochrome etc.) benötigt wird. In freier Form ist es zytotoxisch, sodass seine Synthese in enger Abhängigkeit von der Verfügbarkeit des Komplexierungspartners Eisen sowie der Utilisation des Endproduktes und damit dem Bedarf an funktionellen Hämproteinen reguliert wird. Bei mangelnder Verfügbarkeit von Eisen kann Protoporphyrin in Form seines Zinkchelates ,Zwischengespeichert“ werden und steht dann bei Gegenwart von Eisen sofort für die Hämbereitstellung zur Verfügung.

Untersuchungsmaterial - Entnahmebedingungen EDTAoder Heparin-Vollblut (unzentrifugiert und lichtgeschützt), bei längeren Verwahrungs- und/oder Transportzeiten ( $>3$ Tage) können die Vollblutproben auch komplett tiefgefroren werden $\left(-20^{\circ} \mathrm{C}\right)$. Die dadurch ausgelöste Hämolyse stört die Analytik nicht.

Probenstabilität Antikoagulierte Vollblutproben sind gekühlt und lichtgeschützt mindestens 3 Tage stabil. Bei längerer Verwahrung kommt es zunächst nicht zu einer Abnahme der Gesamtkonzentration an Protoporphyrin, aber zu einer Verschiebung zugunsten des freien Anteils, sodass dieser falsch erhöht erscheinen kann. Diagnostische Signifikanz erreichen diese Verschiebungen jedoch kaum.

Präanalytik S. o.

Analytik Hochdruckflüssigkeitschromatographie mit Fluoreszenz-Detektion und Mesoporphyrin als internem Standard. Die Varianz des Verfahrens liegt bereichsabhängig bei 6-8 \%.
Konventionelle Einheit $\mu \mathrm{g} / \mathrm{dL}$.

Internationale Einheit $\mathrm{nmol} / \mathrm{L}$.

Umrechnungsfaktor zw. konv. u. int. Einheit $\mu \mathrm{g} / \mathrm{dL} \times$ $17,772=\mathrm{nmol} / \mathrm{L}$.

Referenzbereich - Erwachsene $9-89 \mathrm{nmol} / \mathrm{L}$ bzw. $<30 \%$ des Gesamtprotoporphyrins, $0,5-5,0 \mu \mathrm{g} / \mathrm{dL}$.

Referenzbereich - Kinder S. Referenzbereich-Erwachsene.

\section{Indikation}

- Klinischer Verdacht auf hereditäre Stoffwechselstörungen vom Typ der erythropoetischen Protoporphyrie (EPP) oder $\mathrm{X}$-chromosomalen Protoporphyrie (XLPP) bei ausgeprägter kutaner Lichtempfindlichkeit mit konsekutiver Erythem- und/oder Ödembildung

- Abklärung von klinisch ähnlichen, erworbenen Krankheitsbildern (sekundäre Protoporphyrie bei hämatologischen Systemerkrankungen)

- Als Teil eines porphyriediagnostischen Gesamtscreenings zusammen mit Zink-Protoporphyrin bei lichtabhängigen kutanen Veränderungen oder Symptomen; u. a. auch zur Plausibilisierung einer möglichen Homozygotie bzw. Compound-Heterozygotie einer Porphyrinstoffwechselstörung

- Begleitende Diagnostik und Verlaufsbeobachtung von mikrozytären Anämien, z. B. sideroachrestischen Störungen infolge von Pyridoxalphosphatmangel, Schwermetallbelastungen/-intoxikationen und anderen exogen-toxischen Einflüssen

- Diagnostik von Pseudoprotoporphyrien aufgrund mitochondrialer Transporterdefekte, z. B. Mitoferrin 1/2 (SLC25A37/SLC25A28)

Interpretation Die Interpretation eines isoliert bestimmten Wertes von freiem Protoporphyrin ist nur dann eindeutig möglich, wenn Normalbefunde oder aber exzessive Werterhöhungen, d. h. mindestens Überschreitungen der 50-fachen Referenzbereichsgrenze, vorliegen. Die Konzentration von freiem Protoporphyrin liegt bei einem EPP-Patienten im Mittel bei etwa der 180-fachen Referenzbereichsgrenze (14.000-18.000 $\mathrm{nmol} / \mathrm{L})$.

Normale Werte von freiem Protoporphyrin schließen eine Protoporphyrie (unabhängig von Art und Genese) definitiv aus, d. h., es gibt keine Erkrankungsphasen in denen Normalwerte gefunden werden. 
Interpretation von Protoporphyrinkonzentrationen im Blut

\begin{tabular}{|c|c|}
\hline $\begin{array}{l}\text { Freies } \\
\text { Protoporphyrin } \\
(\mathrm{nmol} / \mathrm{L})\end{array}$ & Interpretation \\
\hline$<9$ & $\begin{array}{l}\text { Möglicher Hinweis auf hereditäre oder erworbene } \\
\text { (toxisch, Pyridoxalphosphatmangel o. Ä.) } \\
\text { sideroachrestische Anämie }\end{array}$ \\
\hline $9-89$ & Normalbefund \\
\hline 89-ca. 500 & $\begin{array}{l}\text { Erythropoetische Stimulation möglich (häufig mit } \\
\text { Anämie) }\end{array}$ \\
\hline $500-4000$ & $\begin{array}{l}\text { Signifikante, aber klinisch meist latente } \\
\text { Protoporphyrinämie }\end{array}$ \\
\hline$>4000$ & $\begin{array}{l}\text { Protoporphyrie, bei lichtabhängigen } \\
\text { Hautsymptomen }>7000 \mathrm{nmol} / \mathrm{L}\end{array}$ \\
\hline
\end{tabular}

Diagnostische Wertigkeit Aufgrund der extremen und permanenten Wertveränderungen von freiem Protoporphyrin bei den Stoffwechselstörungen EPP und XLPP können die Kollektive von Kranken und Nichtkranken vollständig getrennt werden (Sensitivität und Spezifität in Bezug auf die genannten Erkrankungen liegen bei $100 \%$ ). In einem $n=4181$ Probanden umfassenden Kollektiv mit 124 Protoporphyriepatienten ergibt die ROC-Analyse nach Hanley \& McNeil einen Cut-off-Wert von $3990 \mathrm{nmol} / \mathrm{L}$.

Die für eine adäquate Therapie der Patienten erforderliche Unterscheidung der klinisch ausgesprochen ähnlichen Erkrankungen EPP und XLPP kann nur unter Einbeziehung des Zink-Protoporphyrins erfolgen. Während bei EPPPatienten der Anteil des Zink-Protoporphyrins signifikant unter $10 \%$ des Gesamtprotoporphyrins liegt (sehr häufig sogar unter $5 \%$ ), finden sich bei XLPP-Patienten Anteile von $30 \%$ und mehr.

\section{Literatur}

Bailey GG, Needham LL (1983) Simultaneous quantification of erythrocyte zinc protoporphyrin and protoporphyrin IX by liquid chromatography. Clin Chem 32:2137-2142

Murphy GM (2003) Diagnosis and management of the erythropoietic protoporphyrias. Dermatol Ther 16:57-64

\section{Freigabe}

O. Colhoun

Synonym(e) Validation technisch

Englischer Begriff release
Definition Vorgang, der einen Messwert im $>$ Labor-EDVSystem nach Prüfung (technische Validation, medizinische Validation) für den Einsender sichtbar macht.

Beschreibung $\mathrm{Zu}$ unterscheiden sind die technische Freigabe durch die MTA nach messtechnischer Beurteilung von Ergebnis und Messvorgang von der medizinischen Freigabe durch einen Akademiker im Labor nach medizinischer Wertung von Plausibilität und Richtigkeit und ggf. Betrachtung des Ergebniskontexts und Kommentierung.

\section{Fremdkörper-Riesenzelle}

\section{H. Baum}

Englischer Begriff foreign-body giant-cell

Definition Durch den örtlichen Reiz eines Fremdkörpers entstandene Syncytiumzelle aus mehreren Monozyten/ - Makrophagen mit der Fähigkeit zur Phagozytose.

Beschreibung Im Rahmen einer intensiven Abwehrreaktion kommt es $\mathrm{zu}$ einer Ummantelung des Fremdkörpers (z. B. Mykobakterien) durch IL-4-aktivierte Makrophagen. Durch Verschmelzung benachbarter Zellen kann es zu mehrkernigen Riesenzellen kommen, in denen die nicht oder nur teilweise abgebauten Fremdkörper nachweisbar sind.

\section{Literatur}

Nerl C (1993) Monozyten-Makrophagen-System. In: Begemann H, Rastetter J (Hrsg) Klinische Hämatologie, 4. Aufl. Georg Thieme Verlag, Stuttgart, S 82-87

\section{Fremdstoffe}

- Xenobiotika

\section{Friedewald-Formel}

K. J. Lackner und D. Peetz

Englischer Begriff Friedewald-Formula 
Beschreibung Die Formel dient der Berechnung von LDLCholesterin aus den Serumkonzentrationen von Cholesterin, Triglyzeriden und HDL-Cholesterin. Sie wurde empirisch gewonnen und geht davon aus, dass das VLDL-Cholesterin $1 / 5$ der Triglyzeride (TG) (jeweils in $\mathrm{mg} / \mathrm{dL}$ ) im Serum entspricht. Daraus ergibt sich die Formel:

$[$ LDL-Chol $]=[$ Gesamt-Chol $]-[$ HDL-Chol $]-$ TG/5 bei Angabe in $\mathrm{mg} / \mathrm{dL}$

bzw.

$[$ LDL-Chol $]=[$ Gesamt-Chol $]-[$ HDL-Chol $]-\mathrm{TG} / 2,2$ bei Angabe in $\mathrm{mmol} / \mathrm{L}$

Die Friedewald-Formel darf nur beim nüchternen Patienten ohne Chylomikronen im Blut und bei Triglyzeridwerten $<400 \mathrm{mg} / \mathrm{dL}$ angewendet werden. Unter diesen Bedingungen weichen ca. $90 \%$ aller errechneten Werte für LDL-Cholesterin um weniger als $10 \%$ von der empfohlenen Bestimmungsmethode ab. Bei Diabetikern ist die Friedewald-Formel weniger zuverlässig.

\section{Fruchtblasen-Punktion}

- Amniocentese

\section{Fruchtwasser}

- Amnionflüssigkeit

\section{Fruchtwasserpunktion}

- Amniocentese

\section{Fruchtzucker}

$>$ Fruktose

\section{Früherkennung angeborener (genetischer) Stoffwechselerkrankungen}

- Neugeborenenscreening auf Stoffwechselerkrankungen und Endokrinopathien

\section{Frühsommer-Meningoenzephalitis-}

\section{Viren}

\FSME-Viren

\section{Fruktaldolase}

$\checkmark$ Aldolase B

\section{Fruktokinase}

K. J. Lackner und D. Peetz

Synonym(e) EC 2.7.1.3

Englischer Begriff fructokinase

Definition Katalysiert die Konversion von $>$ Fruktose zu Fruktose-1-Phosphat.

Molmasse Ca. 32,7kDa.

Beschreibung Fruktokinase kommt hauptsächlich in Leber, Nieren, Darm, Milz und Pankreas vor. Geringere Konzentrationen auch in anderen Geweben. Genetische Defekte verursachen die Fruktosurie, die ein benigner, asymptomatischer Stoffwechseldefekt ist. Aufgrund der Fruktosurie fallen die Patienten bei Urinuntersuchungen mit Teststreifen auf, die nicht spezifisch für $>$ Glukose sind, ohne dass sich eine diabetische Stoffwechsellage nachweisen ließe.

\section{Fruktosamin}

K. J. Lackner und D. Peetz

Englischer Begriff fructosamine

Definition Bezeichnung für die in der Amadori-Reaktion entstehenden Ketoamine spontan glykierter Plasmaproteine; es handelt sich dabei nicht um ein spezifisches Molekül, sondern um eine gemeinsame Struktur verschiedener Proteine.

Struktur $>$ Amadori-Reaktion 
Synthese - Verteilung - Abbau - Elimination Fruktosamine entstehen durch nichtenzymatische Glykierung der Plasmaproteine. Ihre Konzentration im Plasma hängt von der Glukosekonzentration ab. Etwa $70 \%$ des Fruktosamin wird von > Albumin, etwa $15 \%$ von > Immunglobuline repräsentiert, was ungefähr ihrem Anteil am Gesamtprotein ( $\triangleright$ Protein, gesamt im Urin) entspricht.

Halbwertszeit Entsprechend der $\triangleright$ Halbwertszeit der wichtigsten Plasmaproteine ist die Halbwertszeit der Fruktosamine uneinheitlich. Albumin und Immunglobuline haben eine relativ lange Halbwertszeit von $\sim 3$ Wochen.

Funktion und Pathophysiologie Die Glykierung von Proteinen hängt neben dem Vorhandensein freier Aminogruppen und der Glukosekonzentration im Blut vor allem von drei Faktoren ab: Glykoproteine und Proteine mit einem sauren pI werden schlechter nicht-enzymatisch glykiert, und eine kurze Halbwertszeit lässt auch weniger Glykierung zu. Die Fruktosamin-Konzentration repräsentiert die mittlere Glukosekonzentration der letzten etwa 8-10 Tage.

Untersuchungsmaterial - Entnahmebedingungen Serum; Plasma ergibt andere Werte wegen der zusätzlich vorhanden Gerinnungsfaktoren und des Fibrinogens.

Probenstabilität Proben sind $24 \mathrm{~h}$ bei Raumtemperatur stabil.

Präanalytik Längeres Stauen bei der Blutentnahme führt zu falsch hohen Werten.

Analytik Die Bestimmung erfolgt meist durch Reduktion von Nitroblautetrazolium zu Formazan im alkalischen Milieu.

\section{Konventionelle Einheit $\mu \mathrm{mol} / \mathrm{L}$}

Internationale Einheit $\mu \mathrm{mol} / \mathrm{L}$

Umrechnungsfaktor zw. konv. u. int. Einheit 1

Referenzbereich - Erwachsene $205-285 \mu \mathrm{mol} / \mathrm{L}$

Referenzbereich - Kinder s. Erwachsene

Indikation Retrospektive Bewertung der Blutzuckereinstellung

Interpretation Erhöhte Werte sind hinweisend auf eine unzureichende Blutzuckereinstellung in den letzten 8-10 Tagen. Da die Gesamtmenge von Fruktosamin als reduzierende Substanz gemessen wird, sind die Ergebnisse von der Gesamteiweißkonzentration der Serumprobe abhängig. Falsch-hohe Werte können außerdem bei Hyperbilirubinämie oder $\triangleright$ Hämolysin auftreten, falsch-niedrige Werte bei Hypoproteinämien. Korrektur für die Serumproteinkonzentration kann durch Multiplikation mit 72/Gesamtprotein (g/L) erfolgen. Eine $>$ Akute-Phase-Reaktion kann zu falsch hohen Werten führen.

Diagnostische Wertigkeit Gegenüber dem HbAlc sind Fruktosamine in der Therapiekontrolle von Diabetikern in den Hintergrund getreten, weil die Bestimmung anfälliger gegen diverse Stör- und Einflussfaktoren ist. Sie kommen hauptsächlich bei Patienten in Frage, bei denen die HbA1cBestimmung wegen Einfluss- oder Störfaktoren unzuverlässig ist. Klinische Studien weisen darauf hin, dass die Bestimmung von glykiertem Albumin diagnostisch aussagekräftiger als Fruktosamine ist.

\section{Literatur}

Danese E, Montagnana M, Nouvenne A, Lippi G (2015) Advantages and pitfalls of fructosamine and glycated albumin in the diagnosis and treatment of diabetes. J Diab Sci Technol 9:169-176

\section{Fruktose}

K. J. Lackner und D. Peetz

Synonym(e) Fruchtzucker; Laevulose

Englischer Begriff fructose

Definition Hexose, Ketose.

Struktur $\mathrm{C}_{6} \mathrm{H}_{12} \mathrm{O}_{6}$. Struktur als Pyranose (links) und Furanose (rechts):

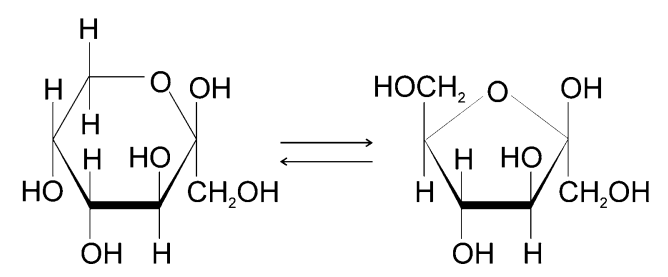

Molmasse $180,16 \mathrm{~g}$.

Synthese - Verteilung - Abbau - Elimination Fruktose ist eine Hexose, die aufgrund ihrer Ketonstruktur als Pyranose oder Furanose in wässriger Lösung vorliegen kann. Diagnostisch spielt die Konzentration der Fruktose im Serum im Gegensatz zur Glukose keine Rolle. Allerdings wird sie im Rahmen der Diagnostik männlicher Fertilitätsstörungen 
im Ejakulat bestimmt. Dazu wird meist eine kolorimetrische Methode mit Resorcinol verwendet, die nur anwendbar ist, weil neben Fruktose andere Zucker im Ejakulat nicht in relevanten Mengen vorkommen. Normalwerte im Ejakulat werden mit $1-5 \mathrm{mg} / \mathrm{mL}(3,5-28 \mathrm{mmol} / \mathrm{L})$ angegeben. Aus wissenschaftlichen Gründen wird Fruktose auch im Serum und Urin bestimmt. Hier beeinträchtigt die Glukose die Analytik massiv. Aus diesem Grund werden meist gaschromatographische Methoden, z. T. mit vorheriger spezifischer chemischer Umsetzung der Fruktose, eingesetzt.

Diagnostische Wertigkeit Die diagnostische Wertigkeit bei der Ejakulatuntersuchung ist umstritten. Eine verminderte Fruktosekonzentration geht meist mit einem auffälligen Spermiogramm einher.

\section{Literatur}

Roe JH (1934) A colorimetric method for the detection of fructose in blood and urine. J Biol Chem 107:15

World Health Organization (1999) WHO laboratory manual for the semen and sperm-cervical mucus interaction. Cambridge University Press, Cambridge

\section{Fruktose im Urin}

W. G. Guder

Synonym(e) Fruktosurie

Englischer Begriff fructose in urine

Definition $>$ Fruktose.

Struktur D-arabino-2-hexulose (s. Abbildung im Beitrag - Fruktose).

Molmasse $180,16 \mathrm{~g}$.

Funktion - Pathophysiologie Angeborene Störungen des Fruktosestoffwechsels (reduzierte Metabolisierung und/oder tubuläre Resorption) können zur Ausscheidung von Fruktose im Urin führen.

Analytik Hochleistungs-Flüssigkeitschromatographie oder enzymatisch mit Sorbitoldehydrogenase. Die Methode mit Hexokinase setzt Elimination von $>$ Glukose voraus.

Referenzbereich - Erwachsene Unterhalb 0,3 $\mathrm{mmol} / \mathrm{L}$ $(<60 \mathrm{mg} / 24 \mathrm{~h})$
Referenzbereich - Kinder Unterhalb $0,3 \mathrm{mmol} / \mathrm{L}$ $(<60 \mathrm{mg} / 24 \mathrm{~h})$.

Indikation Historisch wird bei positivem unspezifischen Nachweis von Hexosen im Urin (mit Teststreifen für Glukose), aber fehlender Glukose der Verdacht auf andere Hexosen geweckt.

Da die Fruktoseintolerenz durch klinische Symptome bei der Einnahme von Früchten und anderen fruktosehaltigen Nahrungsmitteln (Honig, Rohrzucker) auffällt (Erbrechen, Hypoglykämie, Krämpfe bis zum Koma), wird meist die Diagnose durch Nachweis der Fruktose im Urin möglich sein. Defizienz der Fruktose-1-Phosphataldolase wird in Leber oder Darmgewebe nachgewiesen.

Interpretation Der Nachweis von Fruktose im Urin ( $\triangleright$ Seliwanoff-Test) spricht nur in Gegenwart von deutlichen klinischen Symptomen für angeborene Fruktoseintoleranz. Ansonsten kann Fruktose durch hohe Dosen oraler Zufuhr (Honig, „diabetische“ Süßigkeiten, Infusionen) oder Kontamination mit Seminalffüssigkeit (enthält $>8,3 \mathrm{mmol} / \mathrm{L}$ ( $>50 \mathrm{mg} / \mathrm{dL})$ Fruktose!) im Urin nachweisbar sein.

\section{Literatur}

Schleicher E (2009) Fructose. In: Guder WG, Nolte J (Hrsg) Das Laborbuch in Klinik und Praxis, 2. Aufl. Elsevier/Urban und Fisher, München, S 764

Soldin SJ, Rifai N, Hicks JMB (1995) Biochemical basis of pediatric disease, 2. Aufl. AACC Press, Washington, DC

\section{Fruktosebelastungstest}

K. J. Lackner und D. Peetz

Synonym(e) Fruktoseintoleranztest

Englischer Begriff fructose tolerance test; fructose load, oral or intravenous

Definition Belastungstest mit oraler oder intravenöser Gabe von $>$ Fruktose.

Durchführung Fruktosebelastungstests können in der Diagnostik von Resorptions- und Stoffwechselstörungen der Fruktose indiziert sein. Unterschieden werden muss zwischen oraler und intravenöser Fruktosebelastung. Die orale Fruktosebelastung wird i. d. R. in Form eines $\mathrm{H}_{2}$-Atemtests durchgeführt und dient dem Nachweis einer Fruktosemalabsorption, die bei Kindern häufig aufgrund verstärkter intestinaler 
Gasbildung zu abdominellen Beschwerden führt. Dabei gelangt oral applizierte Fruktose zum großen Teil in den Dickdarm, wo sie bakteriell fermentiert wird. Das dabei entstehende $\mathrm{H}_{2}$ wird über die Lunge ausgeatmet und in der Atemluft quantifiziert. Die intravenöse Fruktosebelastung ( $200 \mathrm{mg} / \mathrm{kg}$ Fruktose i.v.) dient dem Nachweis von Störungen des zellulären Fruktosestoffwechsels wie der hereditären Fruktoseintoleranz (Aldolase-B-Mangel) oder dem Fruktose1,6-Bisphosphatasemangel.

$\mathrm{Zu}$ beachten ist, dass die orale Fruktosebelastung bei Kindern mit hereditärer Fruktoseintoleranz zu schwersten Hypoglykämien führen kann und deshalb relativ kontraindiziert ist. Ursache ist die Akkumulation von Fruktose-1-Phosphat infolge des Aldolase-B-Defekts und nachfolgender Hemmung der Glukoneogenese und Glykogenolyse. Vor einer oralen Fruktosebelastung sollte eine hereditäre Fruktoseintoleranz deshalb anamnestisch ausgeschlossen werden. Auch im Rahmen einer i.v. Fruktosebelastung treten bei Kindern mit hereditärer Fruktoseintoleranz innerhalb 1 Stunde symptomatische Hypoglykämien auf, auf deren Behandlung der Untersucher vorbereitet sein muss. Bei Erwachsenen ist der Glukoseabfall meist weniger dramatisch. Es kommt zum Anstieg von Mg und Harnsäure und zum Abfall von Phosphat. Bei Patienten mit Fruktose-1,6-Bisphosphatasemangel kommt es zu einer qualitativ ähnlichen, aber quantitativ weniger ausgeprägten Antwort auf die i.v. Fruktosebelastung, sodass eine orale Fruktosebelastung toleriert wird.

\section{Literatur}

Romangnolo J, Schiller D, Bailey RJ (2002) Using breath tests wisely in a gastroenterology practice: an evidence-based review of indications and pitfalls in interpretation. Am J Gastroenterol 97:1113-1126

Steinmann B, Gitzelmann R, Van den Berghe G. Chapter 70: Disorders of fructose metabolism. In Valle D et al (Hrsg) The online metabolic and molecular bases of inherited disease. McGraw-Hill, New York. https://doi.org/10.1036/ommbid.89

\section{Fruktose-1,6-Diphosphat-Aldolase}

- Aldolase A

- Aldolase B

\section{Fruktose-H2-Atemtest}

\author{
A. M. Gressner und O. A. Gressner
}

Synonym(e) Fruktose-Wasserstoff-Exhalationstest
Englischer Begriff fructose-hydrogen breath test

Definition Der zur Diagnostik einer bakteriellen Überbesiedelung des oberen Dünndarms eingesetzte Atemfunktionstest misst nach oraler Aufnahme einer definierten Menge des Monosaccharids Fruktose deren intestinale, bakterielle Metabolisierung anhand der in einem festgelegten Zeitrahmen nach Testbeginn exhalierten Wasserstoffmenge (H2).

Beschreibung Nach etwa 12-stündiger Nahrungskarenz, während der nur Wasseraufnahme erlaubt ist, trinkt der Patient 25 g Fruktose in ca. $240 \mathrm{ml}$ gewärmten Wasser. Vor und in definierten Zeitintervallen (10-30 Minuten über einen Zeitraum von 2-3 Stunden) nach Fruktoseaufnahme wird in der endexspiratorischen Luft des Patienten die Wasserstoffmenge gemessen. Der im Darm entstehende, resorbierte und mit der Ausatmungsluft ausgeschiedene Wasserstoff steigt bei Gesunden im Verlauf nur gering (um weniger als 20 ppm) an, während bei Fruktoseintoleranz und bei bakterieller intestinaler Überbesiedelung ein frühzeitiger (innerhalb von 30 Minuten) signifikanter Anstieg zu messen ist. Funktionsteste ähnlicher Indikationsstellung und Methodik sind $>$ Glukose- $\mathrm{H}_{2}$ Atemtest; $>$ Laktulose- $\mathrm{H}_{2}$-Atemtest; $>$ Laktose- $\mathrm{H}_{2}$-Atemtest.

\section{Literatur}

Stein J, Wehrmann T (Hrsg) (2005) Funktionsdiagnostik in der Gastroenterologie, 2. Aufl. Springer, Berlin/Heidelberg/New York

\section{Fruktoseintoleranztest}

Fruktosebelastungstest

Fruktosenachweis nach Seliwanoff

- Seliwanoff-Test

Fruktose-Wasserstoff-Exhalationstest

Fruktose-H2-Atemtest

\section{Fruktosurie}

Fruktose im Urin 


\section{FSH}

> Follikelstimulierendes Hormon

\section{FSH-RH}

> Gonadotropin-Releasing-Hormon

\section{FSME-Viren}

W. Stöcker

Synonym(e) Frühsommer-Meningoenzephalitis-Viren

Englischer Begriff TBE virus (tick-borne encephalitis, tickborne meningoencephalitis)

Beschreibung des Erregers Das FSME-Virus gehört zum Genus Flavivirus (Familie Flaviviridae). Das sphärische, etwa $50 \mathrm{~nm}$ große Virion besteht aus einer 10,5 kDa großen Positivstrang-RNA in einem Kapsid, das wiederum von einer Virushülle aus Lipiden der Wirtszelle und dem Protein E umgeben ist. Es sind 3 Subtypen bekannt; neben dem in Deutschland vorkommenden zentraleuropäischen Subtyp gibt es einen fernöstlichen und einen sibirischen Subtyp.

Erkrankungen Frühsommer-Meningoenzephalitis (FSME) ist eine meldepflichtige Erkrankung, die saisonal gehäuft vom Frühsommer bis zum Herbst auftritt. Endemiegebiete liegen in Bayern, Baden-Württemberg, Südhessen, Thüringen und Rheinland-Pfalz sowie in Regionen Saarlands und Sachsens.

Vektoren sind Schildzecken (Ixodidae) jeder Entwicklungsstufe (Larven, Nymphen, Adulte). Sie leben am Waldrand und im hohen Gras und übertragen die Viren bei der Blutmahlzeit. Natürliches Erregerreservoir sind vorwiegend kleine Säugetiere und Vögel.

Jährlich werden in Deutschland etwa 200-300 Neuerkrankungen registriert. Ein Großteil der mit FSME-Viren infizierten Personen bemerkt keine objektivierbaren Krankheitszeichen - die Serokonversion gibt dann den einzigen Hinweis. Nur etwa 10-30 \% der Infizierten zeigen 7-14 Tage nach der Ansteckung grippeähnliche Beschwerden mit Fieber, Kopf- und Gliederschmerzen, Erbrechen und Schwindel. Bei etwa $10 \%$ der symptomatischen Patienten folgt nach etwa einer fieberfreien Woche eine Meningoenzephalitis mit Kopfschmerzen, Erbrechen, meningealen Reizerscheinungen und vereinzelt Stupor oder Koma.
Prävention ist möglich durch aktive Immunisierung und Expositionsprophylaxe: Beim sommerlichen Aufenthalt in Wald und Feld sollte man heutzutage „hübsch“ auf dem Weg bleiben. Die Therapie erfolgt symptomatisch.

Analytik Direktnachweis: In der frühen Krankheitsphase mittels Kulturverfahren oder $>$ PCR (Polymerase-Kettenreaktion) aus Blut oder Liquor möglich.

Serologie: Nachweis FSME-spezifischer Antikörper der Klasse IgG und IgM in Serum oder Liquor durch indirekte Immunfluoreszenz ( $\triangleright$ Immunfluoreszenz, indirekte), \ Enzymimmunoassay oder $\triangleright$ Immunblot-Techniken.

Untersuchungsmaterial - Probenstabilität Direktnachweis und Kultur: Untersucht werden Blut oder Liquor. Das Material sollte bis zur Weiterverarbeitung bei +4 bis $+8{ }^{\circ} \mathrm{C}$ aufbewahrt werden. Direktnachweise sind innerhalb von 24 Stunden durchzuführen, Kulturen innerhalb von 6 Stunden anzulegen. Bei längerer Transportzeit ist das Material einzufrieren.

Serologie: Serum oder Plasma für den Nachweis der Antikörper sind bei $+4{ }^{\circ} \mathrm{C}$ bis zu 2 Wochen lang beständig, bei $-20^{\circ} \mathrm{C}$ über Monate und Jahre hinweg. Zur Tiefkühlkonservierung des IgM kann man den Proben 80 \% gepuffertes Glyzerin beifügen.

Diagnostische Wertigkeit Labordiagnostisch stützt sich die Feststellung einer FSME-Infektion vor allem auf den Nachweis von IgG- und IgM-Antikörpern gegen das FSME-Virus. Beweisend für eine frische Infektion sind eine Serokonversion oder ein signifikanter IgG-Titeranstieg. Bei Verdacht auf eine Beteiligung des zentralen Nervensystems werden die spezifischen Antikörper und die Gesamtantikörper parallel in Liquor und Serum bestimmt und der spezifische LiquorSerum-Quotient errechnet. Ein Wert $>1,5$ spricht für eine intrathekale Antikörpersynthese.

Kreuzreaktionen zu anderen humanpathogenen Flaviviren ( $\triangleright$ Dengue-Viren, $\triangleright$ West-Nil-Fieberviren und $\triangleright$ GelbfieberViren) müssen ausgeschlossen werden. Differenzialdiagnostisch relevant sind Poliomyelitis, Borreliose und virale Meningoenzephalitiden.

\section{Literatur}

Robert-Koch-Institut Berlin. Epidemiol Bull, 9. Mai 2016 / Nr. 18. FSME: Risikogebiete in Deutschland. http://www.rki.de/DE/Con tent/Infekt/EpidBull/Archiv/2016/Ausgaben/18_16.pdf?_blob= publicationFile. Zugegriffen am 22.02.2017

Robert-Koch-Institut Berlin. RKI-Ratgeber für Ärzte, 18. Aug 2015. Frühsommer-Meningoenzephalitis (FSME). http://www.rki.de/DE/Con tent/Infekt/EpidBull/Merkblaetter/Ratgeber_FSME.html. Zugegriffen am 22.02.2017 


\section{FT3}

> Triiodthyronin, freies

\section{FT4}

- Thyroxin, freies

\section{FT4!}

- Thyroxin-Index, freier

\section{FTI}

- Thyroxin-Index, freier

\section{FTP}

- File Transfer Protocol

\section{Fuchs-Rosenthal-Zählkammer}

> Liquor-Fuchs-Rosenthal-Zählkammer

> Zählkammer

\section{Fujiwara-Reaktion}

C. Vidal und W.-R. Külpmann

\section{Englischer Begriff Fujiwara test}

Definition Screening-Test auf chlorierte, bromierte und iodierte Kohlenwasserstoffverbindungen im Urin oder Plasma.

Bewertung Viele chlorierte (z. B. Chloroform, Chloralhydrat) und einige bromierte oder iodierte Kohlenwasserstoffe reagieren in der Hitze mit Pyridin und Natronlauge zu rot gefärbten Reaktionsprodukten. Mit einigen organischen Chloridverbindungen, iodhaltigen Röntgenkontrastmitteln sowie $\mathrm{Cl}^{-}$fällt die Reaktion jedoch negativ aus.

\section{Literatur}

Degel F, Geldmacher-von Mallinckrodt M, Köppel C (2009) Volatile halogenated hydrocarbons. In: Külpmann WR (Hrsg) Clinical toxicological analysis. Wiley-VCH, Weinheim, S 539-553

\section{Fullererde}

T. Arndt

Synonym(e) Bleicherde; Lloyds-Reagenz

Englischer Begriff Fuller's Earth; Lloyd's Reagent

Definition Eine Aluminium-Magnesium-Silikat enthaltende Variante des Kaolins, deren Eigenschaften durch chemische und thermische Behandlung vielfach modifiziert wurde, weshalb eine klare Aussage zu Struktur und Zusammensetzung kaum möglich ist.

Beschreibung Der Name leitet sich aus der früheren Verwendung für die Reinigung von Wolle durch Walken (engl. = full) in einem Fullererdeschlamm ab. Fullererde wurde u. a. Reaktionsansätzen zur Bestimmung von $>$ Kreatinin mit der $\triangleright$ Jaffe-Reaktion zugegeben, um $>$ Pseudokreatinine zu binden und damit die Spezifität der Jaffe-Reaktion zu erhöhen.

\section{Literatur}

MERCK-Index (2006) Whitehouse Station, MERCK

Peake M, Whiting M (2006) Measurement of serum creatinine - current status and future goals. Clin Biochem Rev 27:173-184

\section{Fullscan}

$>$ Scan

\section{Fumarat}

> Fumarsäure

\section{Fumarsåure}

G. F. Hoffmann, C.-D. Langhans und A. Schulze

Synonym(e) Fumarat 


\section{Englischer Begriff fumaric acid}

Definition Die ungesättigte Dicarbonsäure ist ein Zwischenprodukt im Citratzyklus (Krebs-Zyklus).

Struktur $\mathrm{C}_{4} \mathrm{H}_{4} \mathrm{O}_{4}$; Strukturformel:

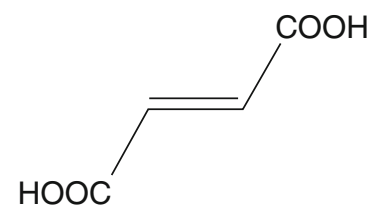

Molmasse $116,07 \mathrm{~g}$.

Synthese - Verteilung - Abbau - Elimination Im Citratzyklus wird aus Succinyl-Coenzym A durch die SuccinylCoenzym A-Transferase zunächst Bernsteinsäure und aus dieser mittels einer durch die Succinat-Dehydrogenase katalysierten Dehydrierung die Fumarsäure gebildet. Im weiteren Verlauf des Citratzyklus wird Fumarsäure durch das homotetramere Enzym Fumarase in einer reversiblen Reaktion zu Äpfelsäure hydratisiert.

Funktion - Pathophysiologie Die Pathophysiologie von Störungen im Citratzyklus, zu denen der Fumarasedefekt gehört, wird durch eine verminderte Energieproduktion sowie durch sekundäre Effekte der sich anstauenden bzw Mangel zu bildender Metabolite verursacht.

Durch den gestörten Substratfluss ist die Zahl Reduktionsäquivalente-bildender Schritte vermindert. Die verminderte Rückbildung von Oxalessigsäure verringert die Menge an einfließendem Acetyl-CoA.

Ein Defekt der Fumarase führt sekundär zu einer Inhibierung der Succinat-Dehydrogenase und der GlutamatDehydrogenase.

Untersuchungsmaterial - Entnahmebedingungen Urin, in Ausnahmefällen Liquor oder Plasma.

\section{Analytik}

- $>$ Flüssig-Flüssig-Extraktion im sauren Medium mittels Ethylacetat oder Diethylether

- Gaschromatographie-Massenspektrometrie (๖ GC-MS) als Di-Trimethylsilylester

Retentionsindex RI: 1348

$\mathrm{M}+(\mathrm{m} / \mathrm{z}): 260$

Quant Ion (m/z): 245

Conf. Ion (m/z): 147

Internationale Einheit $\mathrm{mmol} / \mathrm{mol}$ Kreatinin (Urin). $\mu \mathrm{mol} / \mathrm{L}$ (Plasma, Liquor).
Referenzbereich - Kinder Normalbereich:

- $<20 \mathrm{mmol} / \mathrm{mol} \mathrm{Kreatinin} \mathrm{(Urin)}$

- $<4 \mu \mathrm{mol} / \mathrm{L}$ (Plasma, Liquor)

Pathologischer Bereich:

- $\mathrm{n}$ bis $4000 \mathrm{mmol} / \mathrm{mol}$ Kreatinin (Urin)

- $22-28 \mu \mathrm{mol} / \mathrm{L}$ (Plasma/Serum)

- $6,8 \mu \mathrm{mol} / \mathrm{L}(\mathrm{CSF})$

Indikation Progrediente psychomotorische Retardierung.

Interpretation Vermehrte Ausscheidung von Fumarsäure im Urin ist charakteristisch für eine Fumarazidurie bedingt durch einen Defekt der Fumarase. Im Urin können auch weitere Citratzykluszwischenprodukte wie Bernsteinsäure, Zitronensäure, Äpfelsäure und 2-Oxoglutarsäure erhöht auftreten.

Diagnostische Wertigkeit Die (relative) Höhe der Ausscheidung von Fumarsäure ist für die Wertigkeit bezüglich des Verdachts einer Fumarazidurie entscheidend. Die Bestätigung erfolgt über die enzymatische oder molekularbiologische Bestätigungsdiagnostik.

\section{Literatur}

Blau N, Duran M, Gibson KM, Dionisi-Vici C (Hrsg) (2014) Physician's guide to the diagnosis, treatment, and follow-up of inherited metabolic diseases. Springer, Berlin/Heidelberg

Hoffmann GF, Meier-Augenstein W, Stöckler S et al (1993) Physiology and pathophysiology of organic acids in cerebrospinal fluid. J Inherit Metab Dis 16:648-669

\section{Funk, Casimir}

\section{A. M. Gressner und O. A. Gressner}

Lebensdaten US-amerikanischer Biochemiker polnischer Herkunft, geboren am 23. Februar 1884 in Warschau, gestorben am 20. November 1976 in New York City.

Verdienste Casimir Funk erhielt seine schulische Bildung in Warschau und studierte Biologie und Chemie an den Universitäten Genf und Berlin. Nach der Promotion zum Ph.D. 1904 arbeitete Funk am Pasteur-Institut über organische Basen, 
Aminosäuren/Proteine und Zucker. Im Jahr 1906 wechselte er nach Berlin, wo er u. a. mit Emil Fischer und Emil Abderhalden Experimente zum Proteinstoffwechsel durchführte. Diese Studien, die er 1910 am Lister-Institut in London fortsetzte, lenkten seine Forschung auf die Klärung der Ätiologie und Pathogenese der Beriberi-Krankheit, die durch den Verzehr von poliertem Reis im Orient prävalent war. Er fand heraus, dass spezifische organische Komponenten in den Nahrungsmitteln essenziell für die Prävention und nachfolgende Therapie von Beriberi, Rachitis und Skorbut sind, für die er die kollektive Bezeichnung Vitamine (,vitality amines“) um 1912 einführte. 1915 setzte Funk seine Forschung in den USA fort und wurde 1920 US-Bürger. Von 1920-1939 arbeitete Funk in Polen, kehrt jedoch kriegsbedingt 1939 in die USA (New York) zurück, um in der U.S. Vitamin Corporation bis 1963 zu arbeiten. Funks Entdeckung der Vitamine wies deren präventive und kurative Wirkung für Erkrankungen wie perniziöse Anämie, Beriberi, Osteomalazie, Pellagra, Rachitis, Skorbut und Sprue nach.

\section{Literatur}

Funk C (1924) Die Vitamine, ihre Bedeutung für die Physiologie und Pathologie, 3. Aufl. J.F. Bergmann Verlag, München

\section{Funktionsdiagnostik, hepato-gastro- intestinale}

- Atemteste für Leberfunktionsdiagnostik

\section{FUT3}

- Lewis-(Le-)Blutgruppensystem

FV

$>$ Gerinnungsfaktor V

FV:C

- Gerinnungsfaktor V

\section{FVII}

$>$ Gerinnungsfaktor VII

\section{FVII:C}

$>$ Gerinnungsfaktor VII

\section{FVIIII}

> Gerinnungsfaktor VIII

\section{FVIII:C}

- Gerinnungsfaktor VIII

\section{FWHM}

- Orbitrap

FX

- Gerinnungsfaktor X

\section{FXa-Inhibitoren}

- Faktor-Xa-Inhibitoren

\section{FXI}

> Gerinnungsfaktor XI

FXII

- Gerinnungsfaktor XII 
FXII:Ag

- Gerinnungsfaktor XII

\section{FXIII}

> Gerinnungsfaktor XIII
FY

- Duffy-(FY-)Blutgruppensystem

- Fluorid-Zahl 